\title{
DESENVOLVIMENTO DE UM MODELO PARA PREVISÃO DE OCORRÊNCIA DE Ecdytolopha aurantiana (LIMA, 1927) (LEPIDOPTERA: TORTRICIDAE) E UM SISTEMA WEB INTEGRADO DE APOIO AO CITRICULTOR
}

\author{
Ronaldo ReIS JÚNIOR
}

Tese apresentada à Escola Superior de Agricultura "Luiz de Queiroz", Universidade de São Paulo, para obtenção do título de Doutor em Ciências, Área de Concentração: Entomologia.

P I R A C I C A B A

Estado de São Paulo - Brasil

Fevereiro - 2004 


\title{
DESENVOLVIMENTO DE UM MODELO PARA PREVISÃO DE OCORRÊNCIA DE Ecdytolopha aurantiana (LIMA, 1927) (LEPIDOPTERA: TORTRICIDAE) E UM SISTEMA WEB INTEGRADO DE APOIO AO CITRICULTOR
}

\author{
Ronaldo Reis JÚnior \\ Biólogo \\ Orientador: Prof. Dr. JOSÉ ROBERTO POSTALI PARRA
}

Tese apresentada à Escola Superior de Agricultura "Luiz de Queiroz", Universidade de São Paulo, para obtenção do título de Doutor em Ciências, Área de Concentração: Entomologia.

P I R A C I C A B A

Estado de São Paulo - Brasil

Fevereiro - 2004 
Dados Internacionais de Catalogação na Publicação (CIP)
DIVISÃO DE BIBLIOTECA E DOCUMENTAÇÃO - ESALQ/USP

Reis Júnior, Ronaldo

Desenvolvimento de um modelo para previsão de ocorrência de Ecdytolopha aurantiana (Lima, 1927) (Lepidoptera : Tortricidae) e um sistema web integrado de apoio ao citricultor / Ronaldo Reis Júnior. - - Piracicaba, 2004.

105 p. : il.

Tese (doutorado) - Escola Superior de Agricultura Luiz de Queiroz, 2004.

Bibliografia.

1. Armadilha para inseto 2. Bicho-furão 3. Feromônio sexual de inseto 4. Frutas cítricas 5. Modelo linear generalizado 6. SIAC 7. Sistema de computador I. Título

CDD 634.3

"Permitida a cópia total ou parcial deste documento, desde que citada a fonte - 0 autor" 


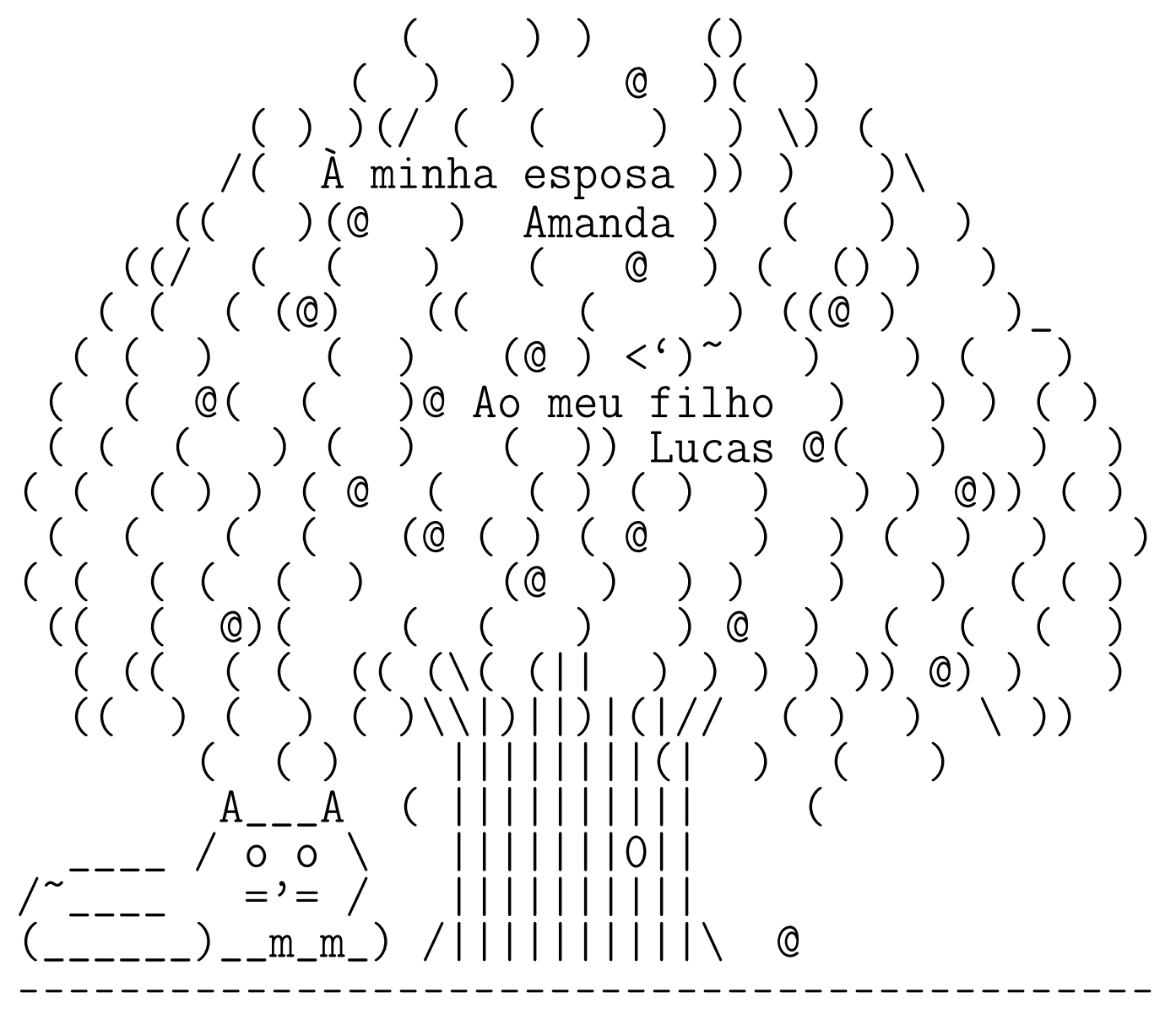




\section{AGRADECIMENTOS}

Ao Conselho Nacional Desenvolvimento Científico e Tecnológico (CNPq) pela bolsa concedida;

Ao Prof. José Roberto Postali Parra, professor titular do Departamento de Entomologia, Fitopatologia e Zoologia Agrícola, da ESALQ/USP, pela orientação, apoio e ensinamentos;

Ao Prof. Evaldo Ferreira Vilela pela compra do livro "Statistical Computing An introduction to data analysis using S-Plus" e pelos valiosos conselhos no decorrer do curso;

Ao Prof. José Maurício Simões Bento, pela amizade e dicas valiosas para desenvolvimento desse trabalho;

Aos professores do Departamento de Entomologia, Fitopatologia e Zoologia Agrícola da ESALQ/USP, pelos conhecimentos transmitidos;

À Fisher e ao Fundecitros pelo suporte, o qual foi imprescindível para o desenvolvimento do trabalho;

À comunidade de software livre que permitiu o uso de ferramentas de alta tecnologia a custo zero (R, LTEX2e, MySQL, PHP, Debian GNU/Linux, XEmacs etc). 


\section{SUMÁRIO}

Página

LISTA DE FIGURAS . . . . . . . . . . . . . . . . . . vii

LISTA DE TABELAS . . . . . . . . . . . . . . . . xiv

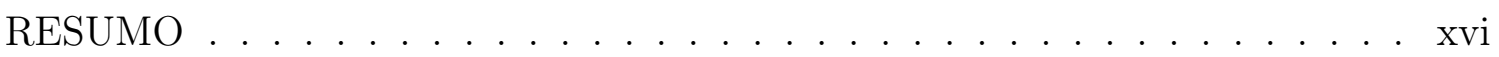

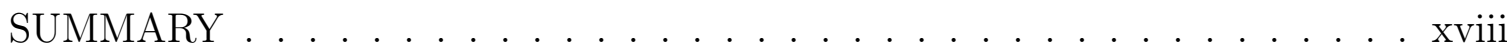

1 INTRODUÇÃ̈O . . . . . . . . . . . . . . . . . . . 1

2 REVISÃO DE LiTERATURA . . . . . . . . . . . . . . . . . . . 3

2.1 Comportamento e biologia . . . . . . . . . . . . . . . 3

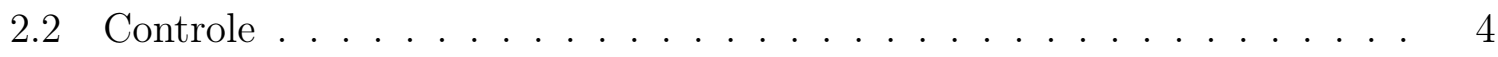

2.3 Monitoramento e tomada de decisão . . . . . . . . . . . . . . . . . . 5

2.3.1 Amostragem de frutos danificados . . . . . . . . . . . . 5

2.3.2 Utilização de dietas . . . . . . . . . . . . . . . . . . . 6

2.3.3 Armadilhas de feromônio . . . . . . . . . . . . . . . . . 6

2.3.4 Uso de exigências térmicas . . . . . . . . . . . . . . . . 7

2.3.5 Modelos Matemáticos . . . . . . . . . . . . . 7

2.4 Estações de aviso e sistemas de alerta . . . . . . . . . . . . . . . . 7

3 MATERIAL E MÉTODOS . . . . . . . . . . . . . . . . . . . 9

3.1 Coleta de dados . . . . . . . . . . . . . . . . . . . 9

3.2 Desenvolvimento dos modelos matemáticos . . . . . . . . . . . . . . . . . 14

3.3 SIAC - Sistema Integrado de Apoio à Citricultura . . . . . . . . . . . . . 18 
3.3.1 Base de dados . . . . . . . . . . . . . . . . . . 19

3.3.2 Interface interna do sistema . . . . . . . . . . . . . . . . . 19

3.3.3 Interface do usuário . . . . . . . . . . . . . . . . . . . 19

4 RESUlTAdOS E DiSCUSSÃO . . . . . . . . . . . . . . . . . 21

4.1 Modelo desenvolvido . . . . . . . . . . . . . . . . . . . . . . . 21

4.1.1 Análise de desvio para seleção das variáveis . . . . . . . . . . . . . . 21

4.1.2 Análises de contraste . . . . . . . . . . . . . . . . . 25

4.1.2.1 Variedade de citros . . . . . . . . . . . . . . . 25

4.1.2.2 Tipos de Solo . . . . . . . . . . . . . . . . . . 26

4.1.2.3 Aplicação de agroquímicos . . . . . . . . . . . . . . . . . . . 26

4.1.3 Estimativas dos parâmetros do modelo simplificado . . . . . . . . . . . 29

4.1.4 Exemplo prático para utilização do modelo . . . . . . . . . . . . 51

4.2 SIAC - Sistema Integrado de Apoio à Citricultura . . . . . . . . . . . . . 55

5 CONCLUSÕES . . . . . . . . . . . . . . . . . . . 77

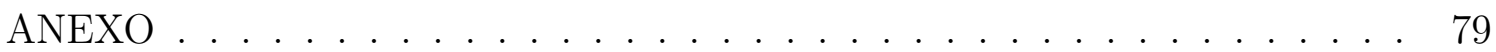

REFERÊNCIAS BIBLIOGRÁFICAS . . . . . . . . . . . . . . . . . 90

APENDICE . . . . . . . . . . . . . . . . . . . . . . . . 98 


\section{LISTA DE FIGURAS}

Página

1 Localização das fazendas onde foram feitas as coletas de machos de Ecdytolopha aurantiana em armadilhas de feromônio sexual. A legenda indica o nome do município onde a maior parte da fazenda está localizada 10

2 Posicionamento das armadilhas de feromônio sexual no campo para coleta de machos de Ecdytolopha aurantiana (Bento et al., 2001b) . . . . . . . . 11

3 Esquema utilizado para o cálculo da distância dos pontos de coleta de Ecdytolopha aurantiana em relação ao oceano com base na eq. (1) (Vasconcelos \& Tarifa, 1983) . . . . . . . . . . . . . . . . . . . . 12

4 Passos que foram seguidos no processo de modelagem para Ecdytolopha

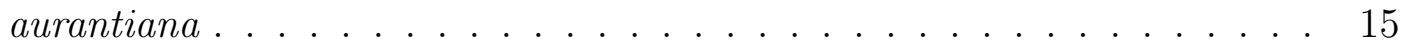

5 Rotina utilizada para acessar o modelo e simular as diversas situações de ocorrência de Ecdytolopha aurantiana . . . . . . . . . . . . . . . . . . . . 18

6 Resíduos com envelopes de intervalos de confiança mostrando o ajuste adequado do modelo para previsão de ocorrência de Ecdytolopha aurantiana 21

7 Viabilidade do ciclo de Ecdytolopha aurantiana em relação a temperatura. Estimativa feita a partir de resultados de laboratório (Garcia, 1998) . . . 24 
8 Estimativas de ocorrência de Ecdytolopha aurantiana para o solo GS1 (LV4, LE1 e TR1) em função da temperatura, variedades de citros, aplicação de agroquímicos e idade das plantas. A - plantas com idade de 5 anos e com aplicação de agroquímicos; B - plantas com idade de 5 anos e sem aplicação de agroquímicos; C - plantas com idade de 10 anos e com aplicação de agroquímicos; D - plantas com idade de 10 anos e sem aplicação de agroquímicos; E - plantas com idade de 15 anos e com aplicação de agroquímicos; F - plantas com idade de 15 anos e sem aplicação de

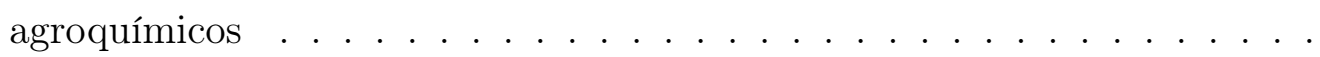

9 Estimativas de ocorrência de Ecdytolopha aurantiana para o solo GS2 (LEP2) em função da temperatura, variedades de citros, aplicação de agroquímicos e idade das plantas. A - plantas com idade de 5 anos e com aplicação de agroquímicos; B - plantas com idade de 5 anos e sem aplicação de agroquímicos; C - plantas com idade de 10 anos e com aplicação de agroquímicos; D - plantas com idade de 10 anos e sem aplicação de agroquímicos; E - plantas com idade de 15 anos e com aplicação de agroquímicos; F - plantas com idade de 15 anos e sem aplicação de

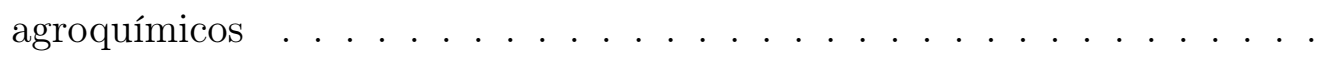

10 Estimativas de ocorrência de Ecdytolopha aurantiana para o solo GS3 (LV1 e GH) em função da temperatura, variedades de citros, aplicação de agroquímicos e idade das plantas. A - plantas com idade de 5 anos e com aplicação de agroquímicos; B - plantas com idade de 5 anos e sem aplicação de agroquímicos; C - plantas com idade de 10 anos e com aplicação de agroquímicos; D - plantas com idade de 10 anos e sem aplicação de agroquímicos; E - plantas com idade de 15 anos e com aplicação de agroquímicos; F - plantas com idade de 15 anos e sem aplicação de

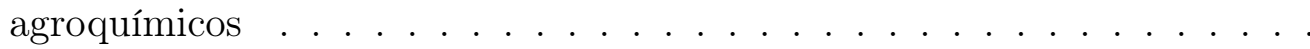


11 Estimativas de ocorrência de Ecdytolopha aurantiana para o solo GS4 (PEL2, LE4 e HO) em função da temperatura, variedades de citros, aplicação de agroquímicos e idade das plantas. A - plantas com idade de 5 anos e com aplicação de agroquímicos; B - plantas com idade de 5 anos e sem aplicação de agroquímicos; C - plantas com idade de 10 anos e com aplicação de agroquímicos; D - plantas com idade de 10 anos e sem aplicação de agroquímicos; E - plantas com idade de 15 anos e com aplicação de agroquímicos; F - plantas com idade de 15 anos e sem aplicação de

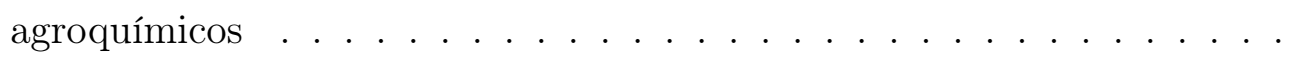

12 Estimativas de ocorrência de Ecdytolopha aurantiana para o solo GS5 (PV4, LR2) em função da temperatura, variedades de citros, aplicação de agroquímicos e idade das plantas. A - plantas com idade de 5 anos e com aplicação de agroquímicos; B - plantas com idade de 5 anos e sem aplicação de agroquímicos; C - plantas com idade de 10 anos e com aplicação de agroquímicos; D - plantas com idade de 10 anos e sem aplicação de agroquímicos; E - plantas com idade de 15 anos e com aplicação de agroquímicos; F - plantas com idade de 15 anos e sem aplicação de

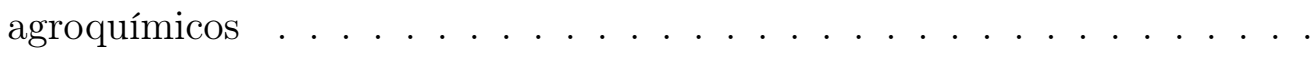

13 Estimativas de ocorrência de Ecdytolopha aurantiana para o solo GS6 (LEP1) em função da temperatura, variedades de citros, aplicação de agroquímicos e idade das plantas. A - plantas com idade de 5 anos e com aplicação de agroquímicos; B - plantas com idade de 5 anos e sem aplicação de agroquímicos; C - plantas com idade de 10 anos e com aplicação de agroquímicos; D - plantas com idade de 10 anos e sem aplicação de agroquímicos; E - plantas com idade de 15 anos e com aplicação de agroquímicos; F - plantas com idade de 15 anos e sem aplicação de

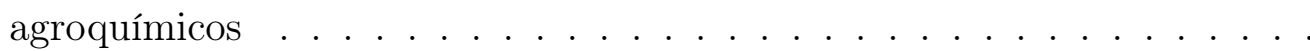


14 Estimativas de ocorrência de Ecdytolopha aurantiana para o solo GS7 (LE2) em função da temperatura, variedades de citros, aplicação de agroquímicos e idade das plantas. A - plantas com idade de 5 anos e com aplicação de agroquímicos; B - plantas com idade de 5 anos e sem aplicação de agroquímicos; C - plantas com idade de 10 anos e com aplicação de agroquímicos; D - plantas com idade de 10 anos e sem aplicação de agroquímicos; E - plantas com idade de 15 anos e com aplicação de agroquímicos; F - plantas com idade de 15 anos e sem aplicação de

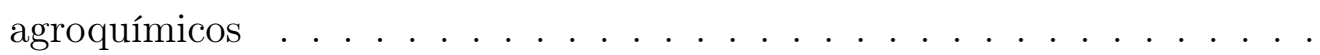

15 Estimativas de ocorrência de Ecdytolopha aurantiana para o solo GS8 (PV3) em função da temperatura, variedades de citros, aplicação de agroquímicos e idade das plantas. A - plantas com idade de 5 anos e com aplicação de agroquímicos; B - plantas com idade de 5 anos e sem aplicação de agroquímicos; C - plantas com idade de 10 anos e com aplicação de agroquímicos; D - plantas com idade de 10 anos e sem aplicação de agroquímicos; E - plantas com idade de 15 anos e com aplicação de agroquímicos; F - plantas com idade de 15 anos e sem aplicação de

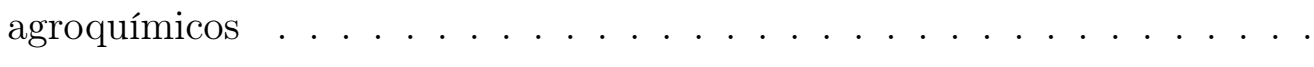

16 Estimativas de ocorrência de Ecdytolopha aurantiana para o solo GS9 (LE5) em função da temperatura, variedades de citros, aplicação de agroquímicos e idade das plantas. A - plantas com idade de 5 anos e com aplicação de agroquímicos; B - plantas com idade de 5 anos e sem aplicação de agroquímicos; C - plantas com idade de 10 anos e com aplicação de agroquímicos; D - plantas com idade de 10 anos e sem aplicação de agroquímicos; E - plantas com idade de 15 anos e com aplicação de agroquímicos; F - plantas com idade de 15 anos e sem aplicação de agroquímicos . . . . . . . . . . . . . . . . . 
17 Estimativas de ocorrência de Ecdytolopha aurantiana para o solo GS10 (LV3) em função da temperatura, variedades de citros, aplicação de agroquímicos e idade das plantas. A - plantas com idade de 5 anos e com aplicação de agroquímicos; B - plantas com idade de 5 anos e sem aplicação de agroquímicos; C - plantas com idade de 10 anos e com aplicação de agroquímicos; D - plantas com idade de 10 anos e sem aplicação de agroquímicos; E - plantas com idade de 15 anos e com aplicação de agroquímicos; F - plantas com idade de 15 anos e sem aplicação de

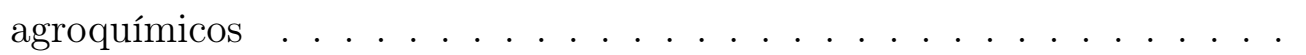

18 Estimativas de ocorrência de Ecdytolopha aurantiana para o solo GS11 (LE3) em função da temperatura, variedades de citros, aplicação de agroquímicos e idade das plantas. A - plantas com idade de 5 anos e com aplicação de agroquímicos; B - plantas com idade de 5 anos e sem aplicação de agroquímicos; C - plantas com idade de 10 anos e com aplicação de agroquímicos; D - plantas com idade de 10 anos e sem aplicação de agroquímicos; E - plantas com idade de 15 anos e com aplicação de agroquímicos; F - plantas com idade de 15 anos e sem aplicação de

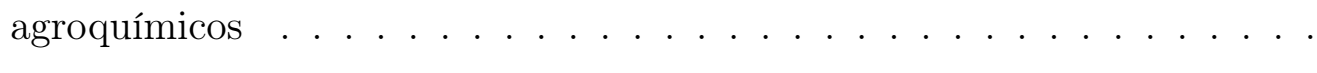

19 Estimativas de ocorrência de Ecdytolopha aurantiana para o solo GS12 (AQ e HI) em função da temperatura, variedades de citros, aplicação de agroquímicos e idade das plantas. A - plantas com idade de 5 anos e com aplicação de agroquímicos; B - plantas com idade de 5 anos e sem aplicação de agroquímicos; C - plantas com idade de 10 anos e com aplicação de agroquímicos; D - plantas com idade de 10 anos e sem aplicação de agroquímicos; E - plantas com idade de 15 anos e com aplicação de agroquímicos; F - plantas com idade de 15 anos e sem aplicação de

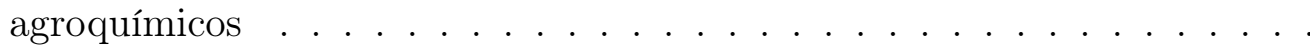


20 Estimativas de ocorrência de Ecdytolopha aurantiana para o solo GS13 (PE1, LR1 e TR2) em função da temperatura, variedades de citros, aplicação de agroquímicos e idade das plantas. A - plantas com idade de 5 anos e com aplicação de agroquímicos; B - plantas com idade de 5 anos e sem aplicação de agroquímicos; C - plantas com idade de 10 anos e com aplicação de agroquímicos; D - plantas com idade de 10 anos e sem aplicação de agroquímicos; E - plantas com idade de 15 anos e com aplicação de agroquímicos; F - plantas com idade de 15 anos e sem aplicação de

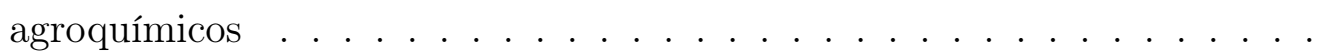

21 A - Estimativas de ocorrência de Ecdytolopha aurantiana (número de machos por armadilha por mês) em função da temperatura. B - Estimativas de ocorrência de Ecdytolopha aurantiana durante o ano (número de machos por armadilha por semana). A seta indica que o agricultor deve estar alerta, instalando armadilhas de feromônio na área, a partir desta data. Estimativa feita para a variedade Pera Rio, solo tipo LE2 e idade do pomar de 15 anos . . . . . . . . . . . . . . . . 54

22 Módulo do SIAC que pode ser utilizado para a simulação de ocorrência de Ecdytolopha aurantiana utilizando-se o modelo desenvolvido . . . . . 59

23 Página principal do SIAC. Esta é o ponto de partida para os usuários . . 60

24 Módulo de artigos do SIAC, onde poderão ser lidos artigos diversos relacionados ao setor citrícola . . . . . . . . . . . . . . . . . . 61

25 Módulo de "downloads" do SIAC, onde os usuários terão acesso a arquivos, como por exemplo o programa para simular o potencial de ocorrência de

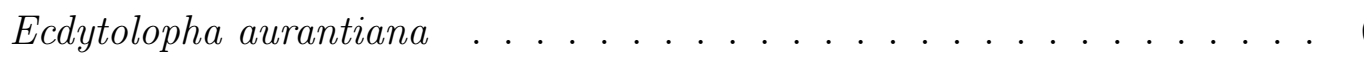

26 Módulo de enciclopédia do SIAC, neste local os usuário poderão ter acesso a informações técnicas de forma fácil de ser entendida . . . . . . . . . . 63

27 Módulo de FAQ (Frequently Asked Questions) do SIAC, neste local estarão um conjunto das perguntas mais freqüentes com as respectivas respostas 64 
28 Módulo de fórum do SIAC, local onde os usuário poderão debater qualquer assunto pertinente de forma pública . . . . . . . . . . . . . . . 65

29 Módulo de usuários do SIAC, local onde os usuário poderão se cadastrar no sistema e personalizar o SIAC para suas preferências . . . . . . . . . 66

30 Módulo de mensagens do SIAC, aqui os usuário poderão debater assuntos pertinentes de forma privada . . . . . . . . . . . . . . . . 67

31 Módulo de indicações do SIAC, local para indicar o SIAC a uma pessoa que ainda não conheça o sistema . . . . . . . . . . . . . . . . . . . 68

32 Módulo de revisões do SIAC, local onde os usuário poderão ter conhecimento de revisões, feitas por pesquisadores, de produtos e técnicas utili-

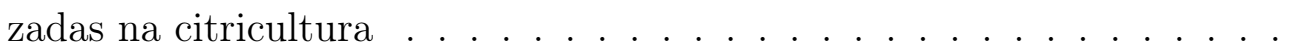

33 Módulo de envio de revisões do SIAC, local onde o pesquisador poderá redigir suas revisões e enviar ao sistema . . . . . . . . . . . . . . 70

34 Módulo de procura do SIAC, local onde os usuário poderão procurar por qualquer informação dentro do SIAC . . . . . . . . . . . . . . . . 71

35 Módulo de seções do SIAC, local onde os artigos estarão organizados por assunto de forma a facilitar a leitura . . . . . . . . . . . . . . . . 72

36 Módulo de estatistica do SIAC, local onde são mostradas as estatísticas de acesso ao sistema . . . . . . . . . . . . . . . . . . . 73

37 Módulo de notícias do SIAC, local onde os usuário terão acesso a todas as notícias publicadas no sistema . . . . . . . . . . . . . . . . 74

38 Módulo para envio de notícias do SIAC, neste local os usuários poderão disponibilizar toda e qualquer notícia pertinente ao SIAC . . . . . . . . . 75

39 Módulo de enquetes do SIAC, neste local estarão os resultados das enquetes realizadas com os usuário . . . . . . . . . . . . . . . . 76 


\section{LISTA DE TABELAS}

Página

1 Tipos de solos encontrados nas áreas de amostragem de Ecdytolopha aurantiana e suas principais características . . . . . . . . . . . . 13

2 Análise de desvio contendo somente as variáveis e interações que foram significativas para o desenvolvimento do modelo para Ecdytolopha aurantiana. Para a relação da variáveis não significativas, consultar o modelo completo em material e métodos . . . . . . . . . . . . . . . . 22

3 Análises de contraste das variedades de citros analisadas influenciando a ocorrência de Ecdytolopha aurantiana em função da temperatura. O sinal + indica agrupamento formado e o sinal | indica a comparação . . . . . .

4 Média ( \pm erro padrão), valor máximo e mínimo de captura de machos de Ecdytolopha aurantiana em armadilhas de feromônio sexual e grupos de variedades definidos pela análise de contraste . . . . . . . . . . . . . 26

5 Análises de contraste dos tipos de solos influenciando a ocorrência de Ecdytolopha aurantiana em função da temperatura. O sinal + indica agrupamento formado e o sinal | indica a comparação . . . . . . . . . . . 27

6 Média ( \pm erro padrão), valor máximo e mínimo de captura de macho de Ecdytolopha aurantiana em armadilhas de feromônio sexual e grupos de solos definidos pela análise de contraste . . . . . . . . . . . . . 
7 Análises de contraste da utilização de agroquímicos para controle de bicho-furão em função da temperatura, para coleta da espécie. O sinal | indica a comparação . . . . . . . . . . . . . . . . . . . . 28

8 Média ( \pm erro padrão), valor máximo e mínimo de captura de macho de Ecdytolopha aurantiana em armadilhas de feromônio sexual e grupos definidos pela análise de contraste para o uso de agroquímicos . . . . . 28

9 Estimativa dos parâmetros utilizados na definição das equações que compõem o modelo para previsão de ocorrência de Ecdytolopha aurantiana . 


\title{
DESENVOLVIMENTO DE UM MODELO PARA PREVISÃO DE OCORRÊNCIA DE Ecdytolopha aurantiana (LIMA, 1927) (LEPIDOPTERA: TORTRICIDAE) E UM SISTEMA WEB INTEGRADO DE APOIO AO CITRICULTOR
}

\author{
Autor: RONALDO REIS JÚNIOR \\ Orientador: Prof. Dr. JOSÉ ROBERTO POSTALI PARRA
}

\section{RESUMO}

Os frutos cítricos são uma das principais fontes de exportação do Brasil, sendo que São Paulo responde por cerca de $80 \%$ da produção total. Dentre os fatores que limitam a produção citrícola brasileira, especialmente no estado de São Paulo, vem se sobressaindo nos últimos anos, a clorose variegada dos citros (CVC), a podridão floral, o minador-dos-citros e o bicho-furão-dos-citros, Ecdytolopha aurantiana (Lima, 1927) (Lepidoptera: Tortricidae), além dos ácaros, moscas-das-frutas, pinta preta e mais recentemente a morte súbita. O presente trabalho teve como objetivo desenvolver um modelo para previsão de ocorrência de E. aurantiana, baseado em dados de monitoramento através de armadilhas de feromônio sexual e desenvolver um sistema computacional que possa utilizar este modelo para gerar as previsões de 
ocorrência, além de fornecer um local de troca de informações entre o citricultor e a comunidade científica. O tipo de solo, temperatura do local, variedade de citros, idade das plantas e uso de agroquímicos para controle de E. aurantiana, influenciaram na dinâmica populacional deste inseto. A maior influência sobre a flutuação do bicho-furão foi exercida pelo tipo de solo, seguido pela temperatura local, variedade de citros, idade das plantas e uso de agroquímicos para controle de E. aurantiana. A ocorrência de E. aurantiana em função da temperatura é diferente para cada combinação de tipo de solo, variedade de citros, idade das plantas e uso de agroquímicos. O modelo desenvolvido pode prever o potencial de ocorrência de E. aurantiana em função da temperatura ou dos meses do ano, levando-se em consideração o tipo de solo, variedade de citros, idade das plantas e aplicação de agroquímicos. O programa (BF) elaborado na linguagem $\mathrm{R}$ conta com equações para simular as diversas situações de ocorrência de E. aurantiana. O SIAC (Sistema Integrado de Apoio ao Citricultor) é um sistema que facilita o uso do modelo, sem a necessidade de conhecimento de $\mathrm{R}$ e fornece uma gama de recursos que visa facilitar o acesso do citricultor às informações e ao pesquisador aos problemas do citricultor, criando com isto uma maior interação de ambos. O modelo de previsão de ocorrência de bicho-furão pode ser aperfeiçoado com coleta de dados mais regulares e de forma contínua. 


\title{
DEVELOPMENT OF A MODEL TO PREDICT THE OCCURRENCE OF Ecdytolopha aurantiana (LIMA, 1927) (LEPIDOPTERA: TORTRICIDAE) AND AN INTEGRATED WEB SYSTEM TO SUPPORT CITRUS PRODUCERS
}

\author{
Author: RONALDO REIS JÚNIOR \\ Adviser: Prof. Dr. JOSÉ ROBERTO POSTALI PARRA
}

SUMMARY

Citrus fruits are Brazil's major exporting sources, and São Paulo is accountable for approximately $80 \%$ of the total production. Among the factors that limit the Brazilian citriculture, especially in the state of São Paulo, one points in the past few years the citrus variegated chlorosis (CVC), flower rot, citrus leaf miner and citrus fruit borer, Ecdytolopha aurantiana (Lima, 1927) (Lepidoptera: Tortricidae), in addition to mites, fruit flies, black spot, and more recently, sudden death. The goal of this work was to develop a model to predict the occurrence of $E$. aurantiana, based on monitoring data collected through sexual pheromone traps, and to develop a computer system capable of using such model to generate occurrence predictions and to provide a place for information exchange between citriculturists 
and the scientific community. Soil type, site temperature, citrus variety, age of plants and use of chemicals to control E. aurantiana influenced the population dynamics of the insect. The highest influence on the citrus fruit borer dynamics was exerted by the soil type, followed by site temperature, citrus variety, age of plants and use of chemicals for E. aurantiana control. The occurrence of E. aurantiana according to temperature is different for each combination of soil type, citrus variety, age of plants and use of chemicals. The model developed can predict the occurrence potential of $E$. aurantiana according to temperature or months of the year, taking into account soil type, citrus variety, age of plants and chemicals spraying. The elaborated software (BF), designed in $\mathrm{R}$ language, includes equations that simulate the various situations of E. aurantiana occurrence. SIAC ("Sistema Integrado de Apoio ao Citricultor") is a system that simplifies the use of the model, does not require previous knowledge on $\mathrm{R}$, and provides a wide range of resources to facilitates the access of citriculturists to information and that of researchers to citriculturists' problems, thus creating a better interaction between them. The predicting model of citrus fruit borer occurrence can be improved with more frequent and continuous data collecting. 


\section{INTRODUÇÃO}

Os frutos cítricos são uma das principais fontes de exportação do Brasil, sendo que São Paulo responde por cerca de $80 \%$ da produção total (FNP Consultoria \& Comércio, 2001). Dentre os fatores que limitam a produção citrícola brasileira, especialmente no estado de São Paulo, vem se sobressaindo nos últimos anos, a clorose variegada dos citros (CVC), a podridão floral, o minador-dos-citros e o bicho-furãodos-citros, Ecdytolopha aurantiana (Lima, 1927) (Lepidoptera: Tortricidae), além dos ácaros, moscas-das-frutas, pinta preta e mais recentemente a morte súbita (Parra et al., 2003).

E. aurantiana é uma praga conhecida no Brasil há muito tempo, porém sempre foi de ocorrência esporádica, sem causar grandes danos (Prates et al., 1981). Foi na década de 80 que os ataques desta praga ficaram realmente intensos, principalmente em São Paulo, onde passaram a ser observadas perdas superiores a $50 \%$ da produção, provavelmente devido a desequilíbrios ecológicos causados pela excessiva aplicação de produtos químicos (Prates, 1992).

No estado de São Paulo o ataque desta praga tem início a partir de novembro, intensificando-se nos meses de janeiro, fevereiro e março. As variedades mais atacadas são a Pera, Natal e Valência (Prates, 1992). Levantamentos da ocorrência de bicho-furão realizados nas principais regiões citrícolas do estado de São Paulo em 1994/1995 registraram a presença do inseto em todas as regiões amostradas (Fundecitrus, 1996). 
Hoje a praga é de ocorrência generalizada no estado e em vários outros pontos do Brasil. Somente para São Paulo causa perdas da ordem de 50 milhões de dólares anuais (Fundecitrus, 2000b).

Embora exista um feromônio sintético para seu monitoramento populacional (Bento et al., 2001b; Leal et al., 2001), existem áreas onde, por várias razões, tal monitoramento não é realizado.

Assim, o objetivo do presente trabalho é desenvolver um modelo para previsão de ocorrência de E. aurantiana, baseado em dados de monitoramento através de armadilhas de feromônio sexual e desenvolver um sistema computacional que possa utilizar este modelo para gerar as previsões de ocorrência, além de fornecer um local de troca de informações entre o citricultor e a comunidade científica. 


\section{REVISÃO DE LITERATURA}

\subsection{Comportamento e biologia}

Ecdytolopha aurantiana (Lima, 1927) (Lepidoptera: Tortricidae) é um microlepidóptero cujos danos podem ser verificados em diversas plantas frutíferas tais como: citros, goiaba, lichia, manga, macadâmia, fruta-do-conde, dentre outras (Zucchi et al., 1993; Nakano \& Soares, 1995).

Sua ocorrência foi constatada em praticamente toda a América do Sul (Zucchi et al., 1993), sendo que sua presença já foi relatada em pelo menos nove estados (Prates \& Pinto, 1991a).

E. aurantiana é de hábito crepuscular, efetuando a postura na superfície do fruto. Geralmente é colocado somente um ovo por fruto, com um total de 150-200 ovos por fêmea (Garcia \& Parra, 1999); desta forma pode-se ter uma noção do potencial de prejuízos desta praga. A colocação de apenas um ovo por fruto deve estar relacionada à ação de feromônio de marcação que seria liberado por ocasião da postura (Parra J. R. P., inf. pessoal).

Em alta população, esta praga ataca tanto frutos verdes quanto maduros; embora a lagarta não consiga atingir a polpa do fruto verde, pois morre em grande porcentagem nos primeiros ínstares, o seu dano já é o suficiente para levar ao apodrecimento e à perda total do fruto (Parra et al., 2001). 
Após a eclosão, a lagarta penetra no fruto, onde inicia seu desenvolvimento que durará cerca de 25 dias, sofrendo 5 ecdises antes de se transformar em pupa (Nakano \& Soares, 1995; Prates \& Pinto, 1991a,b, 1995; Garcia, 1998).

Com cerca de $18 \mathrm{~mm}$, a lagarta já completamente desenvolvida abandona o fruto indo em direção ao solo para se transformar em pupa, permanecendo neste estágio por cerca de 15 a 20 dias (Prates \& Pinto, 1991a,b; Pinto, 1994; Nakano \& Soares, 1995).

Uma vez emergido, o adulto terá cerca de $17 \mathrm{~mm}$ de envergadura e coloração predominantemente acinzentada (Fonseca, 1934). A possibilidade de criação de E. aurantiana em dietas artificiais abriu perspectivas para o desenvolvimento de alternativas de controle (Garcia \& Parra, 1999). As fêmeas liberam um feromônio sexual que atrai os machos para cópula sendo que no terceiro e quarto dias $80 \%$ das cópulas já aconteceram (Bento et al., 2001a).

\subsection{Controle}

O controle do bicho-furão é baseado principalmente na utilização de produtos químicos ou produtos biológicos à base de Bacillus thuringiensis (Prates et al., 1981; Nakano \& Soares, 1995; Fundecitrus, 2000a). Estudos para uso de parasitóides, especialmente do gênero Trichogramma, vêm sendo feito com resultados animadores (Garcia, 1998; Molina, 2003), podendo este parasitóide ser mais um componente em programas de manejo da praga (Parra, 2002). Além destes métodos de controle, práticas culturais como a catação de frutos no chão e na própria planta devem ser feitas para que se tenha a eficiência desejada de controle (Pinto, 1994, 1996).

Algumas características biológicas deste insetos dificultam o seu controle. O fato de ser um inseto cuja fase imatura se desenvolve dentro do fruto é uma 
destas dificuldades, pois ao penetrar o fruto, este se torna um abrigo que a protege dos produtos químicos e biológicos; além disto, uma vez no interior do fruto, o dano já foi causado. Outra característica que dificulta o seu controle é a oviposição dispersa da espécie, pois cada fêmea tende a colocar um só ovo por fruto, aumentando assim a sua capacidade de dano (Garcia, 1998; Garcia et al., 1998).

Com a globalização e crescente necessidade de um agricultura competitiva, sustentável e "ecologicamente correta" (Lewis et al., 1997), métodos mais modernos e precisos têm sido empregados nas diversas áreas da agricultura, alguns sofisticados baseados em modelos matemáticos complexos utilizados na previsão de ocorrência de pragas.

\subsection{Monitoramento e tomada de decisão}

Considerando-se tais avanços e a importância da praga, torna-se necessário haver um maior conhecimento da dinâmica populacional deste inseto, para assim, poder efetuar o controle na época e locais adequados. Este conhecimento da dinâmica populacional é feito com base em um sistema de monitoramento. Este monitoramento pode ser feito de várias formas:

\subsubsection{Amostragem de frutos danificados}

Até há pouco tempo, o monitoramento era feito baseando-se em amostras de frutos danificados. O problema deste tipo de abordagem é que somente se detecta a praga quando parte do dano já foi causado. Uma vez detectados os danos eram feitas aplicações indiscriminadas de inseticidas, acarretando desequilíbrios do agro-ecossistema (Fundecitrus, 2000a). Um outro problema é a ocorrência da praga que apresenta características de "explosões" populacionais após a constatado o dano, 
o que, na maioria dos casos, inviabiliza o controle. O controle para esta praga, portanto, deve ser feito antes da constatação do dado (Parra J. R. P., inf. pessoal).

\subsubsection{Utilização de dietas}

Outro método de monitoramento, que foi recentemente desenvolvido pelo laboratório de Biologia de Insetos da Escola Superior de Agricultura Luiz de Queiroz/Universidade de São Paulo (ESALQ/USP), é aquele utilizando-se dietas artificiais para prever quando os adultos emergirão no campo (Garcia, 1998; Garcia et al., 1998; Fundecitrus, 2000a). Este método consiste basicamente em se colocar lagartas coletadas no campo, dentro de fruto, em tubos com dietas. Estes tubos são mantidos no pomar, em local protegido, e monitorados de tempo em tempo. O alerta para o inicio do controle é dado quando $60 \%$ de lagartas que se desenvolveram nos tubos de dietas se tornam adultas, indicando o momento de se aplicar o agroquímico, sempre no crepúsculo (horário de postura) e com variações da época de aplicação dependendo do tipo de produto a ser utilizado (biológico ou químico) (Gallo et al., 2002). Segundo Carvalho (2003) este método de monitoramento se mostrou eficiente, podendo ser utilizado para a adoção de medidas de controle.

\subsubsection{Armadilhas de feromônio}

Recentemente, com a identificação e síntese do feromônio sexual desta praga (Leal et al., 2001), este passou a ser uma forma importante no seu monitoramento (Bento et al., 2001b), sendo comercializado pela Copercitrus com o nome de Ferocitros-Furãoß. O uso de feromônios sexuais como método de monitoramento já é uma realidade em várias culturas (Vilela \& Della Lucia, 2001). Com o uso de armadilhas de feromônio, este monitoramento pode ser feito de forma mais rápida e segura (Carvalho, 2003). 


\subsubsection{Uso de exigências térmicas}

O método das exigências térmicas baseia-se na contagem de graus-dia necessários para o desenvolvimento completo do inseto, ou seja, o somatório de grausdia acima da temperatura base $(\mathrm{Tb})$ (limiar térmico inferior de desenvolvimento) do inseto até que se complete a constante térmica e esse inseto se torne adulto. Desta forma, seria possível prever o momento em que a maior parte da população se transformaria em adulto, momento este ideal para início do controle (Carvalho, 2003). De acordo com este mesmo autor, este método é aplicável no verão, sendo necessárias correções para sua utilização em outras épocas do ano.

\subsubsection{Modelos Matemáticos}

O uso de modelos matemáticos como forma de prever picos populacionais tem grande fundamentação teórica, porém é muito pouco utilizado. Estes modelos são mais utilizados em simulações ecológicas, principalmente para se trabalhar com sistemas tróficos (Gutierrez et al., 1991a,b, 1994, 1988a,b,c, 1999; Acuña \& Barchini de Giménez, 1996). Como sistema de previsão para controle de pragas, os modelos têm sido utilizados de forma restrita, como o de Focks et al. (1993). Por outro lado, os modelos de previsão de ocorrências de doenças (Butt \& Xu, 1994) têm uso mais freqüente devido a uma maior simplicidade do sistema. No caso de pragas, as dificuldades são maiores, pois o número de fatores envolvidos aumenta consideravelmente. Neste caso, os fatores que dificultam a utilização prática estão relacionados à falta de dados contínuos, completos e de longo prazo.

\subsection{Estações de aviso e sistemas de alerta}

Estações de aviso são locais que centralizam a coleta e análise de dados provenientes de monitoramento, sendo responsáveis pela difusão destas informações 
aos produtores interessados. Uma parte fundamental das estações de aviso é representada pelos sistemas de alerta. Estes são sistemas computacionais (programas), cuja função é, com base em algum sistema de monitoramento, analisar os dados coletados, prever a ocorrência da praga em determinados locais, e alertar o produtor para a tomada de decisão. Estações de aviso já são adotadas em algumas culturas de vários países (Espanha, 1991a,b; Getz et al., 1992; Butt \& Xu, 1994; Kitron et al., 1994; Chow \& Bernard, 1999). O sistema computacional pode ser expandido para todas as funções da estação de aviso, ou seja, coleta, armazenamento, manipulação e análise de dados, alerta dos locais de possível ocorrência e difusão desta informação.

No Brasil recentemente a Empresa Brasileira de Pesquisa Agropecuária (EMBRAPA) iniciou um projeto de "Produção Integrada de Frutas" (PIF) que visa, dentre outras coisas, a redução do uso de produtos químicos para o controle de pragas através de um conjunto de normas a serem seguidas (http://www.embrapa.br/ linhas_acao/alimentos/fruticultura/frutas.htm). Este programa teve início no Brasil em 1996/1997 com a implementação do "Programa de Produção Integrada de Maçã". Hoje já existem implementações do PIF em diversas fruteiras, tais como: uva, manga, pêssego, melão, dentre outras e várias estão em processo de estudo e implementação (Fachinello, 2001a,b; Fraguas et al., 2001; Haji et al., 2001; Lopes et al., 2001; Silva et al., 2001). 


\section{MATERIAL E MÉTODOS}

\subsection{Coleta de dados}

O trabalho foi realizado com dados coletados em 553 áreas localizadas em 17 fazendas do estado de São Paulo no período de 08/2000 a 08/2001 (Figura 1). A coleta de dados foi feita utilizando-se armadilhas de feromônio sexual de Ecdytolopha aurantiana (Lima, 1927) (Lepidoptera: Tortricidae) (Bento et al., 2001a,b). Foi colocada 1 armadilha para cada 10ha da cultura em toda a área experimental (Figura 2), portanto, correspondendo a um total de 553 armadilhas. As contagens de machos de E. aurantiana capturados foram feitas semanalmente. Os dados foram agrupados mensalmente, computando-se o total de machos de $E$. aurantiana capturados na armadilha por mês.

Além do total de machos de E. aurantiana capturados (variável resposta) foram coletadas diversas variáveis para cada área, incluindo-se:

Variedade de citros cultivada. Nas diferentes áreas encontravam-se as seguintes variedades: Baianinha, Cravo, Hamlin, Murcott, Natal, Pera Rio, Rubi, Tahiti, Valência, Valência Americana, Valência Americana Precoce, Valência Argentina e Westin.

Tipo de solos. Os seguintes tipos de solos foram encontrados nas áreas amostradas: AQ, GH, HI, HO, LE1, LE2, LE3, LE4, LE5, LEP1, LEP2, LR1, LR2, LV1, 


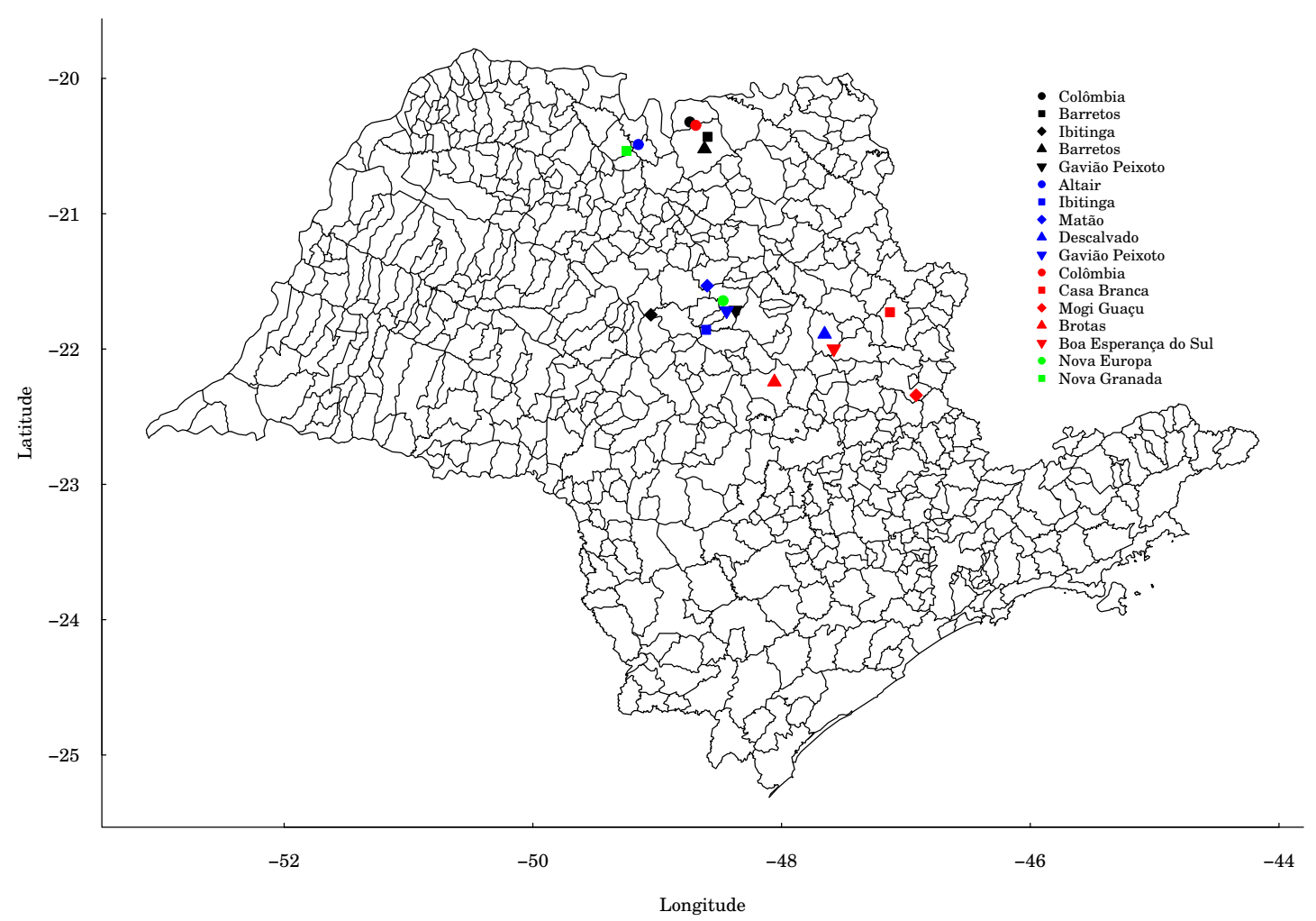

Figura 1 - Localização das fazendas onde foram feitas as coletas de machos de Ecdytolopha aurantiana em armadilhas de feromônio sexual. A legenda indica o nome do município onde a maior parte da fazenda está localizada

LV3, LV4, PE1, PEL2, PV3, PV4, TR1 e TR2. Detalhes sobre cada tipo de solo encontran-se na Tabela 1.

Aplicação de agroquímicos para controle de $\boldsymbol{E}$. aurantiana. Os seguintes agroquímicos foram utilizados em algumas áreas: Deltametrina (Decis@25CE), na concentração de 25 g/l e Bacillus thuringiensis (Dipel@) na concentração de $33.60 \mathrm{~g} / 1$.

Idade das plantas de citros. A idade das plantas em cada área variou de 2 a 22 anos.

Latitude. Latitude de cada área. Dados coletados através de GPS. 


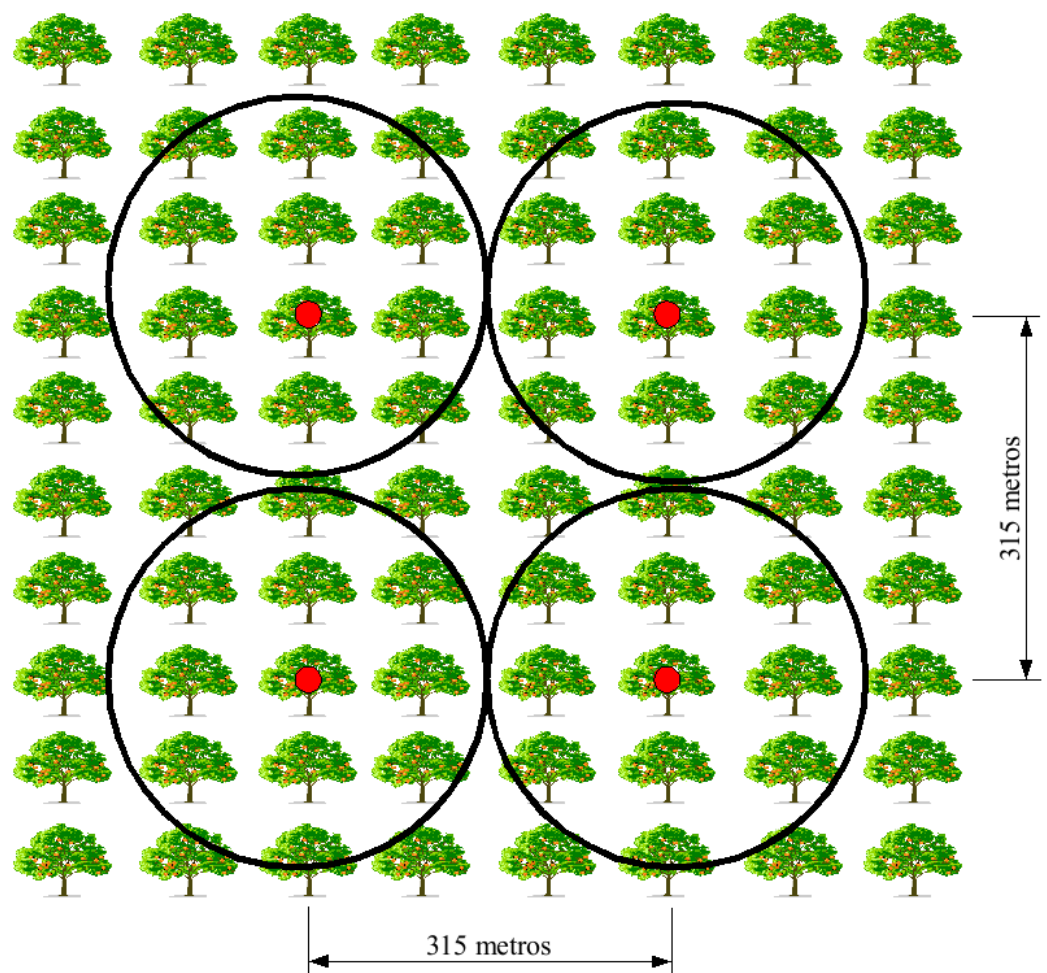

Figura 2 - Posicionamento das armadilhas de feromônio sexual no campo para coleta de machos de Ecdytolopha aurantiana (Bento et al., 2001b)

Longitude. Longitude de cada área. Dados coletados através de GPS.

Altitude. Altitude de cada área. Dados estimados utilizando-se os dados de topografia georeferenciada pela NASA e disponível no site http://edcdaac.usgs . gov/gtopo30/.

Distância do oceano. Distância dos pontos de coleta até o oceano, medido de forma perpendicular ao litoral. Dados estimados segundo método de Vasconcelos \& Tarifa (1983) através da seguinte equação (eq. (1)):

$$
\text { doceano }=1.721 \times(\text { longlocal }- \text { longlit }) \times 0.5016
$$

onde, doceano é a distância do oceano (km) estimada; longlocal é a longitude do local de coleta em minutos, longlit é a longitude do litoral em minutos 
correspondente à latitude do ponto de coleta, 1.721 é uma constante para corrigir os valores de minutos para quilômetros e 0.5016 é o ângulo aproximado do litoral paulista em radianos (Figura 3).

Temperatura média. Temperatura média mensal de cada área. Estes dados foram estimados utilizando-se as equações propostas por Vasconcelos \& Tarifa (1983) para cada mês do ano. Utilizaram-se quatro variáveis para sua estimativa: latitude, longitude, altitude e distância do oceano.

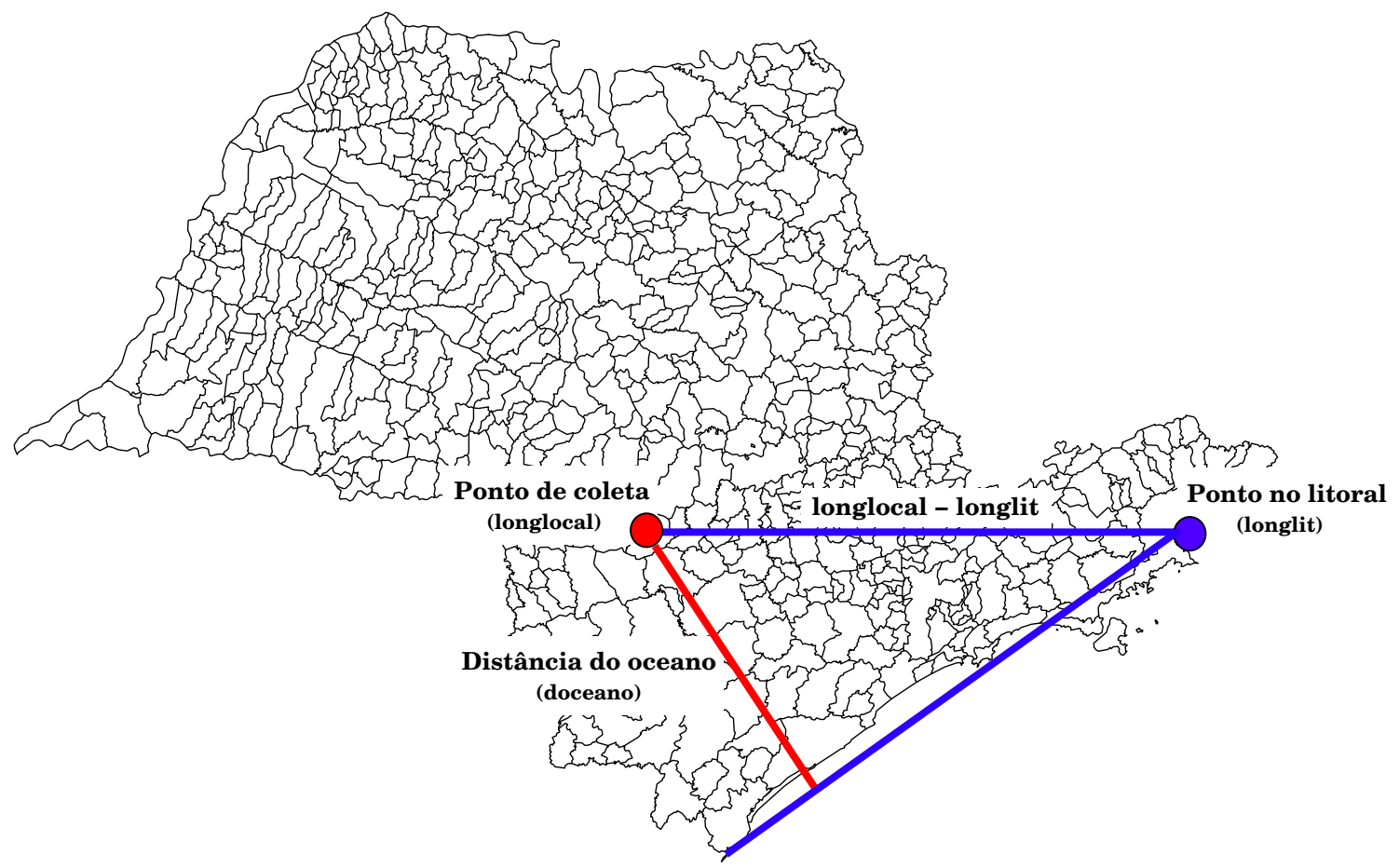

Figura 3 - Esquema utilizado para o cálculo da distância dos pontos de coleta de Ecdytolopha aurantiana em relação ao oceano com base na eq. (1) (Vasconcelos \& Tarifa, 1983) 


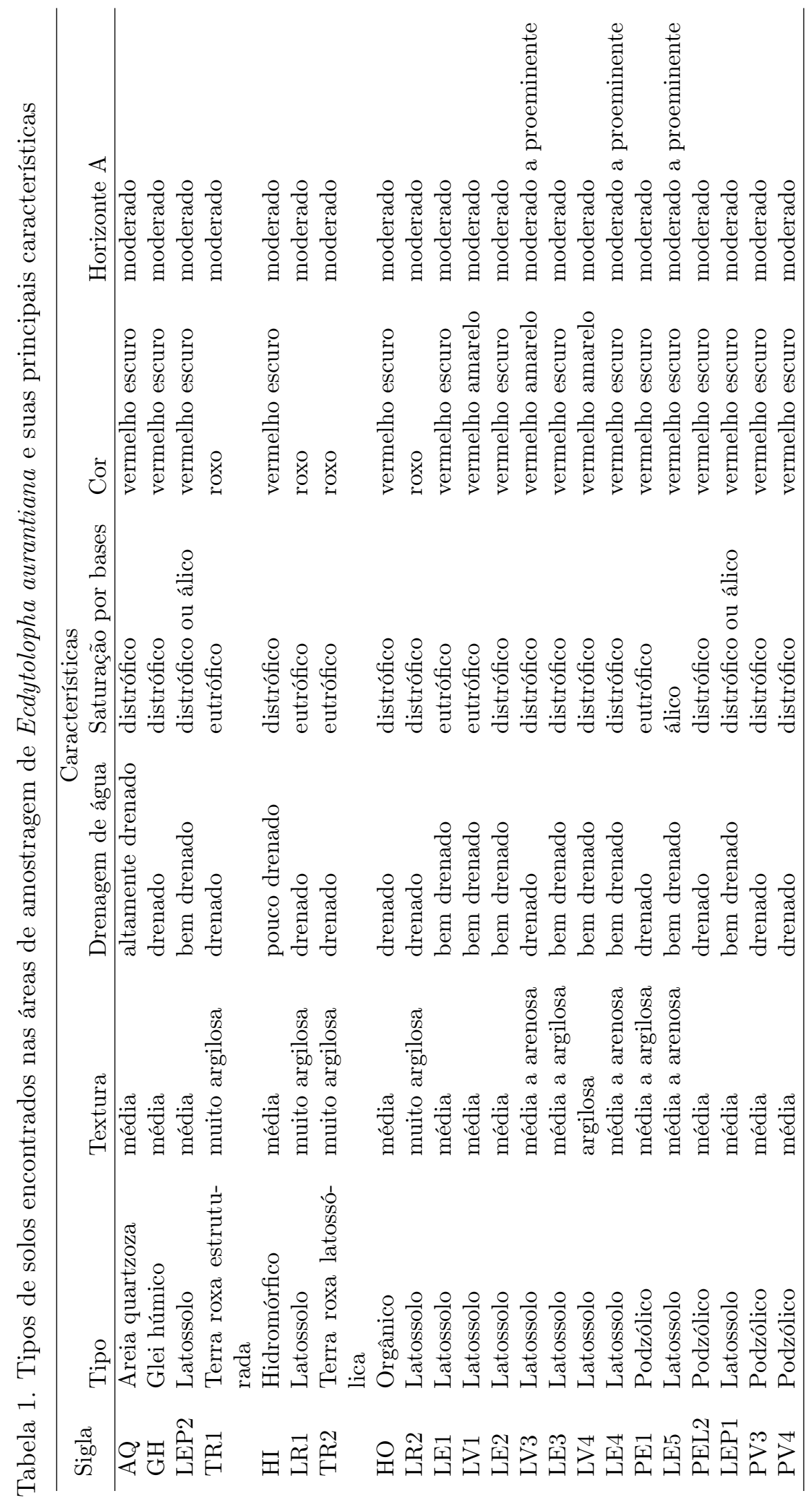


Para a análise, foram consideradas as seguintes variáveis explicativas: variedade de citros, tipo de solo, idade das plantas, aplicação de agroquímicos para controle de E. aurantiana e temperatura. As outras variáveis (latitude, longitude, altitude e distância do oceano) foram auxiliares para a estimativa da temperatura de cada área.

\subsection{Desenvolvimento dos modelos matemáticos}

Para o desenvolvimento do modelo foi utilizado o sistema estatístico $\mathrm{R}$ (Ihaka \& Gentleman, 1996) (http://www.r-project.org/). A modelagem foi feita utilizando-se o módulo GLM ("Generalized Linear Models") com distribuição de erros binomial negativa (função de ligação logarítmica) para correção de sobredispersão (Crawley, 2002). Uma análise de resíduos com envelopes de intervalo de confiança foi feita para verificar o ajuste do modelo. No desenvolvimento do modelo, alguns passos foram seguidos (Figura 4). A primeira parte do processo foi a coleta dos dados. Com os dados, iniciou-se a seleção das variáveis. Esta seleção foi feita através de regressões múltiplas utilizando-se o método "backward", onde se construiu um modelo com todas as variáveis e todas as interações e depois foi se retirando o que não era estatisticamente significante a $5 \%$ de probabilidade, simplificando o modelo. Esta simplificação de modelo culmina em um Modelo Mínimo Adequado (MMA), onde somente variáveis importantes integram o modelo. A partir desta seleção, estas variáveis foram utilizadas para definir e compor o modelo. 


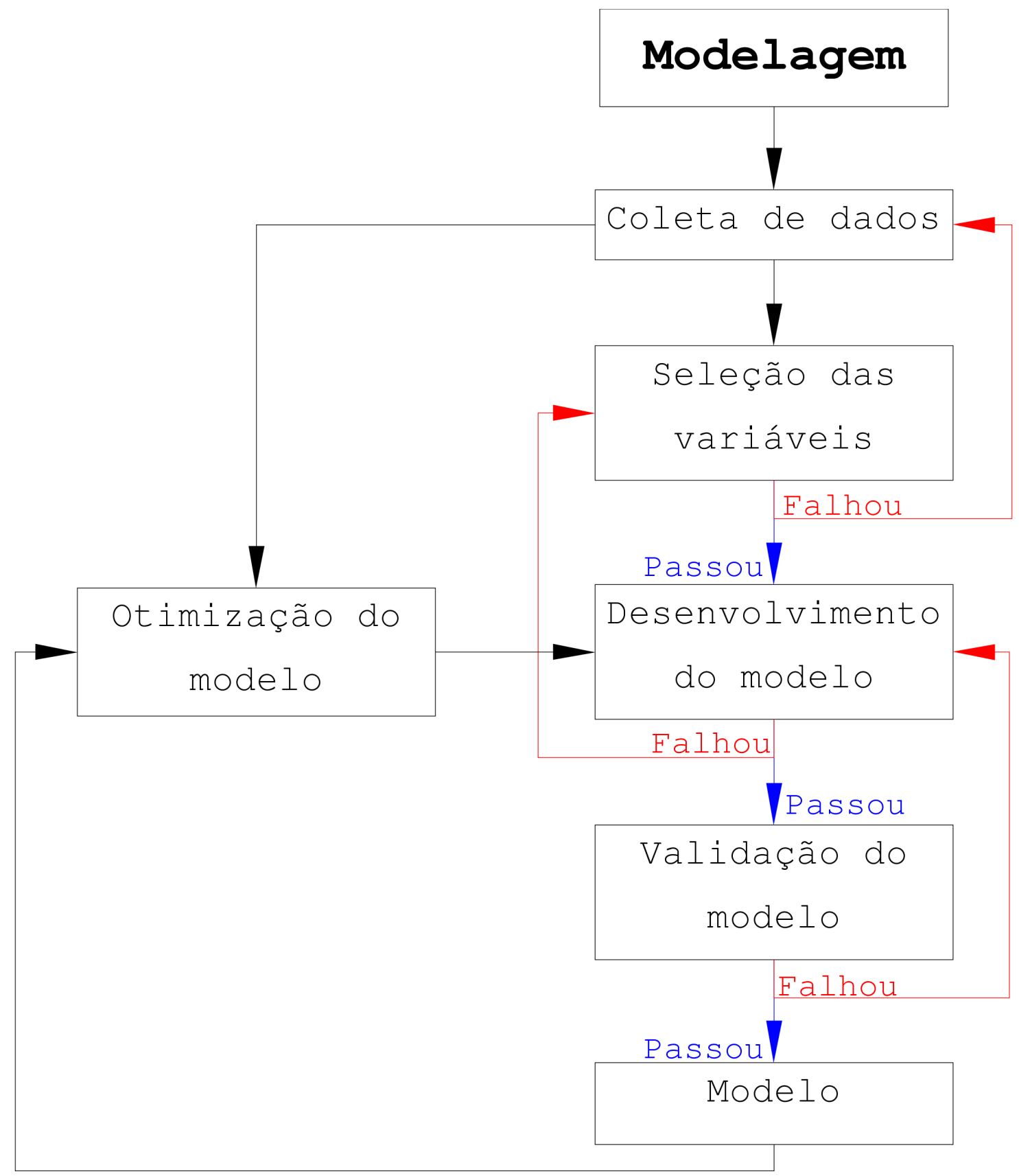

Figura 4 - Passos que foram seguidos no processo de modelagem para Ecdytolopha aurantiana 
O modelo completo foi construído como se segue (eq. (2)):

$$
\begin{array}{r}
\text { Coleta }=\text { Temperatura }+ \text { Variedade }+ \text { Solo }+ \text { Idade }+ \text { Temperatura }{ }^{2}+ \\
\text { Agroquímico }+ \text { Temperatura }: \text { Variedade }+ \text { Temperatura }: \text { Solo }+ \\
\text { Variedade }: \text { Solo }+ \text { Temperatura }: \text { Idade }+ \text { Variedade }: \text { Idade }+ \\
\text { Solo }: \text { Idade }+ \text { Variedade }: \text { Temperatura }{ }^{2}+\text { Solo }: \text { Temperatura }{ }^{2}+ \\
\text { Idade }: \text { Temperatura }{ }^{2}+\text { Temperatura }: \text { Variedade }: \text { Solo }+ \\
\text { Temperatura }: \text { Variedade }: \text { Idade }+ \text { Temperatura }: \text { Solo }: \text { Idade }+ \\
\text { Variedade }: \text { Solo }: \text { Idade }+ \text { Variedade }: \text { Solo }: \text { Temperatura }{ }^{2}+ \\
\text { Variedade }: \text { Idade }: \text { Temperatura }{ }^{2}+\text { Solo }: \text { Idade }: \text { Temperatura }{ }^{2}+ \\
\text { Temperatura }: \text { Varied }: \text { Solo }: \text { Idade }^{+} \\
\text {Variedade }: \text { Solo }: \text { Idade }: \text { Temperatura }
\end{array}
$$

onde, "Coleta" é o total de machos de E. aurantiana capturados pela armadilha de feromônio sexual; "Temperatura" é a temperatura na área e data de captura; "Variedade" é a variedade cultivada na área coletada; "Solo" é o tipo de solo predominante na área de coleta; "Idade" é a idade das plantas na área de coleta; "Temperatura2" é a temperatura na área e data de captura elevada ao quadrado; "Agroquímico" é se houve aplicação de agroquímicos para controle de E. aurantiana na área durante o período de coleta e as interações das variáveis indicadas pelos dois pontos (:).

O quadrado da temperatura foi adicionado ao modelo devido ao fato de que os organismos normalmente respondem a ela desta forma, ou seja, existe um ponto de máximo em relação à temperatura. Este ponto de máximo se refere à temperatura ideal para o desenvolvimento do organismo, aonde este poderá atingir seu potencial máximo.

A seguir foi feita a simplificação do modelo retirando-se interações e variáveis não significativas (MMA) e, a seguir, feito testes de contraste para amalgamar os níveis das variáveis. Amalgamar os níveis de uma variável significa testar-se, por exemplo, se a variedade Pera Rio é estatisticamente diferente da variedade Valência; caso sejam iguais, elas se tornam um grupo (Crawley, 2002). Os testes de 
contraste foram feitos para as variáveis qualitativas (variedade de citros, tipo de solo e aplicação de agroquímicos). Com este teste, chegou-se ao final da simplificação do modelo, criando-se o Modelo Mínimo Adequado Amalgamado (MMAA).

Terminada a simplificação do modelo, foram obtidas as estimativas do parâmetros necessários para a construção das equações. Estas equações, associadas a um programa, é que irão simular a ocorrência de E. aurantiana.

Para a utilização do modelo, é necessária a criação de um programa que possa, a partir de algumas informações, simular as diversas possibilidades de ocorrência de E. aurantiana. Este programa foi desenvolvido utilizando-se a própria linguagem R (Ihaka \& Gentleman, 1996). No entanto, para se utilizar este programa, o usuário deve possuir conhecimento básico da linguagem $\mathrm{R}$ e ter o programa $\mathrm{R}$ instalado em seu computador. No presente caso, foi desenvolvido um sistema "web" para a utilização do modelo. Este sistema "web" tem a vantagem de ser de fácil utilização e de não necessitar, por parte do usuário, a instalação de nenhum programa extra, sendo necessário somente um navegador de internet. Um esquema da rotina utilizada para acessar o modelo e simular a ocorrência de E. aurantiana pode ser visualizada na Figura 5.

Quando se desenvolve algum pacote tecnológico, é necessário que se desenvolva também um sistema que facilite a aprendizagem e utilização deste pacote. Com este intuito, além do sistema "web" para a utilização do modelo, foi desenvolvido/adaptado um sistema completo de apoio ao usuário (no nosso caso, o citricultor). Este sistema, doravante denominado SIAC, possui inúmeras funcionalidades além da simulação de ocorrência de E. aurantiana utilizando-se o modelo. 


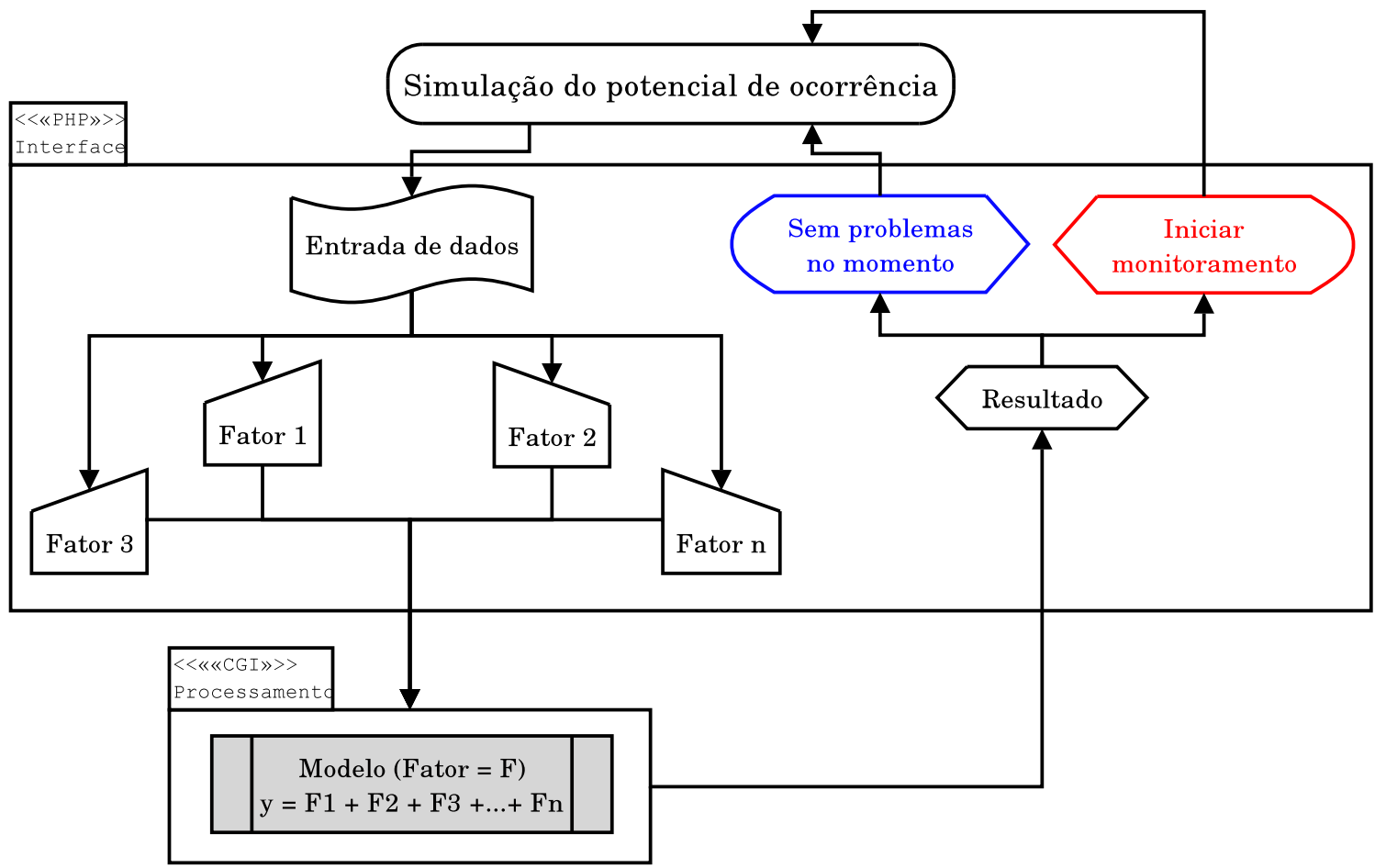

Figura 5 - Rotina utilizada para acessar o modelo e simular as diversas situações de ocorrência de Ecdytolopha aurantiana

\subsection{SIAC - Sistema Integrado de Apoio à Citricultura}

O SIAC é um sistema "web" destinado a prover ao citricultor um local onde ele possa utilizar o modelo aqui desenvolvido para simular o potencial de ocorrência de E. aurantiana em determinadas situações; poderá também se manter atualizado em relação ao setor, com informações veiculadas por pesquisadores de diversas áreas, além de ser possível fazer reivindicações quanto aos diversos problemas da citricultura, diminuindo com isto a distância entre os setores produtivo e científico. Este sistema é composto de:

1. uma base de dados onde será guardada toda a informação,

2. uma interface interna que consulta esta base de dados retornando ao usuário a informação solicitada, 
3. uma interface responsável por apresentar os resultados das consultas ao usuário de forma apropriada.

\subsubsection{Base de dados}

A base de dados, responsável por guardar todas as informações, foi instalada sob linguagem SQL ("Structured Query Language") (http://www.sql.org/), por se tratar de uma linguagem adequada para este tipo de implementação e promover independência de um sistema de gerenciamento de base de dados específico. Foi utilizado neste processo o programa MySQL (http://www.mysql.com/); esta escolha foi feita devido à alta performance e custo zero deste programa que está sob a licença GPL (http://www.gnu.org/copyleft/gpl.html).

\subsubsection{Interface interna do sistema}

A interface interna são programas responsáveis por receber um comando do usuário, analisá-lo, acessar a base de dados e retornar com um resultado para este usuário. Para fazer esta interface do sistema, foi utilizada a linguagem de programação PHP (http://www.php.org/) e PERL (http://www.perl.org/).

\subsubsection{Interface do usuário}

A interface do usuário é responsável pela comunicação entre o usuário e a interface interna. Esta é a interface que mostra ao usuário que informações ele precisa fornecer e que operações ele pode realizar no sistema. Esta interface do usuário foi construída utilizando-se tecnologias de linguagens voltadas para a Internet. Para tal, foi utilizada a linguagem de programação PHP, usando como base o sistema PHPNuke (http://www.phpnuke.org/). 
Foi escolhida este tipo de interface, via navegador, pelos seguintes motivos:

1. ser independente de plataforma, ou seja, qualquer que seja o computador e o sistema operacional utilizado, haverá acesso ao sistema;

2. maior velocidade na coleta dos dados, uma vez que estes entram diretamente no servidor;

3. maior centralização dos dados, pois o programa só poderá ser rodado acessando o servidor;

4. não serem necessários treinamentos e deslocamento de pessoal para instalação de programas, uma vez que o programa já estará instalado no servidor;

5. menor tempo gasto no desenvolvimento dos programas.

Com esta interface, o usuário entrará com os dados de determinada fazenda, para simular o potencial de ocorrência de E. aurantiana, via navegadores de internet (Netscape®, Internet Explorer@, Konqueror@ etc). 


\section{RESULTADOS E DISCUSSÃO}

\subsection{Modelo desenvolvido}

\subsubsection{Análise de desvio para seleção das variáveis}

Após o desenvolvimento e simplificação do modelo, para o Modelo Mínimo Adequado (MMA), constatou-se que as variáveis que influenciaram na captura de machos de Ecdytolopha aurantiana (Lima, 1927) (Lepidoptera: Tortricidae), em armadilha de feromônio, foram: temperatura, variedade de citros, agroquímico, tipo de solo e algumas interações (Tabela 2). O modelo desta análise, foi binomial negativo com função de ligação logarítmica, sendo considerado adequado pela análise de resíduos (Figura 6).
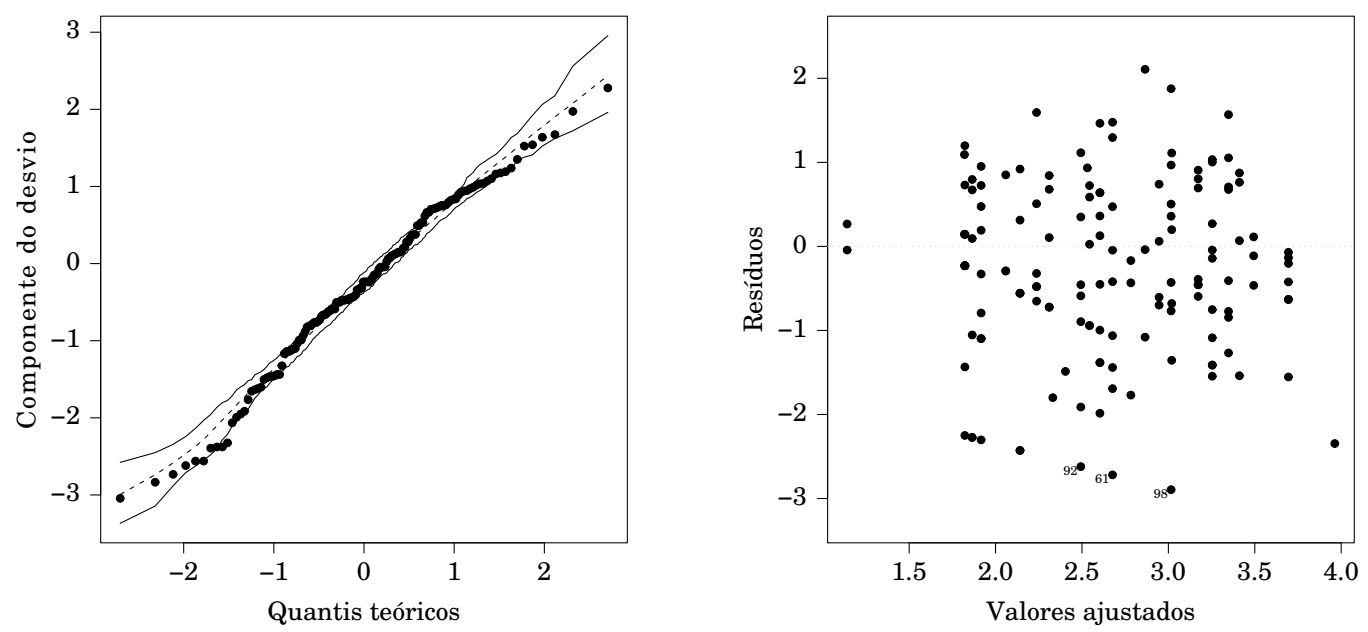

Figura 6 - Resíduos com envelopes de intervalos de confiança mostrando o ajuste adequado do modelo para previsão de ocorrência de Ecdytolopha aurantiana 
Tabela 2. Análise de desvio contendo somente as variáveis e interações que foram significativas para o desenvolvimento do modelo para Ecdytolopha aurantiana. Para a relação da variáveis não significativas, consultar o modelo completo em material e métodos

\begin{tabular}{|c|c|c|c|}
\hline Fonte de variação & GL & Desvio & $\mathrm{P}$ \\
\hline Modelo & 182 & 945.626 & $<0.0000$ \\
\hline Variedade & 6 & 104.7 & $<0.0000$ \\
\hline Solo & 12 & 220.5 & $<0.0000$ \\
\hline Agroquímico & 1 & 56.2 & $<0.0000$ \\
\hline Temperatura & 1 & 19.5 & $<0.0000$ \\
\hline Temperatura $^{2}$ & 1 & 79.2 & $<0.0000$ \\
\hline Variedade:Temperatura & 6 & 46.4 & $<0.0000$ \\
\hline Solo:Temperatura & 12 & 63.1 & $<0.0000$ \\
\hline Variedade:Temperatura ${ }^{2}$ & 6 & 15.5 & 0.0169 \\
\hline Solo:Temperatura ${ }^{2}$ & 12 & 47.5 & $<0.0000$ \\
\hline Variedade:Solo:Temperatura & 47 & 138.4 & $<0.0000$ \\
\hline Variedade:Temperatura:Idade & 6 & 14.8 & 0.0216 \\
\hline Solo:Temperatura:Idade & 12 & 91.6 & $<0.0000$ \\
\hline Variedade:Solo:Temperatura ${ }^{2}$ & 47 & 167 & $<0.0000$ \\
\hline Solo:Temperatura ${ }^{2}$ :Idade & 13 & 22.6 & 0.0472 \\
\hline Resíduo & 2965 & 3562.4 & \\
\hline Total & 3147 & 4649.5 & \\
\hline
\end{tabular}

A variedade de citros cultivada teve influência na ocorrência de $E$. aurantiana (Tabela 2), representando cerca de $51 \%^{1}$ do total explicado pelo modelo.

O tipo de solo encontrado na área, onde foram coletados os machos de E. aurantiana, influenciou na ocorrência deste inseto (Tabela 2). Esta variável foi que teve maior influência na ocorrência de E. aurantiana, representando cerca de $79 \%^{1}$ dentre as diferentes variáveis.

A idade do pomar também teve uma pequena influência, na forma de interações, na presença de E. aurantiana (Tabela 2), com um valor de, aproximadamente, $14 \%^{1}$.

\footnotetext{
${ }^{1}$ Este valor foi calculado somando-se o desvio da variável isolada ao desvio de suas interações e dividindo-os pelo desvio total do modelo. Neste caso, a soma dos valores poderá ultrapassar 100\%, uma vez que existe sobreposição de desvios nas interações.
} 
A aplicação de agroquímicos para controle de E. aurantiana foi o que menos influenciou na ocorrência deste inseto (Tabela 2), sendo responsável por apenas $5 \%^{1}$ da mesma.

A temperatura influenciou a captura de machos de E. aurantiana (Tabela 2), explicando cerca de $75 \%^{2}$ da variação no referido modelo. Este resultado era esperado, pois é sabido que os insetos em geral respondem de forma acentuada a este parâmetro climático, ocorrendo uma grande influência deste parâmetro também para o bicho-furão Garcia (1998); a partir dos resultados obtidos por este autor elaborou-se a Figura 7, utilizando-se modelos lineares generalizados com distribuição binomial (Crawley, 2002). Pôde-se constatar a relação existente entre a temperatura e viabilidade do ciclo de E. aurantiana. Assim, no presente trabalho, o objetivo então não foi testar simplesmente se o inseto responde à temperatura, mas como e quanto as outras variáveis influenciam nesta resposta, levando a variações desta curva.

A interação da variedade de citros com a temperatura indica, principalmente, que o pico de ocorrência de E. aurantiana e a temperatura em que este pico ocorre, não são as mesmas para todas as variedades. Assim, a variedade Natal pode ter um pico de ocorrência em torno de $25^{\circ} \mathrm{C}$, enquanto a variedade Pera Rio pode ter este pico em torno de $22^{\circ} \mathrm{C}$ (Figura $13 \mathrm{~F}$ ).

A interação do tipo de solo com a temperatura indica que, a mesma variedade de citros, plantada tipos diferentes de solo, pode levar a diferentes padrões de ocorrência de E. aurantiana. Esta diferença pode ser notada tanto no pico de ocorrência, quanto na temperatura onde ocorre este pico. Assim, a variedade Natal plantada em solo tipo LEP1, tem um pico de ocorrência em torno de 50 insetos e uma temperatura para este pico em torno de $25^{\circ} \mathrm{C}$ (Figura $13 \mathrm{~F}$ ). Esta mesma variedade

\footnotetext{
${ }^{2}$ Este valor foi calculado somando-se o desvio da variável isolada ao desvio de suas interações e dividindo-os pelo desvio total do modelo. Neste caso, a soma dos valores poderá ultrapassar 100\%, uma vez que existe sobreposição de desvios nas interações.
} 
plantada em solo tipo LE2, tem um pico de ocorrência maior, em torno de 100 insetos e uma temperatura mais elevada para este pico, em torno de $28^{\circ} \mathrm{C}$ (Figura $14 \mathrm{~F}$ ).

A interação da variedade com o tipo de solo e com a temperatura aumentam as diferenças já definidas pelas interações anteriores.

A interação da variedade com a idade e com a temperatura e a interação do tipo de solo com a idade e com a temperatura, fazem com que a o pico de ocorrência e a temperatura onde ocorre este pico sejam modificadas, para cada variedade em cada tipo de solo, dependendo da idade das plantas. Assim, de modo geral, com o aumento da idade das plantas, aumenta-se o pico de ocorrência (maior ocorrência de E. aurantiana) e aumenta-se a temperatura onde este pico populacional ocorre (Figuras de 8 a 20).

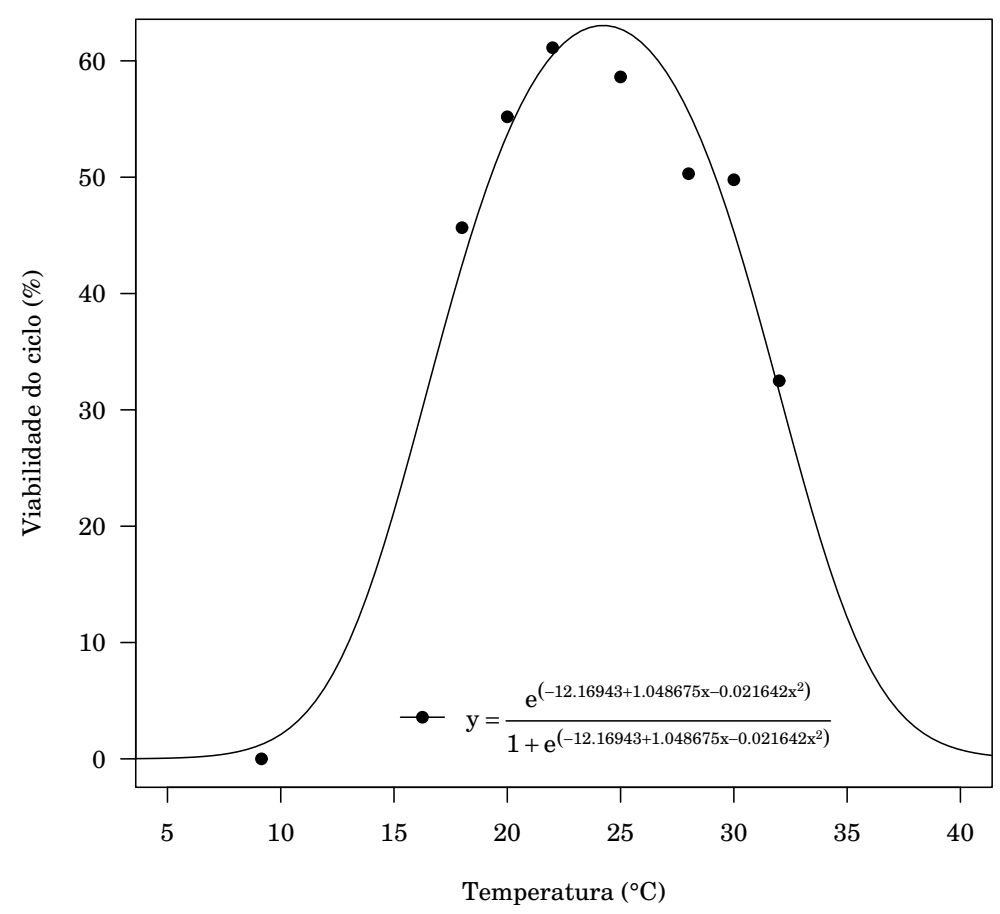

Figura 7 - Viabilidade do ciclo de Ecdytolopha aurantiana em relação a temperatura. Estimativa feita a partir de resultados de laboratório (Garcia, 1998) 
Definidas as variáveis que fazem parte do modelo e seu papel no modelo, foram feitas análises de contraste com as variáveis qualitativas (variedade de citros, tipo de solo, aplicação de agroquímicos) para simplificar ainda mais este modelo até o nível de Modelo Mínimo Adequado Amalgamado (MMAA).

\subsubsection{Análises de contraste}

\subsubsection{Variedade de citros}

A partir da análise de contraste, as diversas variedades de citros foram agrupadas conforme suas similaridades estatísticas de acordo com o tipo de influência sobre a população de E. aurantiana (Tabela 3).

Tabela 3. Análises de contraste das variedades de citros analisadas influenciando a ocorrência de Ecdytolopha aurantiana em função da temperatura. O sinal + indica agrupamento formado e o sinal | indica a comparação

\begin{tabular}{lrrr}
\hline Contrastes & GL & $\chi^{2}$ & P \\
\hline Cravo | Murcott & 1 & 0.0021 & 0.9993 \\
Cravo + Murcott | Baianinha & 1 & 0.2234 & 0.6364 \\
Cravo + Murcott + Baianinha | Westin & 1 & 1.5593 & 0.2117 \\
Cravo + Murcott + Baianinha + Westin | Tahiti & 1 & $<0.0000$ & 0.9999 \\
Cravo + Murcott + Baianinha + Westin + Tahiti | & 1 & 0.6276 & 0.4282 \\
Valência Americana & & & \\
Cravo + Murcott + Baianinha + Westin + Tahiti + & 8 & 29.5411 & 0.0002 \\
Valência Americana | Rubi & & & \\
Rubi | Hamlin & 8 & 35.9080 & $<0.0000$ \\
Hamlin | Valência & 11 & 100.9425 & $<0.0000$ \\
Valência | Pera Rio & 12 & 52.2941 & $<0.0000$ \\
Pera Rio | Valência Argentina & 17 & 29.5193 & 0.0300 \\
Valência Argentina | Natal & 23 & 83.4510 & $<0.0000$ \\
Natal | Valência Americana Precoce & 3 & 6.9492 & 0.0735 \\
\hline
\end{tabular}

Foram definidos sete grupos de variedades, nos quais a ocorrência de E. aurantiana foi semelhante (Tabela 4). Durante o trabalho, serão referidos estes grupos e não mais variedades de forma isolada. 
Tabela 4. Média ( \pm erro padrão), valor máximo e mínimo de captura de machos de Ecdytolopha aurantiana em armadilhas de feromônio sexual e grupos de variedades definidos pela análise de contraste

\begin{tabular}{lrrrr}
\hline Variedade & Média $( \pm$ erro padrão $)$ & Máximo Mínimo Grupo \\
\hline Cravo & $1.57( \pm 0.75)$ & 4 & 0 & \\
Murcott & $2.50( \pm 2.50)$ & 5 & 0 & \\
Baianinha & $3.00( \pm 1.22)$ & 6 & 0 & \\
Westin & $3.90( \pm 0.57)$ & 15 & 0 & GV1 \\
Tahiti & $4.50( \pm 4.50)$ & 9 & 0 & \\
Valência Americana & $6.41( \pm 1.90)$ & 22 & 0 & \\
Rubi & $7.07( \pm 0.92)$ & 48 & 0 & GV2 \\
Hamlin & $7.17( \pm 0.65)$ & 61 & 0 & GV3 \\
Valência & $10.65( \pm 0.65)$ & 84 & 0 & GV4 \\
Pera Rio & $10.75( \pm 0.45)$ & 238 & 0 & GV5 \\
Valência Argentina & $10.81( \pm 0.46)$ & 149 & 0 & GV6 \\
Natal & $12.83( \pm 0.70)$ & 95 & 0 & \\
Valência Am. Precoce & $15.08( \pm 4.52)$ & 54 & 2 & GV7 \\
\hline
\end{tabular}

\subsubsection{Tipos de Solo}

A partir da análise de contraste, os diversos tipos de solos foram agrupados conforme suas similaridades estatísticas de acordo com o tipo de influência sobre a população de E. aurantiana (Tabela 5).

Dos 22 tipos de solos, foram definidos 13 grupos com características semelhantes para a ocorrência de E. aurantiana (Tabela 6). Neste trabalho, a partir desta definição, serão referidos grupos e não mais solos de forma isolada.

\subsubsection{Aplicação de agroquímicos}

Feita a análise de contraste para se definir como a ocorrência de $E$. aurantiana se comporta em relação à utilização ou não de agroquímicos para seu controle e se existe diferença entre os agroquímicos utilizados, chegou-se ao agrupamento final (Tabela 7).

Verificaram-se dois grupos quanto à utilização de agroquímicos para controle de E. aurantiana: um grupo formado pela ausência do uso de agroquímicos e 
Tabela 5. Análises de contraste dos tipos de solos influenciando a ocorrência de Ecdytolopha aurantiana em função da temperatura. O sinal + indica agrupamento formado e o sinal | indica a comparação

\begin{tabular}{lrrr}
\hline Contrastes & GL & $\chi^{2}$ & P \\
\hline LV4 | LE1 & 1 & 0.1942 & 0.6594 \\
LV4 + LE1 | TR1 & 1 & 3.5294 & 0.0602 \\
LV4 + LE1 + TR1 | LEP2 & 7 & 23.7569 & 0.0012 \\
LEP2 | LV1 & 7 & 23.0030 & 0.0017 \\
LV1 | GH & 7 & 9.9797 & 0.1897 \\
LV1 + GH | PEL2 & 8 & 16.004 & 0.0423 \\
PEL2 | LE4 & 3 & 3.8323 & 0.2801 \\
PEL2 + LE4 | HO & 3 & 1.5929 & 0.6609 \\
PEL2 + LE4 + HO | PV4 & 11 & 25.1418 & 0.0080 \\
PV4 | LR2 & 3 & 7.4809 & 0.0580 \\
PV4 + LR2 | LEP1 & 13 & 52.6575 & $<0.0000$ \\
LEP1 | LE2 & 12 & 40.0918 & $<0.0000$ \\
LE2 | PV3 & 15 & 28.3326 & 0.0195 \\
PV3 | LE5 & 11 & 24.3938 & 0.0111 \\
LE5 | LV3 & 9 & 17.5967 & 0.0401 \\
LV3 | LE3 & 9 & 28.4741 & 0.0007 \\
LE3 | AQ & 9 & 67.6692 & $<0.0000$ \\
AQ | HI & 3 & 4.2861 & 0.2321 \\
AQ + HI | PE1 & 7 & 36.6852 & $<0.0000$ \\
PE1 | LR1 & 5 & 3.7574 & 0.5848 \\
PE1 + LR1 | TR2 & 7 & 6.7983 & 0.4501 \\
\hline
\end{tabular}

outro grupo formado pelo uso dos agroquímicos Decis25CE (25g/l) e Dipel (33.60g/l) (Tabela 8).

Terminadas todas as análises de contraste, determinou-se o modelo final, representado pelo máximo nível de simplificação (MMAA). Este é então o modelo final. 
Tabela 6. Média ( \pm erro padrão), valor máximo e mínimo de captura de macho de Ecdytolopha aurantiana em armadilhas de feromônio sexual e grupos de solos definidos pela análise de contraste

\begin{tabular}{lrrrr}
\hline Solo & Média & $( \pm$ erro padrão $)$ & Máximo Mínimo Grupos \\
\hline LV4 & $3.32( \pm 0.48)$ & 10 & 0 & \\
LE1 & $5.22( \pm 1.47)$ & 29 & 0 & GS1 \\
TR1 & $5.53( \pm 0.90)$ & 19 & 0 & \\
LEP2 & $6.45( \pm 0.43)$ & 48 & 0 & GS2 \\
LV1 & $6.72( \pm 0.68)$ & 77 & 0 & \\
GH & $6.83( \pm 0.64)$ & 22 & 0 & GS3 \\
PEL2 & $7.56( \pm 1.18)$ & 89 & 0 & \\
LE4 & $7.86( \pm 0.79)$ & 38 & 0 & GS4 \\
HO & $8.25( \pm 4.62)$ & 22 & 2 & \\
PV4 & $8.46( \pm 0.78)$ & 56 & 0 & \\
LR2 & $8.98( \pm 1.50)$ & 74 & 0 & GS5 \\
LEP1 & $9.93( \pm 1.62)$ & 238 & 0 & GS6 \\
LE2 & $10.69( \pm 1.84)$ & 87 & 0 & GS7 \\
PV3 & $11.54( \pm 0.62)$ & 109 & 0 & GS8 \\
LE5 & $11.63( \pm 0.66)$ & 149 & 0 & GS9 \\
LV3 & $12.38( \pm 0.92)$ & 84 & 0 & GS10 \\
LE3 & $13.50( \pm 1.14)$ & 88 & 0 & GS11 \\
AQ & $13.51( \pm 0.82)$ & 85 & 0 & \\
HI & $14.43( \pm 3.18)$ & 46 & 0 & GS12 \\
PE1 & $14.50( \pm 1.46)$ & 110 & 0 & GS13 \\
LR1 & $15.56( \pm 4.46)$ & 70 & 1 & \\
TR2 & $16.77( \pm 4.43)$ & 64 & 0 & \\
\hline
\end{tabular}

Tabela 7. Análises de contraste da utilização de agroquímicos para controle de bicho-furão em função da temperatura, para coleta da espécie. O sinal | indica a comparação

\begin{tabular}{|c|c|c|c|}
\hline Contrastes & GL & $\chi^{2}$ & $\mathrm{P}$ \\
\hline Decis25CE $(25 \mathrm{~g} / \mathrm{l})$ & 1 & 6.2487 & 0.0124 \\
\hline Decis25CE $(25 \mathrm{~g} / \mathrm{l}) \mid$ Dipel $(33.60 \mathrm{~g} / \mathrm{l})$ & 1 & 0.0235 & 0.8780 \\
\hline
\end{tabular}

Tabela 8. Média ( \pm erro padrão), valor máximo e mínimo de captura de macho de Ecdytolopha aurantiana em armadilhas de feromônio sexual e grupos definidos pela análise de contraste para o uso de agroquímicos

\begin{tabular}{lrrrr}
\hline Agroquímico & Média $( \pm$ erro padrão) & Máximo Mínimo & Grupos \\
\hline Nada & $9.22( \pm 0.26)$ & 109 & 0 & Sem agroquímico \\
Decis25CE $(25 \mathrm{~g} / \mathrm{l})$ & $12.40( \pm 0.47)$ & 238 & 0 & \\
Dipel $(33.60 \mathrm{~g} / \mathrm{l})$ & $16.16( \pm 2.35)$ & 85 & 0 & Com agroquímico \\
\hline
\end{tabular}




\subsubsection{Estimativas dos parâmetros do modelo simplificado}

Uma vez definido o modelo de previsão de ocorrência de E. aurantiana é necessária a confecção de equações, que têm uma forma geral apresentada a seguir (eq. (3)):

Coleta $=e^{\beta_{0}+\beta_{1} \times \text { Temperatura }+\beta_{2} \times \text { Temperatura }^{2}+\beta 3 \times \text { Temperatura } \times \text { Idade }+\beta 4 \times \text { Temperatura }^{2} \times \text { Idade }}$

nesta equação, $\beta_{0}, \beta_{1}, \beta_{2}, \beta_{3}$ e $\beta_{4}$ são parâmetros estimados (Tabela 9). Para cada combinação incluindo variedade de citros, tipo de solo e agroquímico utilizado obtevese uma equação.

$\beta_{0}$ é o parâmetro de define o intercepto da curva, ou seja, o local onde a curva passa pelo eixo das ordenadas (Y), e seu valor também define o ponto máximo desta curva (pico de ocorrência). $\beta_{1}$ é o parâmetro que multiplica a temperatura; e este parâmetro é responsável pelo comportamento crescente ou decrescente da curva dependendo do sinal (positivo ou negativo), sendo também responsável pelo ponto máximo e sua posição no eixo $\mathrm{X}$ dependendo do valor. $\beta_{2}$ é o parâmetro que multiplica o quadrado da temperatura; este parâmetro é responsável pelo comportamento parabólico da curva; assim, valores positivos definem uma assintótica em Y e valores negativos definem a parábola; a grandeza deste valor também define o ponto máximo e a posição da curva no eixo das abscissas (X). $\beta_{3}$ e $\beta_{4}$ simplesmente modificam $\beta_{1}$ e $\beta_{2}$, respectivamente, dependendo da idade das plantas utilizadas no modelo.

Tabela 9. Estimativa dos parâmetros utilizados na definição das equações que compõem o modelo para previsão de ocorrência de Ecdytolopha aurantiana

\begin{tabular}{|c|c|c|c|}
\hline Parâmetro & Estimativa & Valor de $\mathrm{z}$ & $\operatorname{Pr}(>|z|)$ \\
\hline Intercepto & -59.3 & -2.703 & 0.0068 \\
\hline Sem agroquímico & -0.1305 & -2.614 & 0.0089 \\
\hline GS1 & 18.8 & 1.221 & 0.2220 \\
\hline GS1:temperatura & -2.407 & $<0.0000$ & 0.9999 \\
\hline GS1:temperatura ${ }^{2}$ & 0.1046 & 2.295 & 0.0217 \\
\hline GS1:temperatura ${ }^{2}$ :Idade & -0.001861 & -0.677 & 0.4984 \\
\hline GS1:temperatura:Idade & 0.03874 & 0.62 & 0.5352 \\
\hline
\end{tabular}


Tabela 9. Estimativa dos parâmetros utilizados na definição das equações que compõem o modelo para previsão de ocorrência de Ecdytolopha aurantiana

\begin{tabular}{|c|c|c|c|}
\hline Parâmetro & Estimativa & Valor de $\mathrm{z}$ & $\operatorname{Pr}(>|z|)$ \\
\hline GS2 & 4.362 & 0.363 & 0.7162 \\
\hline GS2:temperatura & 2.747 & 1.653 & 0.0983 \\
\hline GS2:temperatura ${ }^{2}$ & -0.1192 & -2.074 & 0.0381 \\
\hline GS2:temperatura ${ }^{2}$ :Idade & 0.01369 & 2.772 & 0.0055 \\
\hline GS2:temperatura:Idade & -0.329 & -2.847 & 0.0044 \\
\hline GS3 & 8.123 & 0.833 & 0.4050 \\
\hline GS3:temperatura ${ }^{2}$ :Idade & -0.0002273 & -0.22 & 0.8258 \\
\hline GS3:temperatura:Idade & 0.009965 & 0.383 & 0.7019 \\
\hline GS4 & 9.823 & 0.771 & 0.4404 \\
\hline GS4:temperatura & -0.9617 & -0.794 & 0.4272 \\
\hline GS4:temperatura ${ }^{2}$ & 0.02499 & 0.855 & 0.3927 \\
\hline GS4:temperatura ${ }^{2}$ :Idade & 0.0002466 & 0.543 & 0.5869 \\
\hline GS4:temperatura ${ }^{2}$ :Idade & 0.0005669 & 1.288 & 0.1978 \\
\hline GS4:temperatura:Idade & -0.0006532 & -0.04 & 0.9677 \\
\hline GS5 & 31.2 & 3.027 & 0.0024 \\
\hline GS5:temperatura & -3.075 & -3.018 & 0.0025 \\
\hline GS5:temperatura ${ }^{2}$ & 0.06789 & 2.681 & 0.0073 \\
\hline GS5:temperatura ${ }^{2}$ :Idade & 0.0002278 & 0.405 & 0.6856 \\
\hline GS5:temperatura ${ }^{2}$ :Idade & 0.0005903 & 1.079 & 0.2804 \\
\hline GS5:temperatura:Idade & 0.01264 & 0.736 & 0.4616 \\
\hline GS6 & -24.23 & -1.833 & 0.0667 \\
\hline GS6:temperatura & 2.071 & 1.576 & 0.1149 \\
\hline GS6:temperatura ${ }^{2}$ & -0.0543 & -1.482 & 0.1383 \\
\hline GS6:temperatura ${ }^{2}$ :Idade & 0.0005115 & 0.311 & 0.7560 \\
\hline GS6:temperatura:Idade & 0.01353 & 0.346 & 0.7290 \\
\hline GS7 & -36.73 & -2.038 & 0.0415 \\
\hline GS7:temperatura & 3.004 & 0.0002 & 0.9997 \\
\hline GS7:temperatura ${ }^{2}$ & -0.04829 & -1.172 & 0.2412 \\
\hline GS7:temperatura ${ }^{2}$ :Idade & 0.001257 & 0.412 & 0.6807 \\
\hline GS7:temperatura:Idade & -0.02235 & -0.302 & 0.7624 \\
\hline GS8 & 4.038 & 0.421 & 0.6736 \\
\hline GS8:temperatura & -0.3604 & -0.399 & 0.6896 \\
\hline GS8:temperatura ${ }^{2}$ & 0.00952 & 0.446 & 0.6552 \\
\hline GS8:temperatura ${ }^{2}$ :Idade & 0.0003743 & 0.771 & 0.4404 \\
\hline GS8:temperatura ${ }^{2}$ :Idade & 0.0008669 & 1.79 & 0.0734 \\
\hline GS8:temperatura:Idade & -0.01634 & -0.998 & 0.3181 \\
\hline GS9 & 6.241 & 0.721 & 0.4706 \\
\hline GS9:temperatura & -0.7848 & -0.943 & 0.3454 \\
\hline GS9:temperatura ${ }^{2}$ & 0.02303 & 1.139 & 0.254 \\
\hline GS9:temperatura ${ }^{2}$ :Idade & -0.0004468 & -1.048 & 0.2944 \\
\hline GS9:temperatura:Idade & 0.0173 & 1.116 & 0.2643 \\
\hline GS10 & 1.22 & 0.126 & 0.8994 \\
\hline
\end{tabular}


Tabela 9. Estimativa dos parâmetros utilizados na definição das equações que compõem o modelo para previsão de ocorrência de Ecdytolopha aurantiana

\begin{tabular}{|c|c|c|c|}
\hline Parâmetro & Estimativa & Valor de $\mathrm{z}$ & $\operatorname{Pr}(>|z|)$ \\
\hline GS10:temperatura & 0.5063 & 0.519 & 0.6038 \\
\hline GS10:temperatura ${ }^{2}$ & -0.02249 & -0.873 & 0.3825 \\
\hline GS10:temperatura ${ }^{2}$ :Idade & 0.003687 & 2.935 & 0.0033 \\
\hline GS10:temperatura:Idade & -0.08073 & -2.631 & 0.0085 \\
\hline GS11 & -29.04 & -2.914 & 0.0035 \\
\hline GS11:temperatura & 3.208 & $<0.0000$ & 0.9999 \\
\hline GS11:temperatura ${ }^{2}$ & -0.03158 & -1.022 & 0.3067 \\
\hline GS11:temperatura ${ }^{2}:$ Idade & 0.0004395 & 0.476 & 0.6343 \\
\hline GS11:temperatura:Idade & -0.004176 & -0.17 & 0.8648 \\
\hline GS12:temperatura $^{2}:$ Idade & 0.0004364 & 0.853 & 0.3938 \\
\hline GS13 & -30.83 & -2.807 & 0.0049 \\
\hline GS13:temperatura & -7.669 & $<0.0000$ & 0.9999 \\
\hline GS13:temperatura ${ }^{2}$ & 0.4201 & $<0.0000$ & 0.9999 \\
\hline GS13:temperatura ${ }^{2}$ :Idade & 0.00053 & 0.57 & 0.5685 \\
\hline GS13:temperatura:Idade & -0.006404 & -0.255 & 0.7986 \\
\hline GV1:temperatura & 6.617 & 0.0002 & 0.9998 \\
\hline GV1:temperatura ${ }^{2}$ & -0.1487 & -3.138 & 0.0017 \\
\hline GV1:temperatura:Idade & -0.1229 & $<0.0000$ & 0.9999 \\
\hline GV2 & 46.47 & 1.911 & 0.0559 \\
\hline GV2:GS4:temperatura & -0.4655 & -1.91 & 0.0560 \\
\hline GV2:GS4:temperatura ${ }^{2}$ & 0.01861 & 1.703 & 0.0885 \\
\hline GV2:GS6:temperatura & -0.5968 & -1.608 & 0.1079 \\
\hline GV2:GS6:temperatura ${ }^{2}$ & 0.01844 & 1.244 & 0.2136 \\
\hline GV2:GS7:temperatura & -0.2419 & $<0.0000$ & 0.9999 \\
\hline GV2:GS7:temperatura ${ }^{2}$ & -0.001289 & -0.052 & 0.9581 \\
\hline GV2:temperatura & 1.636 & 1.131 & 0.2580 \\
\hline GV2:temperatura ${ }^{2}$ & -0.04522 & -1.341 & 0.1798 \\
\hline GV3 & -45.08 & -1.782 & 0.0747 \\
\hline GV3:GS1:temperatura & 0.1994 & $<0.0000$ & 0.9999 \\
\hline GV3:GS1:temperatura ${ }^{2}$ & -0.03967 & -1.737 & 0.08246 \\
\hline GV3:GS2:temperatura & 1.667 & 5.087 & $<0.0000$ \\
\hline GV3:GS2:temperatura ${ }^{2}$ & -0.07011 & -4.976 & $<0.0000$ \\
\hline GV3:GS4:temperatura & -0.05346 & -0.168 & 0.8668 \\
\hline GV3:GS4:temperatura ${ }^{2}$ & 0.00006078 & 0.004 & 0.9964 \\
\hline GV3:GS6:temperatura & -0.2264 & -0.754 & 0.4510 \\
\hline GV3:GS6:temperatura ${ }^{2}$ & 0.007794 & 0.607 & 0.5436 \\
\hline GV3:GS7:temperatura & 0.573 & $<0.0000$ & 0.9999 \\
\hline GV3:GS7:temperatura ${ }^{2}$ & -0.03454 & -1.79 & 0.0733 \\
\hline GV3:GS8:temperatura & 0.7196 & 1.696 & 0.0898 \\
\hline GV3:GS8:temperatura ${ }^{2}$ & -0.02933 & -1.635 & 0.1020 \\
\hline GV3:GS9:temperatura & 1.398 & 6.039 & $<0.0000$ \\
\hline GV3:GS9:temperatura ${ }^{2}$ & -0.06343 & -6.352 & $<0.0000$ \\
\hline
\end{tabular}


Tabela 9. Estimativa dos parâmetros utilizados na definição das equações que compõem o modelo para previsão de ocorrência de Ecdytolopha aurantiana

\begin{tabular}{|c|c|c|c|}
\hline Parâmetro & Estimativa & Valor de $\mathrm{z}$ & $\operatorname{Pr}(>|z|)$ \\
\hline GV3:GS11:temperatura & -0.06237 & $<0.0000$ & 0.9999 \\
\hline GV3:GS11:temperatura ${ }^{2}$ & -0.04602 & -2.076 & 0.0379 \\
\hline GV3:GS13:temperatura & 10.29 & $<0.0000$ & 0.9999 \\
\hline GV3:GS13:temperatura ${ }^{2}$ & -0.4761 & $<0.0000$ & 0.9999 \\
\hline GV3:temperatura & 8.756 & 6.056 & $<0.0000$ \\
\hline GV3:temperatura ${ }^{2}$ & -0.1858 & -5.641 & $<0.0000$ \\
\hline GV3:temperatura:Idade & 0.00592 & 0.453 & 0.6503 \\
\hline GV4 & 42.72 & 1.932 & 0.0534 \\
\hline GV4:GS4:temperatura & 0.0186 & 0.076 & 0.9394 \\
\hline GV4:GS4:temperatura ${ }^{2}$ & -0.00003906 & -0.004 & 0.9971 \\
\hline GV4:GS5:temperatura & 0.08321 & 0.899 & 0.3686 \\
\hline GV4:GS5:temperatura ${ }^{2}$ & -0.001709 & -0.414 & 0.6791 \\
\hline GV4:GS6:temperatura & -0.2327 & -0.965 & 0.3344 \\
\hline GV4:GS6:temperatura ${ }^{2}$ & 0.01176 & 1.103 & 0.2702 \\
\hline GV4:GS10:temperatura & 0.1298 & 1.278 & 0.2011 \\
\hline GV4:GS10:temperatura ${ }^{2}$ & -0.005493 & -1.232 & 0.2177 \\
\hline GV4:temperatura & 1.928 & 2.42 & 0.0155 \\
\hline GV4:temperatura ${ }^{2}$ & -0.04412 & -2.27 & 0.0232 \\
\hline GV4:temperatura:Idade & -0.01655 & -1.416 & 0.1569 \\
\hline GV5 & 35.37 & 1.693 & 0.0903 \\
\hline GV5:GS1:temperatura & 0.2095 & $<0.0000$ & 0.9999 \\
\hline GV5:GS1:temperatura ${ }^{2}$ & -0.0407 & -2.639 & 0.0083 \\
\hline GV5:GS2:temperatura & 0.4589 & 2.487 & 0.0128 \\
\hline GV5:GS2:temperatura ${ }^{2}$ & -0.01772 & -2.213 & 0.0268 \\
\hline GV5:GS4:temperatura & -0.002212 & -0.011 & 0.9915 \\
\hline GV5:GS4:temperatura ${ }^{2}$ & -0.00008543 & -0.009 & 0.9926 \\
\hline GV5:GS5:temperatura & 0.0297 & 0.154 & 0.8776 \\
\hline GV5:GS5:temperatura ${ }^{2}$ & 0.0002689 & 0.03 & 0.9762 \\
\hline GV5:GS6:temperatura & 0.008369 & 0.043 & 0.9654 \\
\hline GV5:GS6:temperatura ${ }^{2}$ & 0.001373 & 0.158 & 0.8742 \\
\hline GV5:GS7:temperatura & 0.5879 & $<0.0000$ & 0.9999 \\
\hline GV5:GS7:temperatura ${ }^{2}$ & -0.03594 & -2.232 & 0.0256 \\
\hline GV5:GS8:temperatura & -0.1317 & -1.174 & 0.2404 \\
\hline GV5:GS8:temperatura ${ }^{2}$ & 0.006871 & 1.461 & 0.1440 \\
\hline GV5:GS9:temperatura & -0.07278 & -0.693 & 0.4881 \\
\hline GV5:GS9:temperatura ${ }^{2}$ & 0.003995 & 0.874 & 0.3818 \\
\hline GV5:GS10:temperatura & 0.2501 & 1.922 & 0.05455 \\
\hline GV5:GS10:temperatura ${ }^{2}$ & -0.009524 & -1.689 & 0.0912 \\
\hline GV5:GS11:temperatura & -0.6175 & $<0.0000$ & 0.9999 \\
\hline GV5:GS11:temperatura ${ }^{2}$ & -0.02252 & -1.118 & 0.2636 \\
\hline GV5:GS13:temperatura & 10.64 & $<0.0000$ & 0.9999 \\
\hline GV5:GS13:temperatura ${ }^{2}$ & -0.4891 & $<0.0000$ & 0.9999 \\
\hline
\end{tabular}


Tabela 9. Estimativa dos parâmetros utilizados na definição das equações que compõem o modelo para previsão de ocorrência de Ecdytolopha aurantiana

\begin{tabular}{|c|c|c|c|}
\hline Parâmetro & Estimativa & Valor de $\mathrm{z}$ & $\operatorname{Pr}(>|z|)$ \\
\hline GV5:temperatura & 2.549 & 3.325 & 0.0008 \\
\hline GV5:temperatura ${ }^{2}$ & -0.06263 & -3.318 & 0.0009 \\
\hline GV5:temperatura:Idade & -0.005537 & -0.445 & 0.6564 \\
\hline GV6 & 35.98 & 1.689 & 0.0911 \\
\hline GV6:GS1:temperatura & 0.3367 & $<0.0000$ & 0.9999 \\
\hline GV6:GS1:temperatura ${ }^{2}$ & -0.0462 & -3.157 & 0.0015 \\
\hline GV6:GS7:temperatura & 0.6908 & $<0.0000$ & 0.9999 \\
\hline GV6:GS7:temperatura ${ }^{2}$ & -0.04377 & -2.414 & 0.0157 \\
\hline GV6:GS11:temperatura & -0.7584 & $<0.0000$ & 0.9999 \\
\hline GV6:GS11:temperatura ${ }^{2}$ & -0.01796 & -0.961 & 0.3366 \\
\hline GV6:GS13:temperatura & 10.47 & $<0.0000$ & 0.9999 \\
\hline GV6:GS13:temperatura ${ }^{2}$ & -0.4806 & $<0.0000$ & 0.9999 \\
\hline GV6:temperatura & 2.425 & 3.583 & 0.0003 \\
\hline GV6:temperatura ${ }^{2}$ & -0.0574 & -3.509 & 0.0004 \\
\hline GV6:temperatura:Idade & -0.006143 & -0.508 & 0.6116 \\
\hline GV7 & 50.67 & 2.351 & 0.0187 \\
\hline GV7:GS2:temperatura & 0.3552 & 1.894 & 0.0582 \\
\hline GV7:GS2:temperatura ${ }^{2}$ & -0.01252 & -1.536 & 0.1246 \\
\hline GV7:GS4:temperatura & 0.1001 & 0.413 & 0.6795 \\
\hline GV7:GS4:temperatura ${ }^{2}$ & -0.003165 & -0.294 & 0.7689 \\
\hline GV7:GS5:temperatura & -0.04704 & -0.214 & 0.8308 \\
\hline GV7:GS5:temperatura ${ }^{2}$ & 0.01034 & 1.068 & 0.2854 \\
\hline GV7:GS6:temperatura & -0.3558 & -1.07 & 0.2846 \\
\hline GV7:GS6:temperatura ${ }^{2}$ & 0.01833 & 1.305 & 0.1917 \\
\hline GV7:GS7:temperatura & -0.1776 & $<0.0000$ & 0.9999 \\
\hline GV7:GS7:temperatura ${ }^{2}$ & -0.002363 & -0.122 & 0.9028 \\
\hline GV7:GS8:temperatura & -0.02322 & -0.176 & 0.8604 \\
\hline GV7:GS8:temperatura ${ }^{2}$ & 0.003813 & 0.666 & 0.5054 \\
\hline GV7:GS9:temperatura & -0.09104 & -0.713 & 0.4756 \\
\hline GV7:GS9:temperatura ${ }^{2}$ & 0.004759 & 0.852 & 0.3942 \\
\hline GV7:GS10:temperatura & -0.2691 & -0.985 & 0.3244 \\
\hline GV7:GS10:temperatura ${ }^{2}$ & 0.01274 & 1.091 & 0.2753 \\
\hline GV7:GS11:temperatura & -0.5917 & $<0.0000$ & 0.9999 \\
\hline GV7:GS11:temperatura ${ }^{2}$ & -0.02263 & -1.172 & 0.2413 \\
\hline GV7:GS13:temperatura & 10.47 & $<0.0000$ & 0.9999 \\
\hline GV7:GS13:temperatura ${ }^{2}$ & -0.4789 & $<0.0000$ & 0.9999 \\
\hline GV7:temperatura & 1.146 & 1.336 & 0.1815 \\
\hline GV7:temperatura ${ }^{2}$ & -0.03148 & -1.49 & 0.1361 \\
\hline GV7:temperatura:Idade & -0.005798 & -0.472 & 0.6370 \\
\hline
\end{tabular}


Para a localização dos parâmetros e definição das equações, adota-se o seguinte procedimento: analisando-se a Tabela 9, toma-se o parâmetro junto ao intercepto e soma-se os outros valores com base na combinação desejada. Para a compreensão do modelo, um exemplo é citado a seguir. Construir a equação que defina a ocorrência de E. aurantiana no solo GS6 (LEP1), variedade GV5 (Pera Rio) e sem utilização de agroquímicos para controle:

1. a definição de $\beta_{0}$, necessita dos seguintes valores:

- Valor junto ao intercepto (-59.3).

- Valor correspondente ao local onde não há aplicação de agroquímicos $(-0.1305)$.

- Valores onde o solo GS6 aparece isoladamente (-24.23).

- Valores onde a variedade GV5 aparece isoladamente (35.37).

desta forma, $\beta_{0}=(-59.3)+(-24.23)+(35.37)=-48.2905$

2. a definição de $\beta_{1}$, necessita dos seguintes valores:

- Valor onde o solo GS6 aparece associado à temperatura (2.071).

- Valor onde a variedade GV5 aparece associada à temperatura (2.549).

- Valor onde o solo GS6 e a variedade GV5 aparecem associados à temperatura $(0.008369)$.

desta forma, $\beta_{1}=(2.071)+(2.549)+(0.008369)=4.628369$

3. a definição de $\beta_{2}$, necessita dos seguintes valores:

- Valor onde o solo GS6 aparece associado à temperatura ${ }^{2}(-0.0543)$.

- Valor onde a variedade GV5 aparece associada à temperatura² $(-0.06263)$. 
- Valor onde o solo GS6 e a variedade GV5 aparecem associados à temperatura ${ }^{2}(0.001373)$.

desta forma, $\beta_{2}=(-0.0543)+(-0.06263)+(0.001373)=-0.115557$

4. a definição de $\beta_{3}$, necessita dos seguintes valores:

- Valor onde o solo GS6 aparece associado à temperatura e idade (0.01353).

- Valor onde a variedade GV5 aparece associada à temperatura e idade $(-0.005537)$.

desta forma, $\beta_{3}=(0.01353)+(-0.005537)=0.007993$

5. a definição de $\beta_{4}$, necessita dos seguintes valores:

- Valor onde o solo GS6 aparece associado à temperatura ${ }^{2}$ e idade $(0.0005115)$.

- Valor onde a variedade GV5 aparece associada à temperatura² e idade; se o valor não existir deve ser atribuído o valor zero (0).

desta forma, $\beta_{4}=(0.0005115)+(0)=0.0005115$

Os valores obtidos poderão ser substituídos na eq. (3):

Coleta $=e^{(-48.2905)+(4.628369) \times T e m p+(-0.115557) \times T e m p^{2}+(0.007993) \times T e m p \times I d+(0.0005115) \times T e m p^{2} \times I d}$

onde, Temp $=$ Temperatura e Id $=$ Idade

Visando a agilização da confecção destas equações, foi desenvolvido um programa em R que visa compor estas equações e simular situações diversas de ocorrência de E. aurantiana. Este programa foi utilizado para gerar os gráficos das Figuras de 8 a 20, que mostram como as diferentes variáveis influenciam a ocorrência de E. aurantiana. 


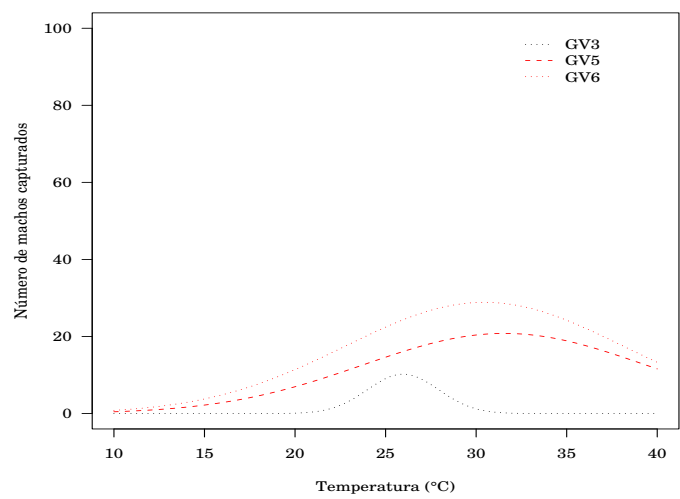

$\mathbf{C}$
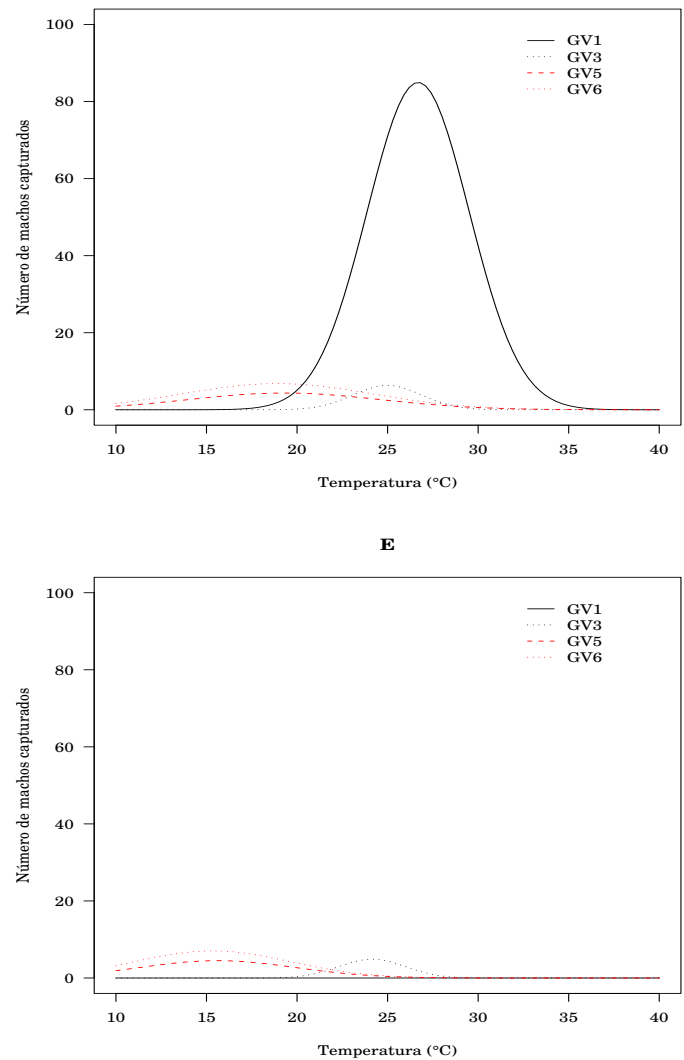

B

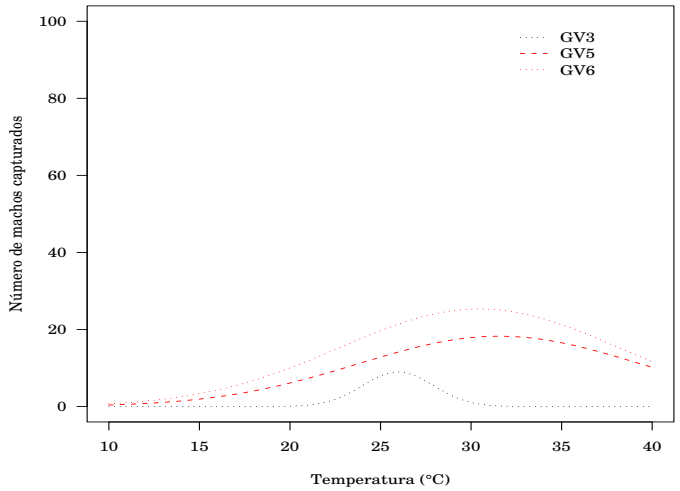

$\mathbf{D}$
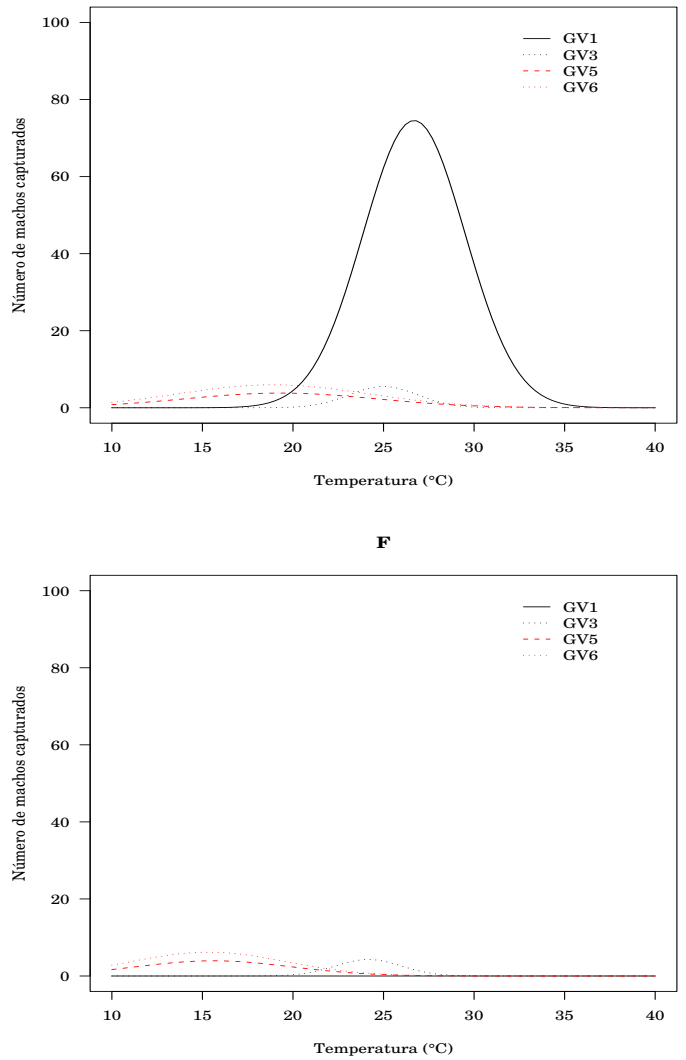

Figura 8 - Estimativas de ocorrência de Ecdytolopha aurantiana para o solo GS1 (LV4, LE1 e TR1) em função da temperatura, variedades de citros, aplicação de agroquímicos e idade das plantas. A - plantas com idade de 5 anos e com aplicação de agroquímicos; B - plantas com idade de 5 anos e sem aplicação de agroquímicos; C - plantas com idade de 10 anos e com aplicação de agroquímicos; D - plantas com idade de 10 anos e sem aplicação de agroquímicos; E - plantas com idade de 15 anos e com aplicação de agroquímicos; F - plantas com idade de 15 anos e sem aplicação de agroquímicos 

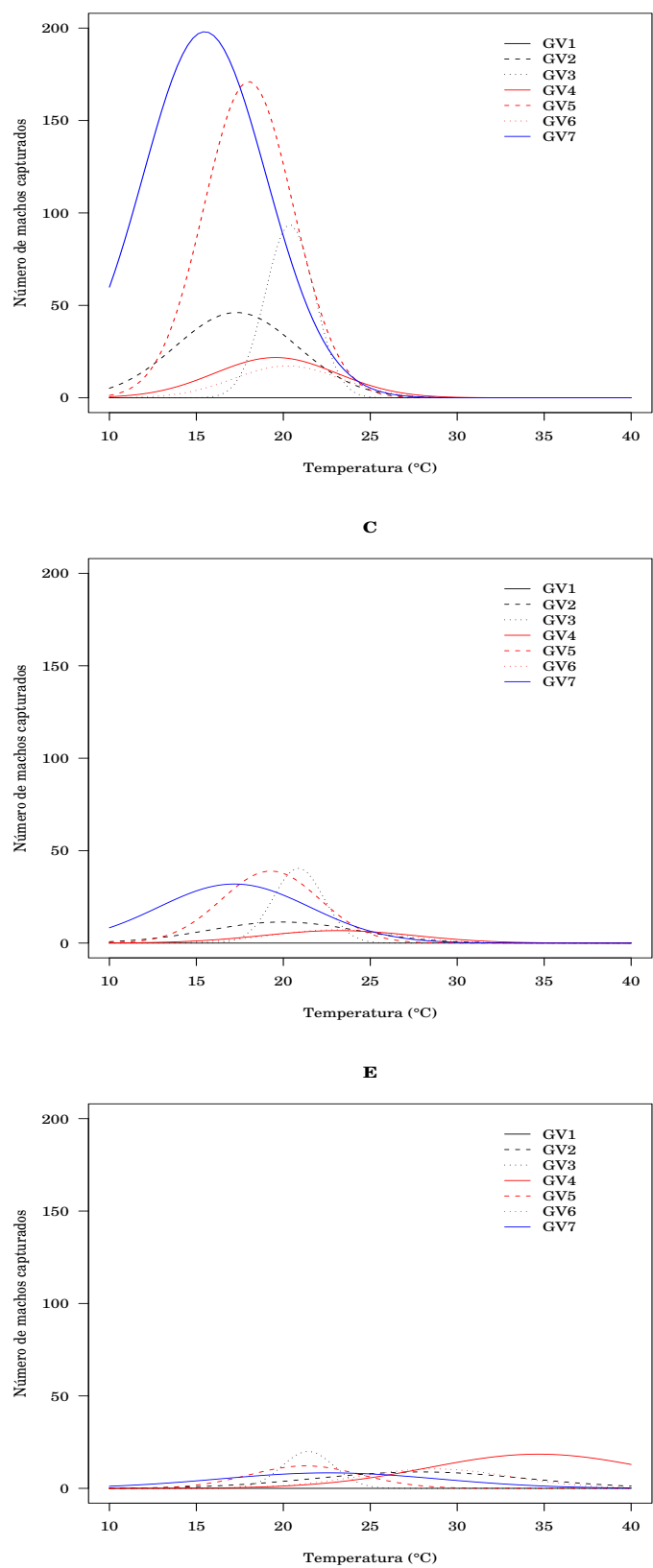

B

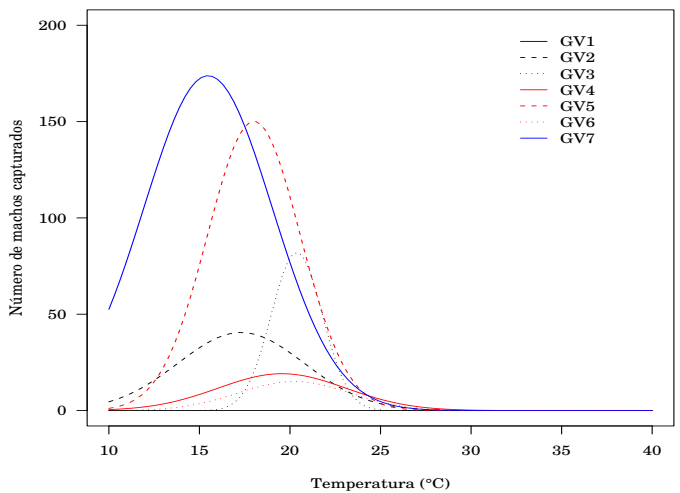

D

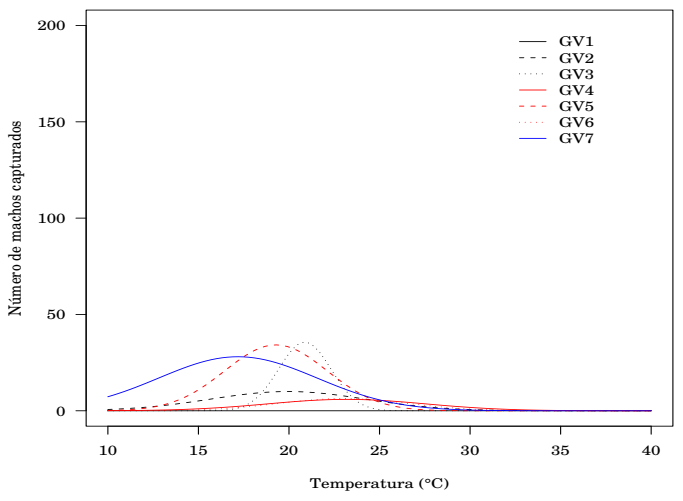

$\mathbf{F}$

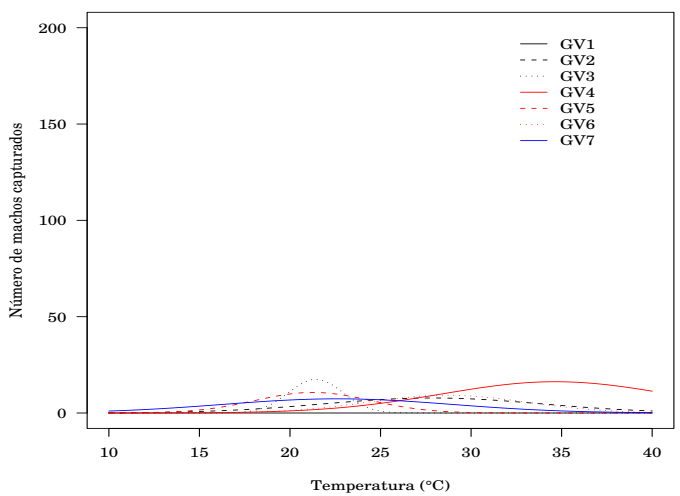

Figura 9 - Estimativas de ocorrência de Ecdytolopha aurantiana para o solo GS2 (LEP2) em função da temperatura, variedades de citros, aplicação de agroquímicos e idade das plantas. A - plantas com idade de 5 anos e com aplicação de agroquímicos; B - plantas com idade de 5 anos e sem aplicação de agroquímicos; C - plantas com idade de 10 anos e com aplicação de agroquímicos; D - plantas com idade de 10 anos e sem aplicação de agroquímicos; E - plantas com idade de 15 anos e com aplicação de agroquímicos; F - plantas com idade de 15 anos e sem aplicação de agroquímicos 
$\mathbf{A}$

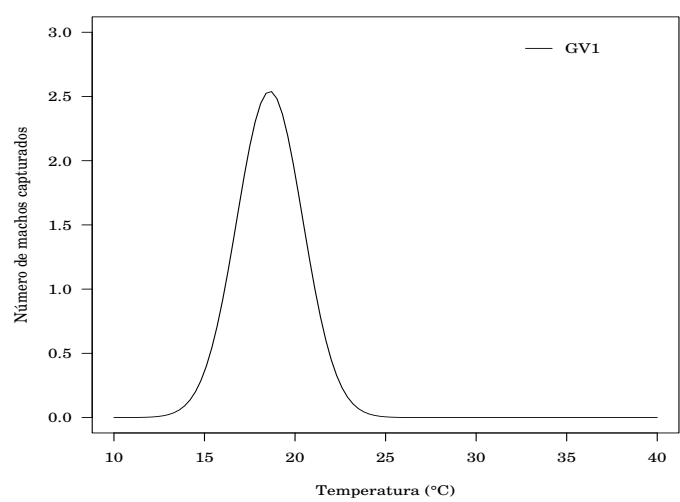

C
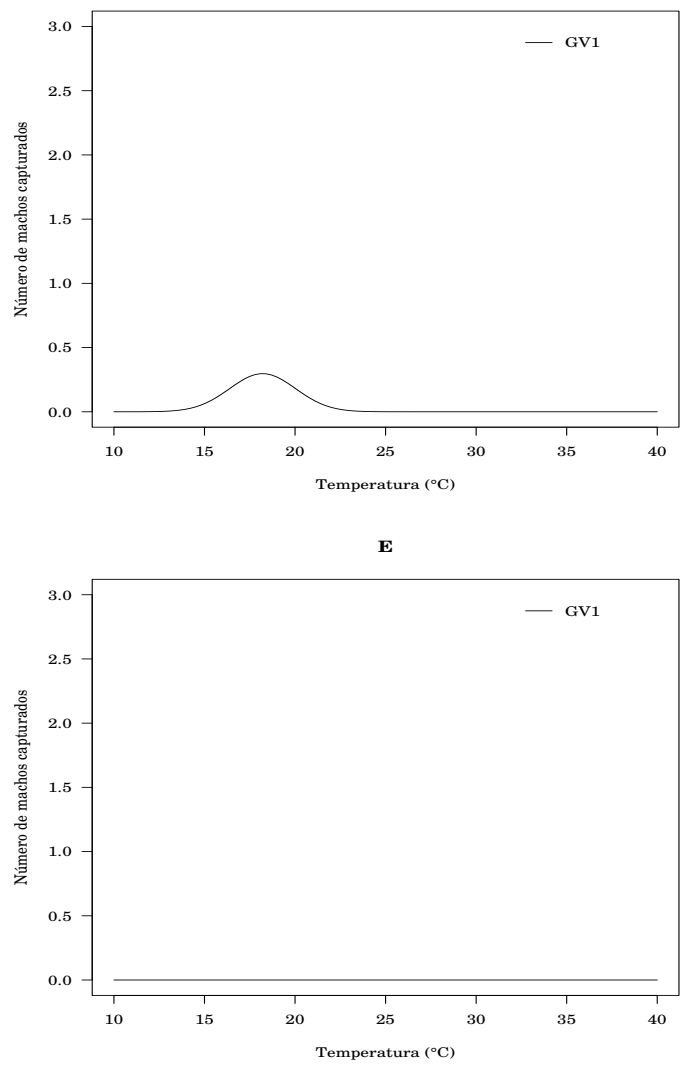

B

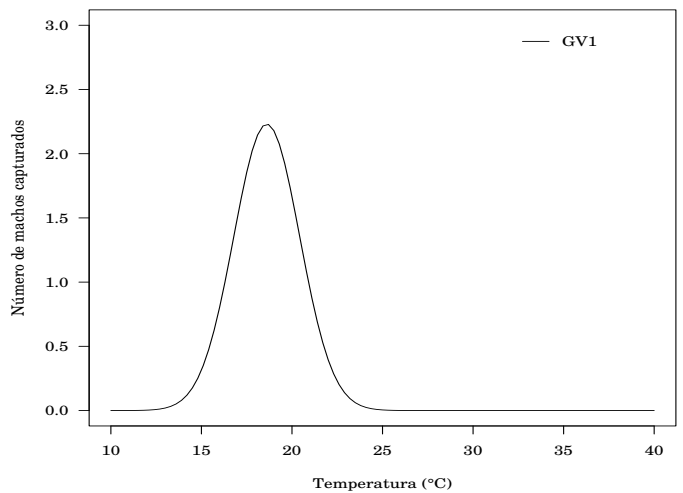

D

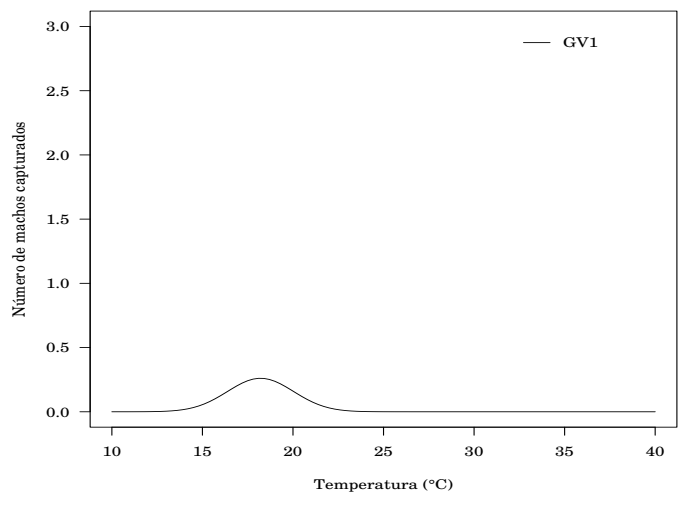

$\mathbf{F}$

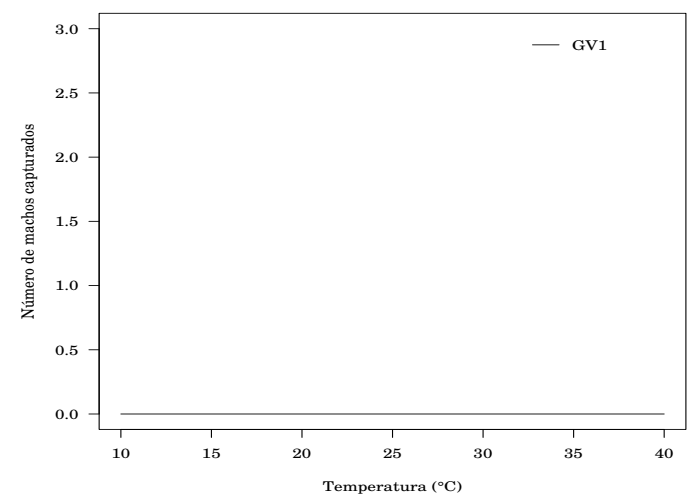

Figura 10 - Estimativas de ocorrência de Ecdytolopha aurantiana para o solo GS3 (LV1 e GH) em função da temperatura, variedades de citros, aplicação de agroquímicos e idade das plantas. A - plantas com idade de 5 anos e com aplicação de agroquímicos; B - plantas com idade de 5 anos e sem aplicação de agroquímicos; $\mathrm{C}$ - plantas com idade de 10 anos e com aplicação de agroquímicos; D - plantas com idade de 10 anos e sem aplicação de agroquímicos; E - plantas com idade de 15 anos e com aplicação de agroquímicos; F - plantas com idade de 15 anos e sem aplicação de agroquímicos 


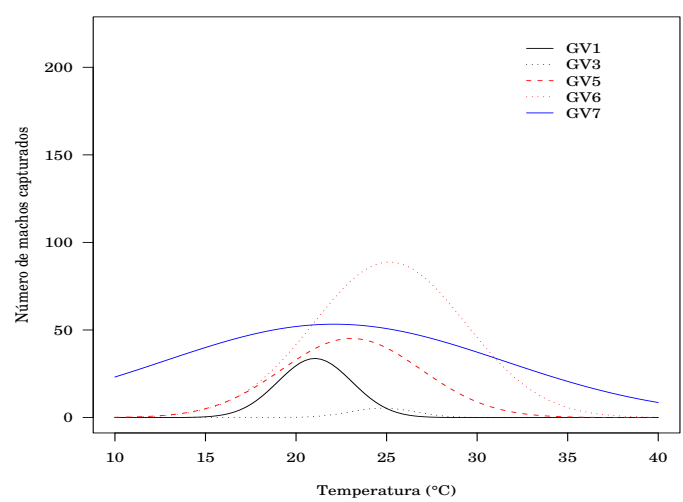

$\mathbf{C}$
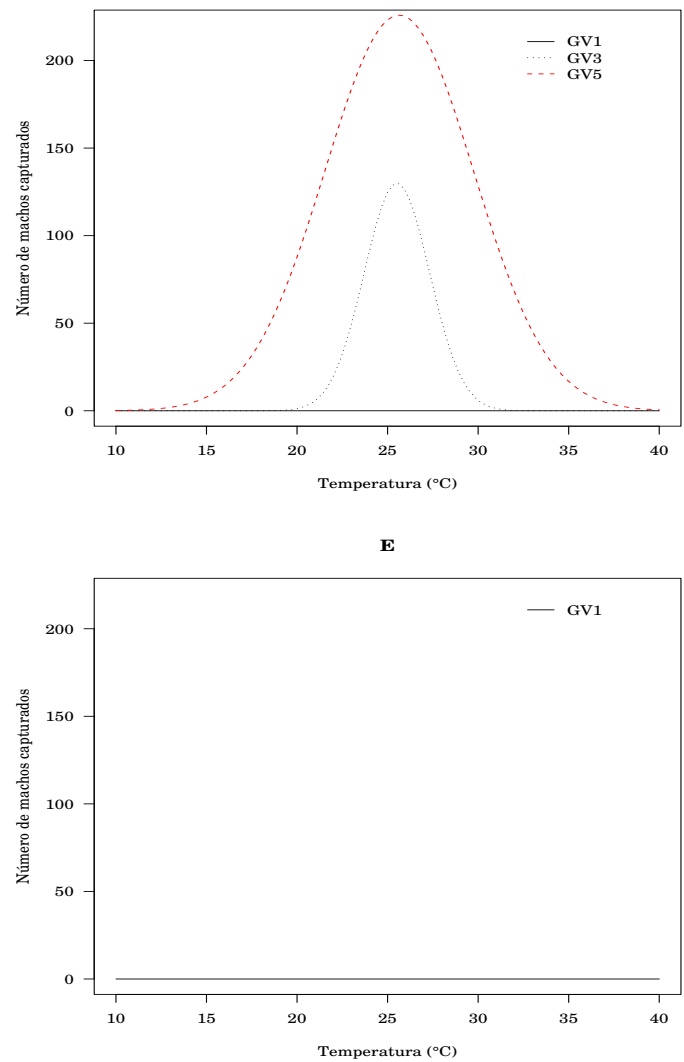

B

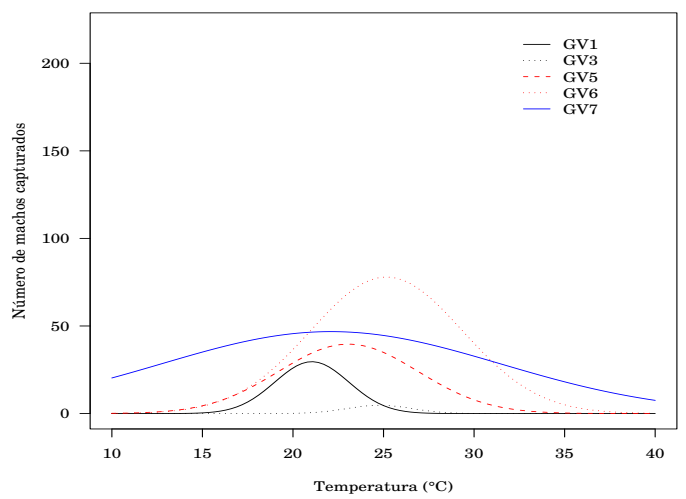

$\mathbf{D}$

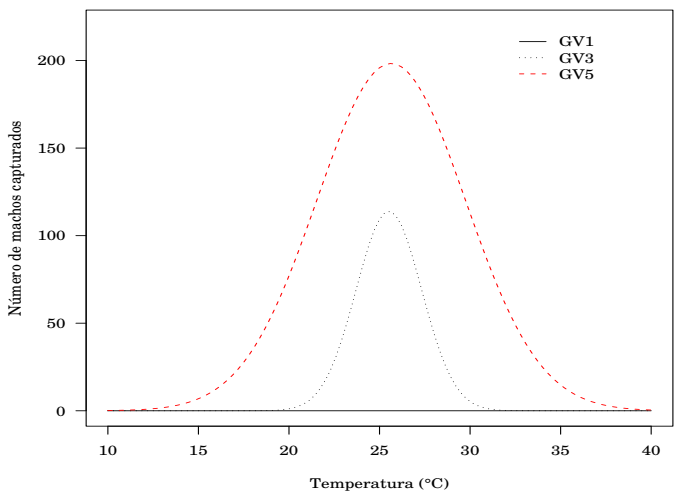

$\mathbf{F}$

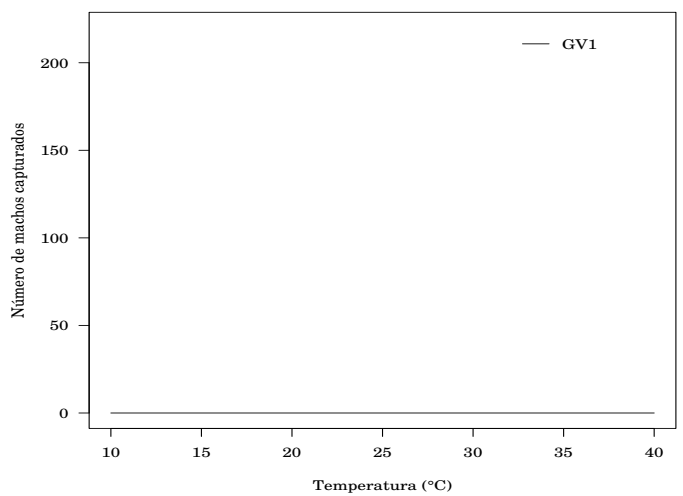

Figura 11 - Estimativas de ocorrência de Ecdytolopha aurantiana para o solo GS4 (PEL2, LE4 e HO) em função da temperatura, variedades de citros, aplicação de agroquímicos e idade das plantas. A - plantas com idade de 5 anos e com aplicação de agroquímicos; B - plantas com idade de 5 anos e sem aplicação de agroquímicos; C - plantas com idade de 10 anos e com aplicação de agroquímicos; D - plantas com idade de 10 anos e sem aplicação de agroquímicos; E - plantas com idade de 15 anos e com aplicação de agroquímicos; F - plantas com idade de 15 anos e sem aplicação de agroquímicos 


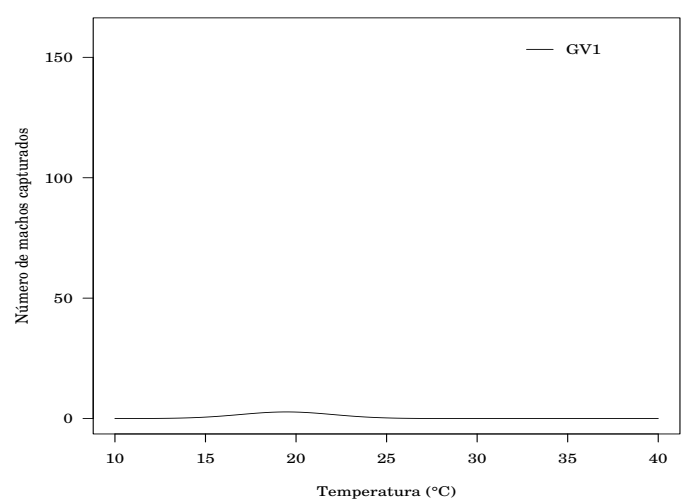

$\mathbf{C}$
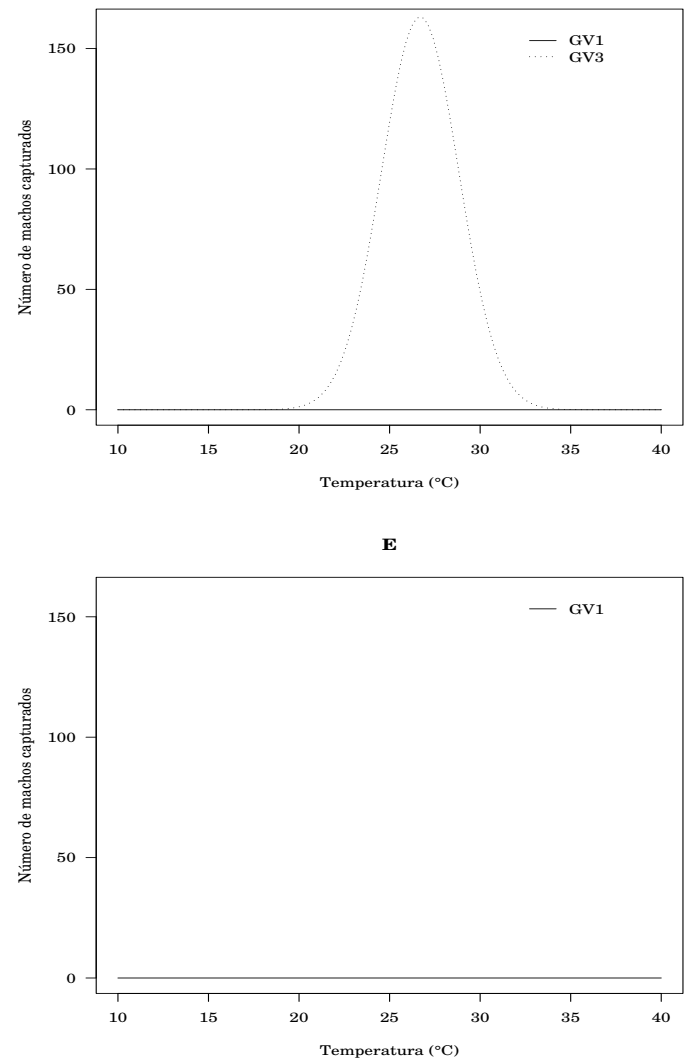

B

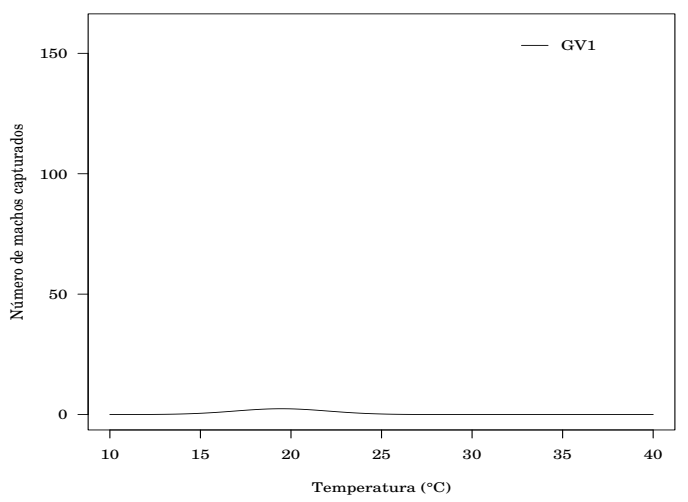

$\mathbf{D}$
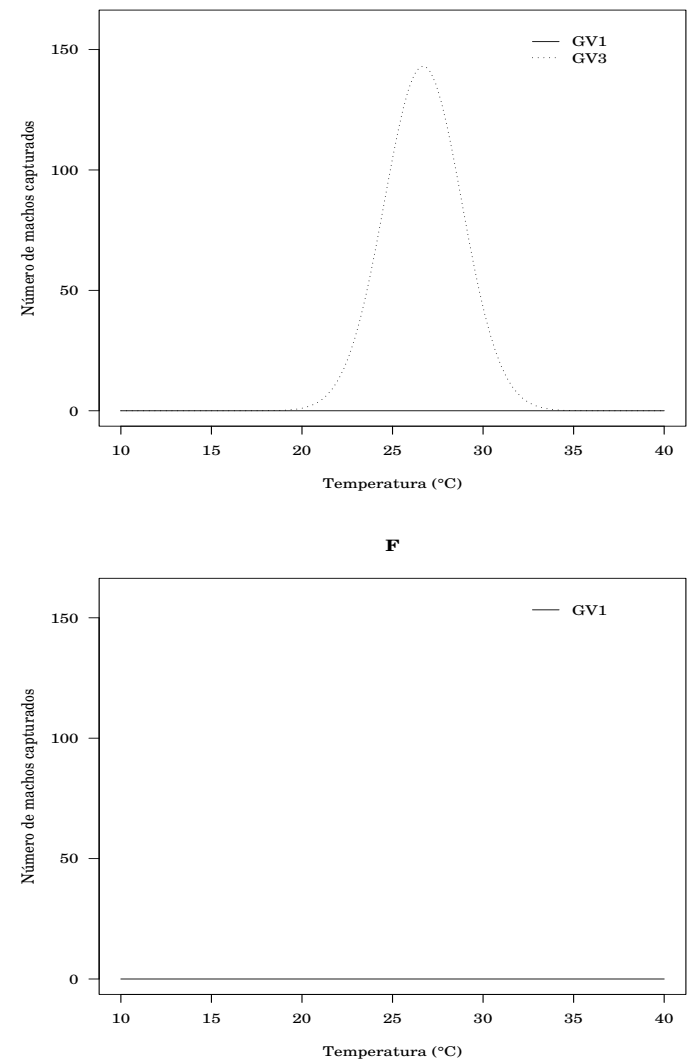

Figura 12 - Estimativas de ocorrência de Ecdytolopha aurantiana para o solo GS5 (PV4, LR2) em função da temperatura, variedades de citros, aplicação de agroquímicos e idade das plantas. A - plantas com idade de 5 anos e com aplicação de agroquímicos; B - plantas com idade de 5 anos e sem aplicação de agroquímicos; C - plantas com idade de 10 anos e com aplicação de agroquímicos; D - plantas com idade de 10 anos e sem aplicação de agroquímicos; E - plantas com idade de 15 anos e com aplicação de agroquímicos; F - plantas com idade de 15 anos e sem aplicação de agroquímicos 
$\mathbf{A}$

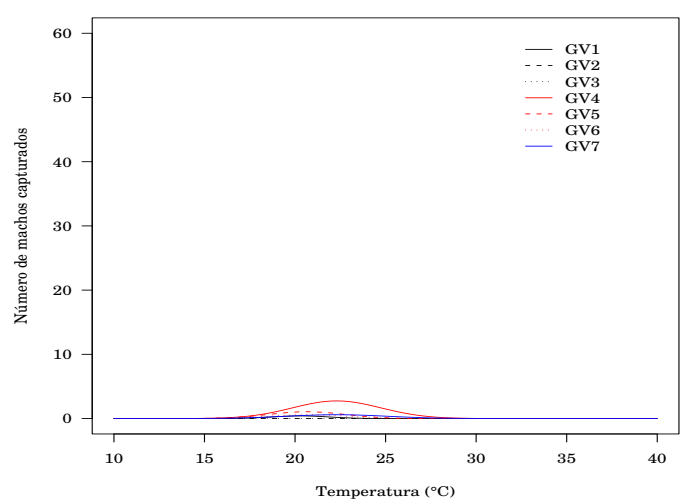

$\mathbf{C}$

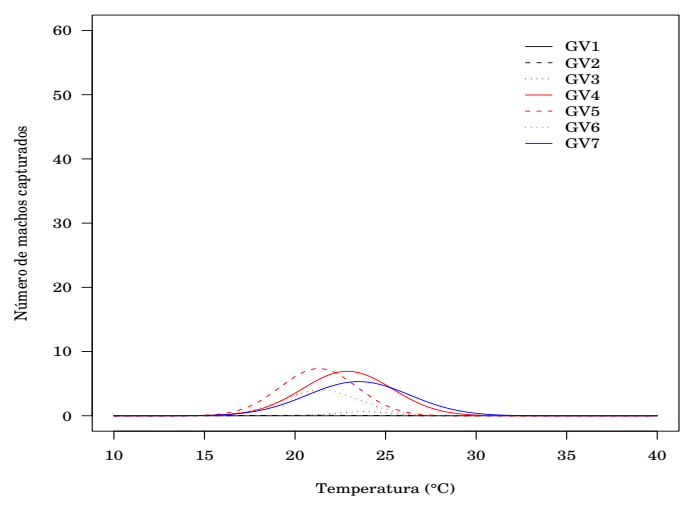

$\mathbf{E}$

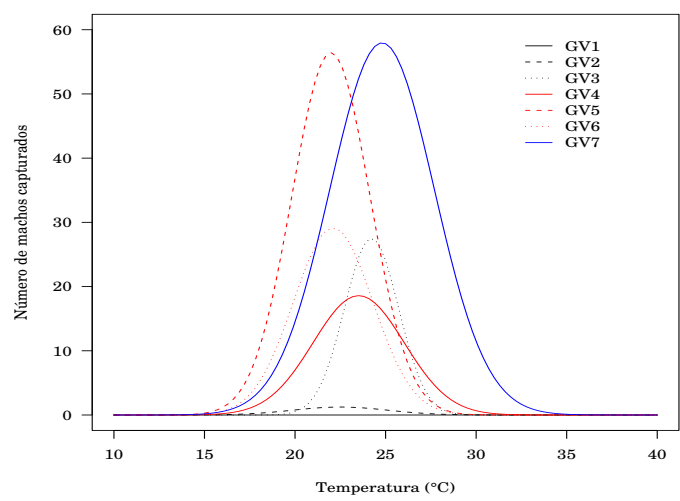

B

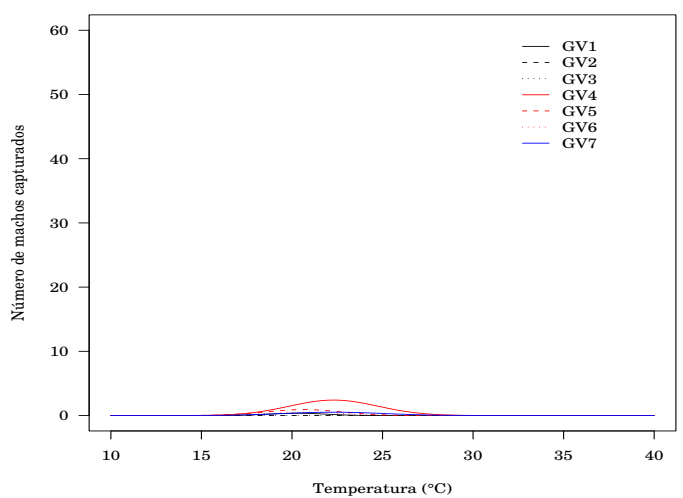

D

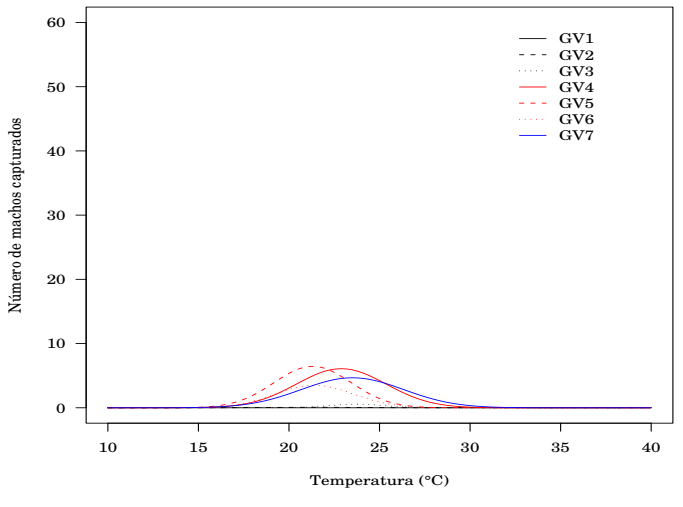

$\mathbf{F}$

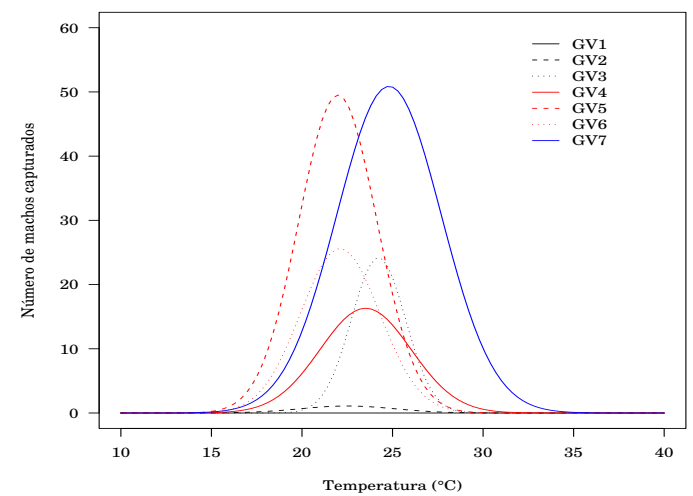

Figura 13 - Estimativas de ocorrência de Ecdytolopha aurantiana para o solo GS6 (LEP1) em função da temperatura, variedades de citros, aplicação de agroquímicos e idade das plantas. A - plantas com idade de 5 anos e com aplicação de agroquímicos; B - plantas com idade de 5 anos e sem aplicação de agroquímicos; C - plantas com idade de 10 anos e com aplicação de agroquímicos; D - plantas com idade de 10 anos e sem aplicação de agroquímicos; E - plantas com idade de 15 anos e com aplicação de agroquímicos; F - plantas com idade de 15 anos e sem aplicação de agroquímicos 
$\mathbf{A}$

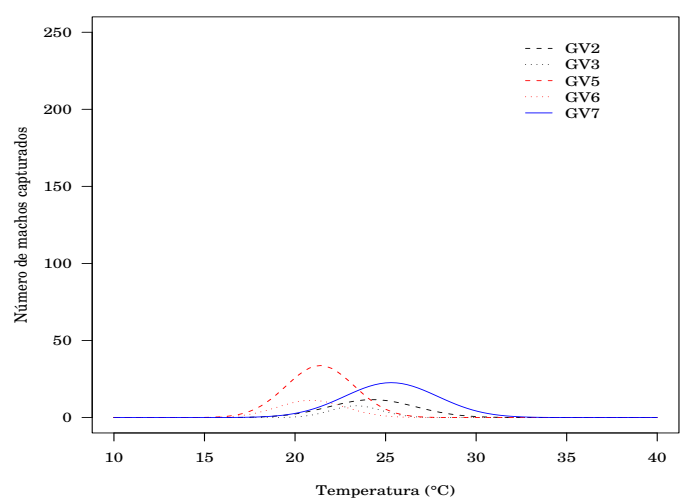

C
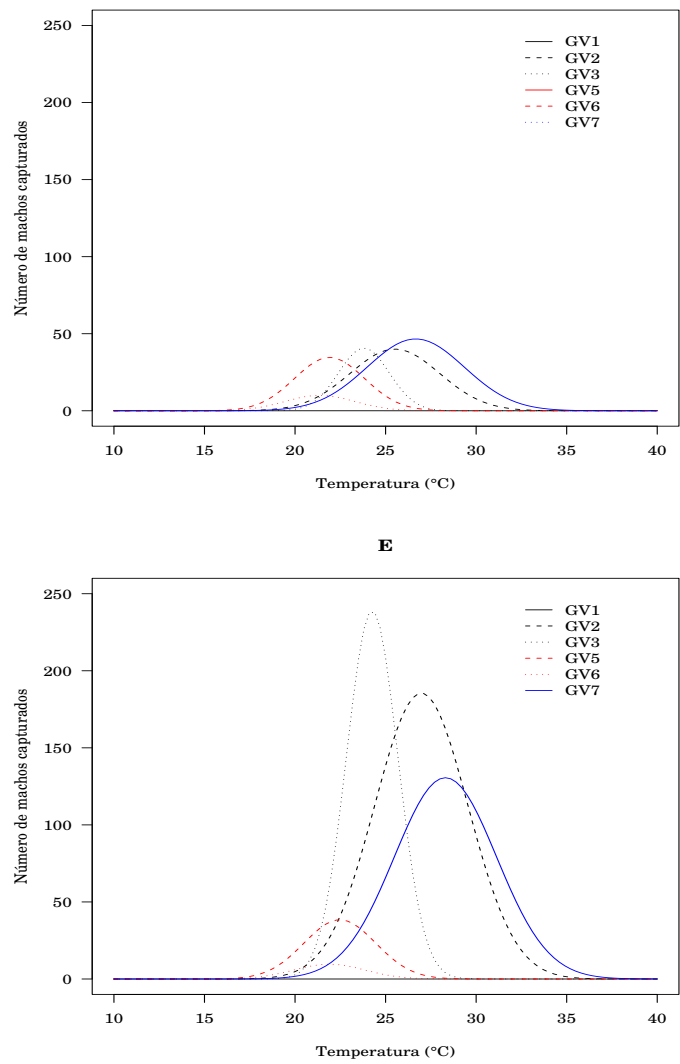

B

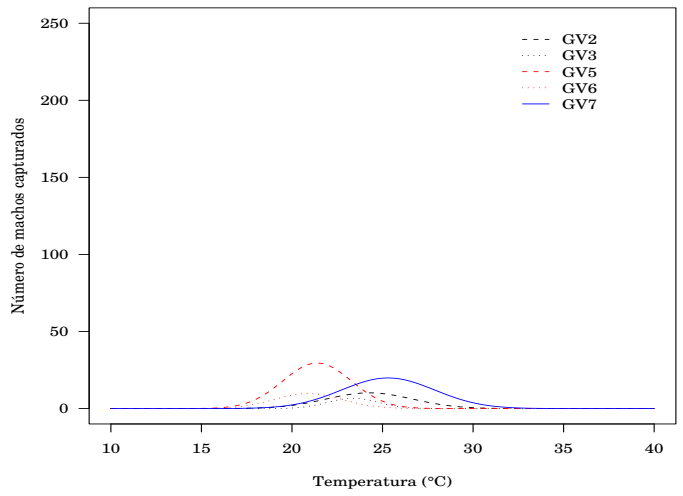

$\mathbf{D}$

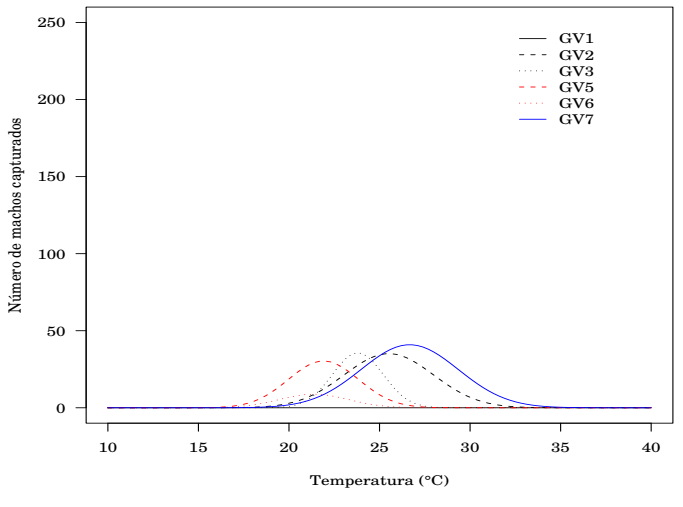

$\mathbf{F}$

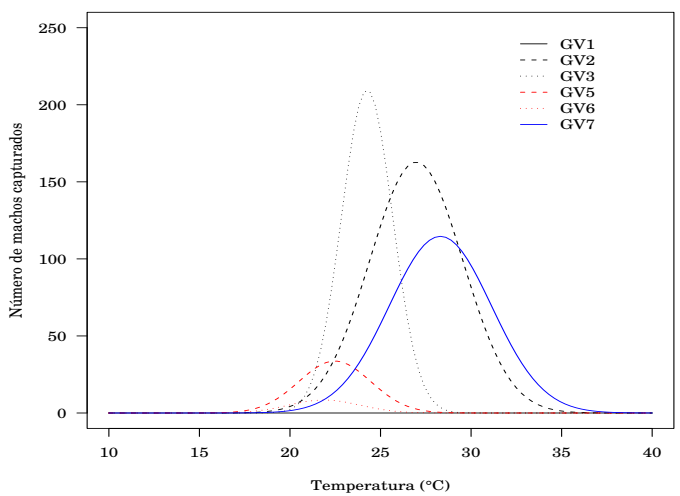

Figura 14 - Estimativas de ocorrência de Ecdytolopha aurantiana para o solo GS7 (LE2) em função da temperatura, variedades de citros, aplicação de agroquímicos e idade das plantas. A - plantas com idade de 5 anos e com aplicação de agroquímicos; B - plantas com idade de 5 anos e sem aplicação de agroquímicos; C - plantas com idade de 10 anos e com aplicação de agroquímicos; D - plantas com idade de 10 anos e sem aplicação de agroquímicos; E - plantas com idade de 15 anos e com aplicação de agroquímicos; F - plantas com idade de 15 anos e sem aplicação de agroquímicos 


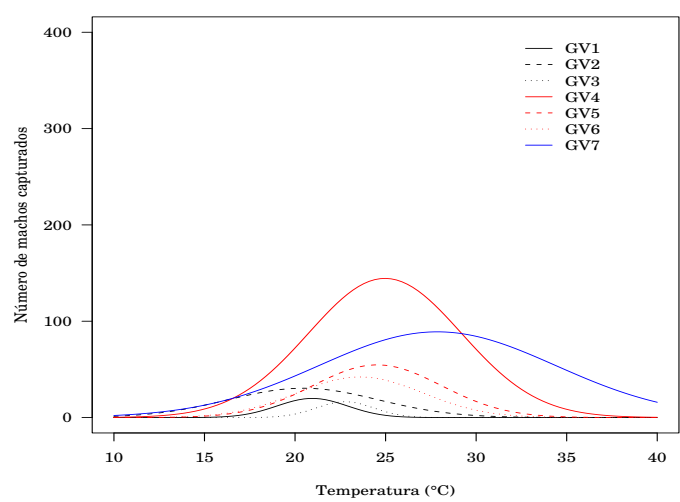

$\mathbf{C}$
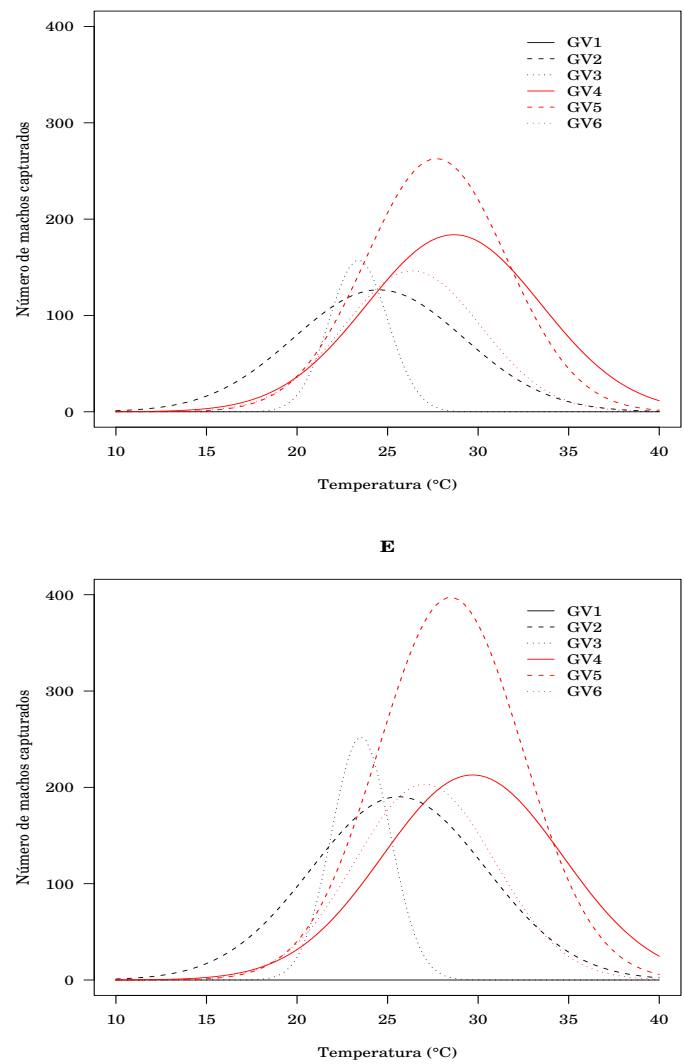

B

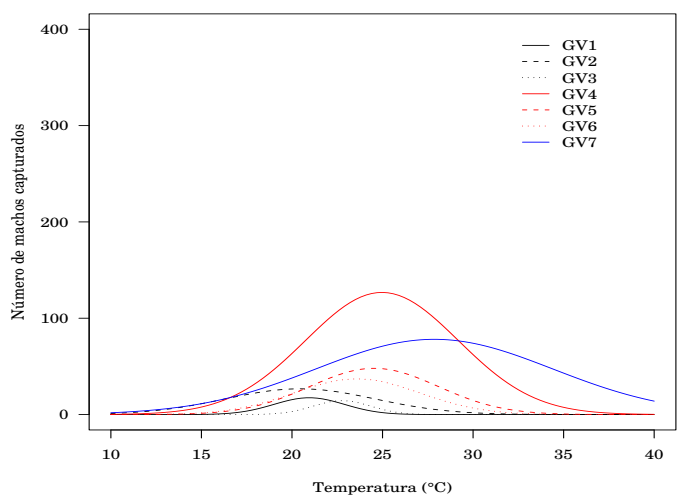

D

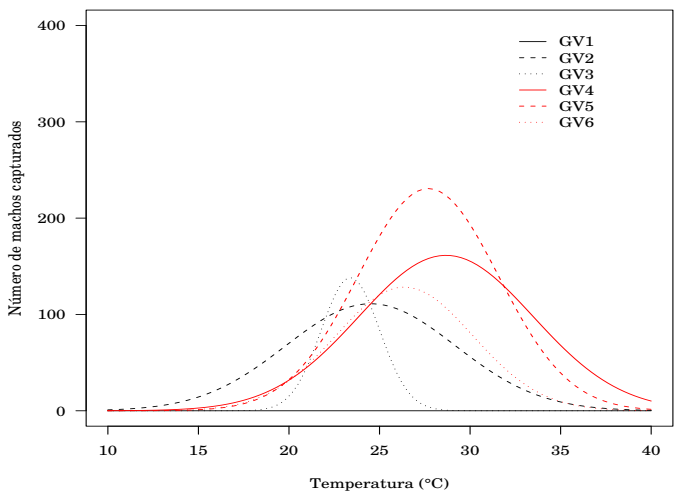

$\mathbf{F}$

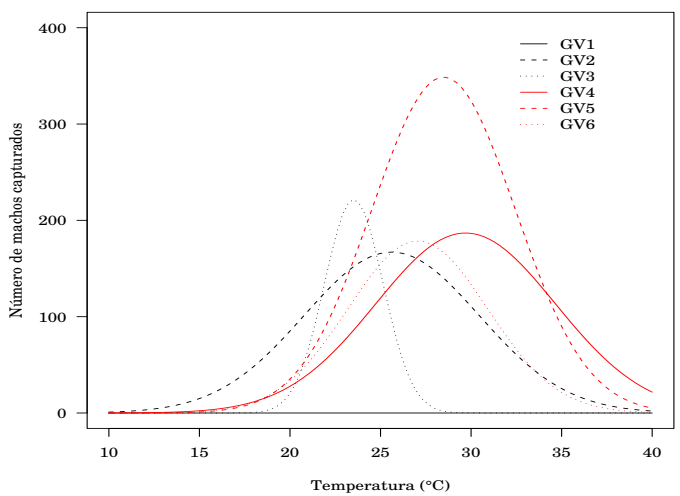

Figura 15 - Estimativas de ocorrência de Ecdytolopha aurantiana para o solo GS8 (PV3) em função da temperatura, variedades de citros, aplicação de agroquímicos e idade das plantas. A - plantas com idade de 5 anos e com aplicação de agroquímicos; B - plantas com idade de 5 anos e sem aplicação de agroquímicos; C - plantas com idade de 10 anos e com aplicação de agroquímicos; D - plantas com idade de 10 anos e sem aplicação de agroquímicos; E - plantas com idade de 15 anos e com aplicação de agroquímicos; F - plantas com idade de 15 anos e sem aplicação de agroquímicos 

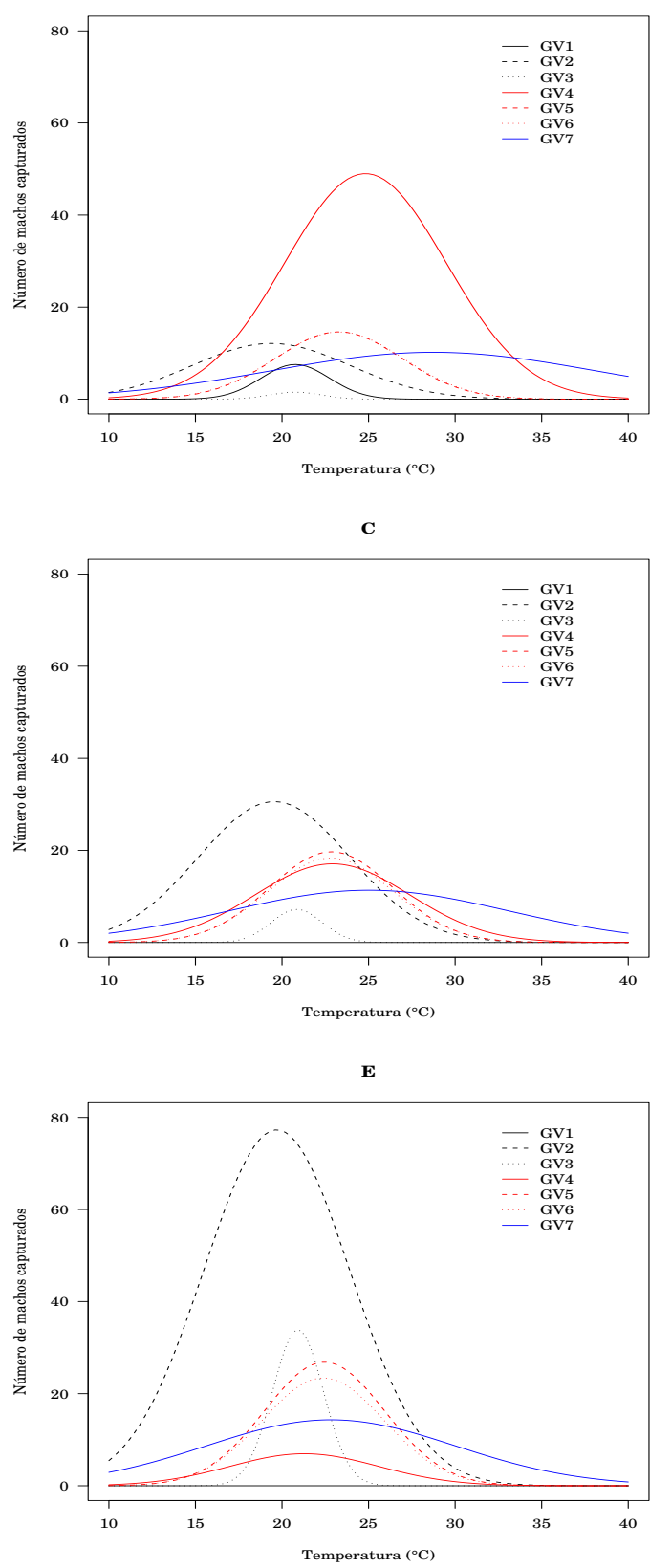

B

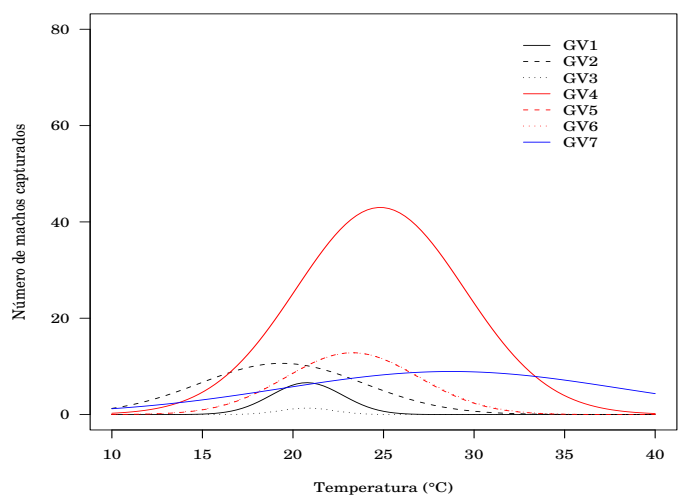

D

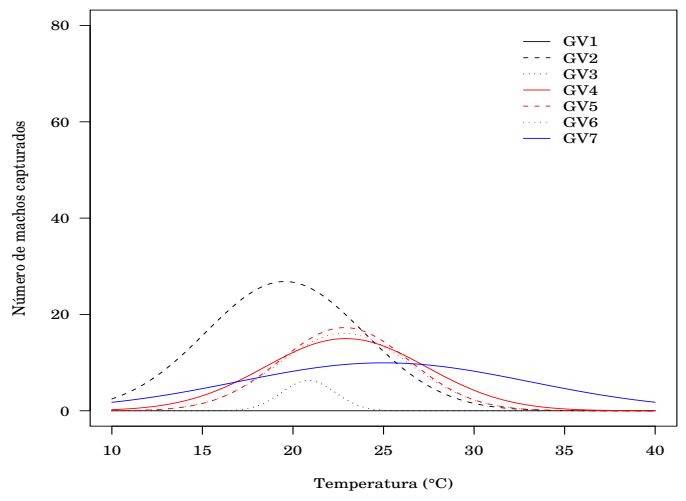

$\mathbf{F}$

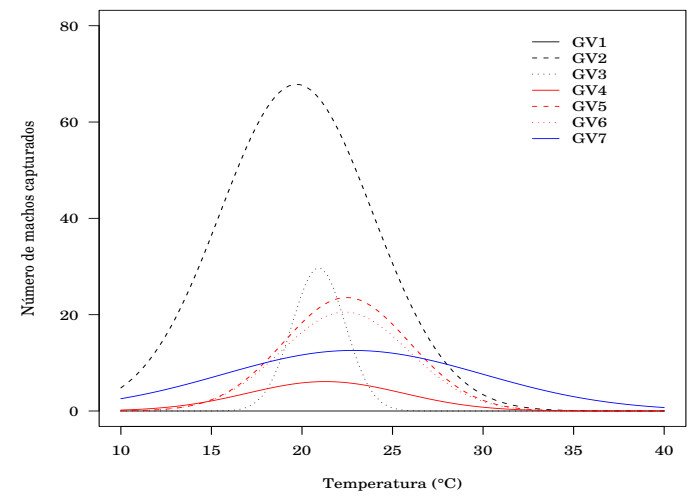

Figura 16 - Estimativas de ocorrência de Ecdytolopha aurantiana para o solo GS9 (LE5) em função da temperatura, variedades de citros, aplicação de agroquímicos e idade das plantas. A - plantas com idade de 5 anos e com aplicação de agroquímicos; B - plantas com idade de 5 anos e sem aplicação de agroquímicos; C - plantas com idade de 10 anos e com aplicação de agroquímicos; D - plantas com idade de 10 anos e sem aplicação de agroquímicos; E - plantas com idade de 15 anos e com aplicação de agroquímicos; F - plantas com idade de 15 anos e sem aplicação de agroquímicos 


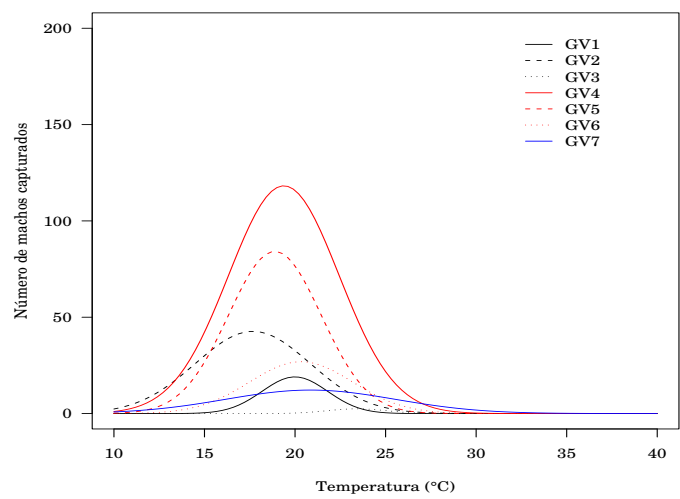

$\mathbf{C}$

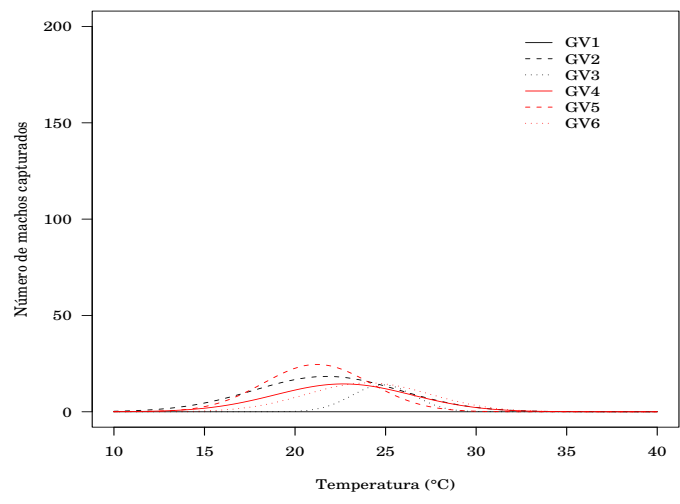

$\mathbf{E}$

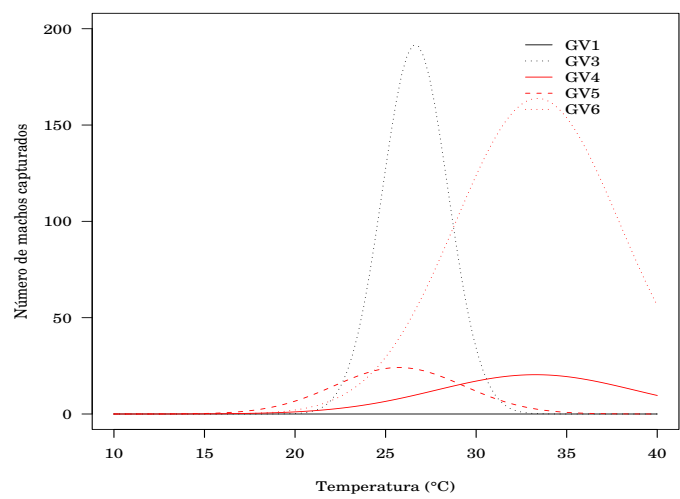

B

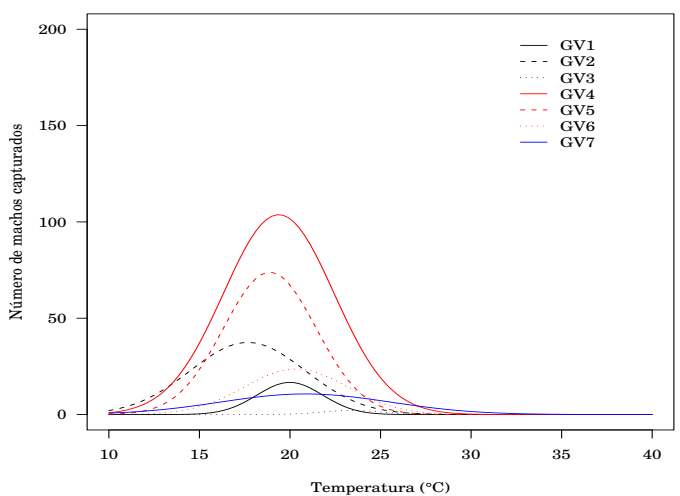

D

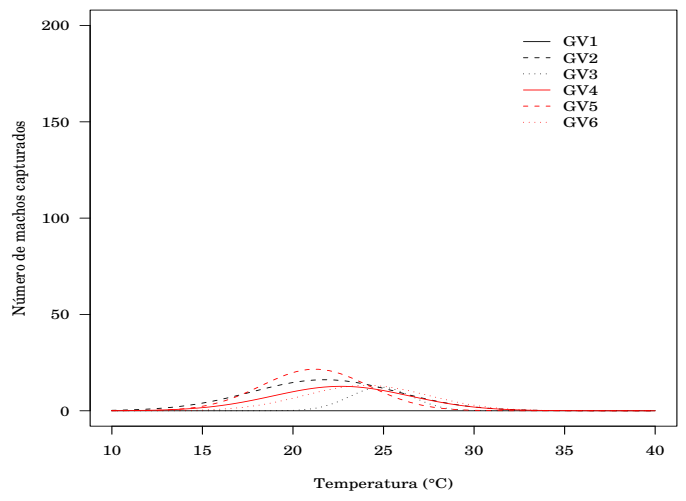

$\mathbf{F}$

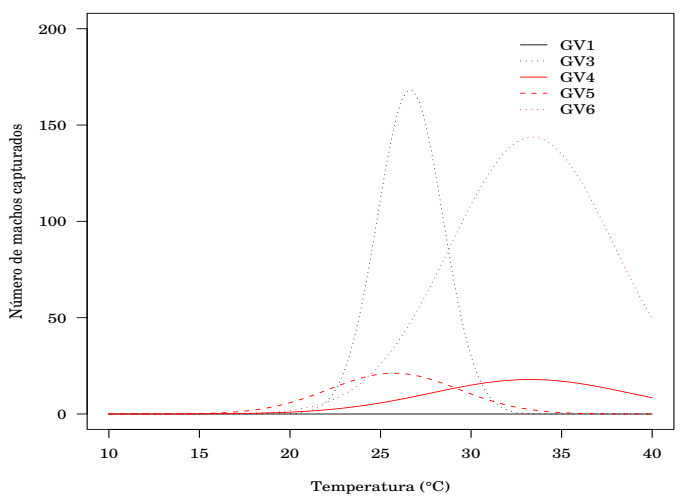

Figura 17 - Estimativas de ocorrência de Ecdytolopha aurantiana para o solo GS10 (LV3) em função da temperatura, variedades de citros, aplicação de agroquímicos e idade das plantas. A - plantas com idade de 5 anos e com aplicação de agroquímicos; B - plantas com idade de 5 anos e sem aplicação de agroquímicos; $\mathrm{C}$ - plantas com idade de 10 anos e com aplicação de agroquímicos; D - plantas com idade de 10 anos e sem aplicação de agroquímicos; E - plantas com idade de 15 anos e com aplicação de agroquímicos; F - plantas com idade de 15 anos e sem aplicação de agroquímicos 


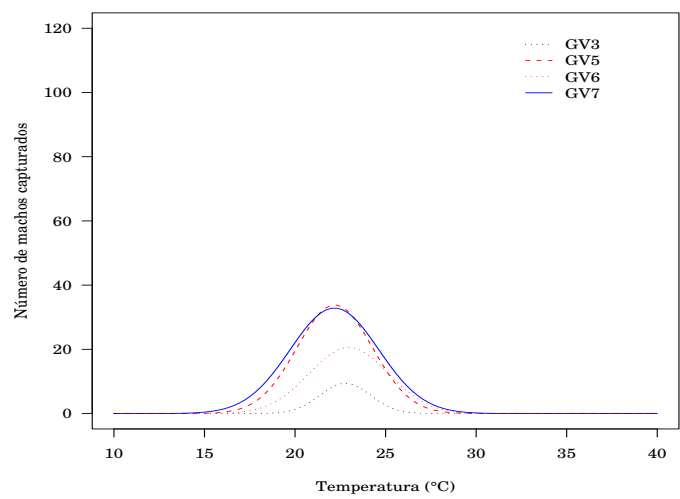

C

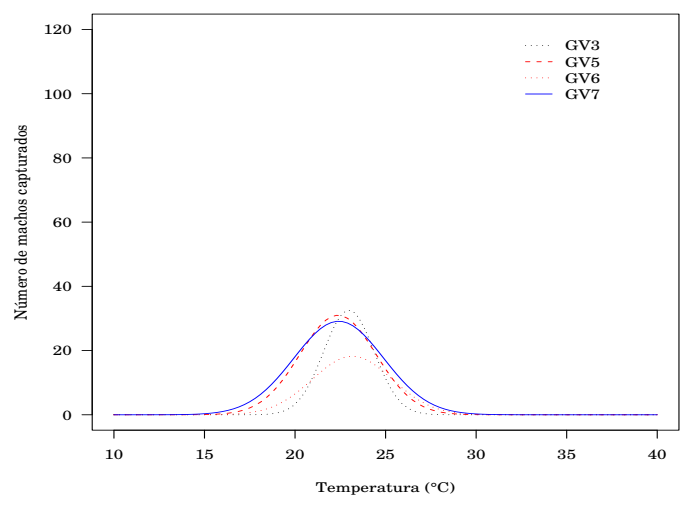

$\mathbf{E}$

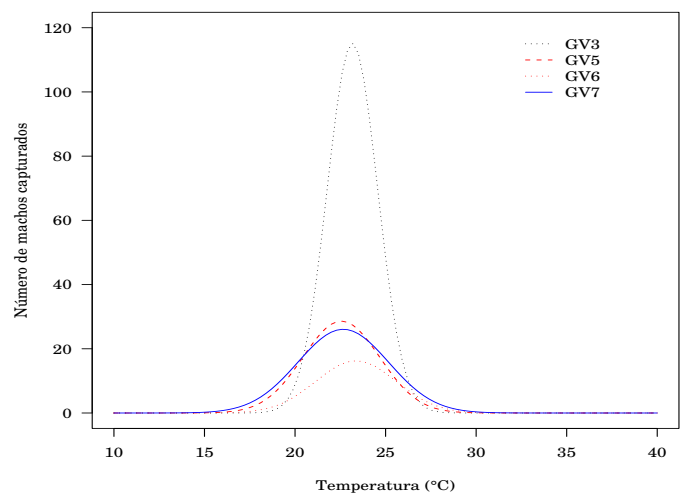

B

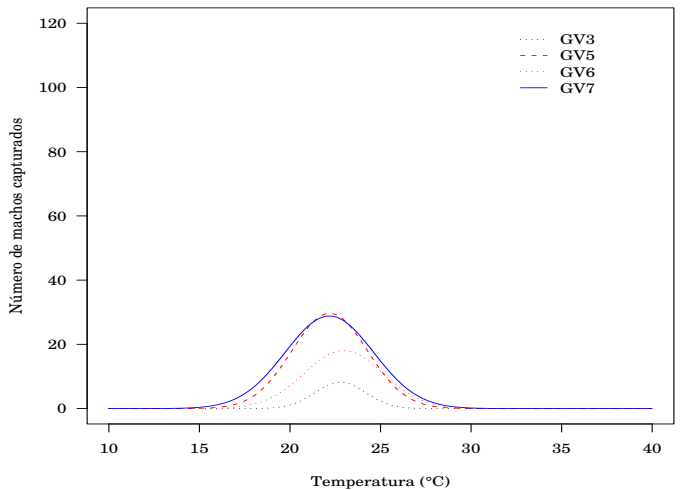

D

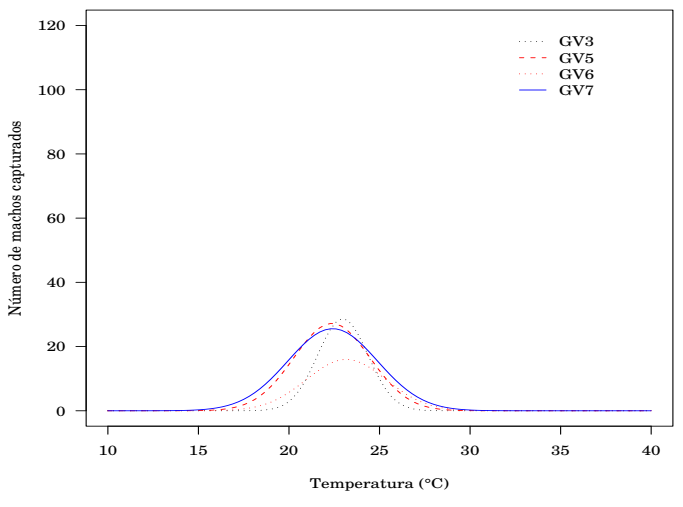

$\mathbf{F}$

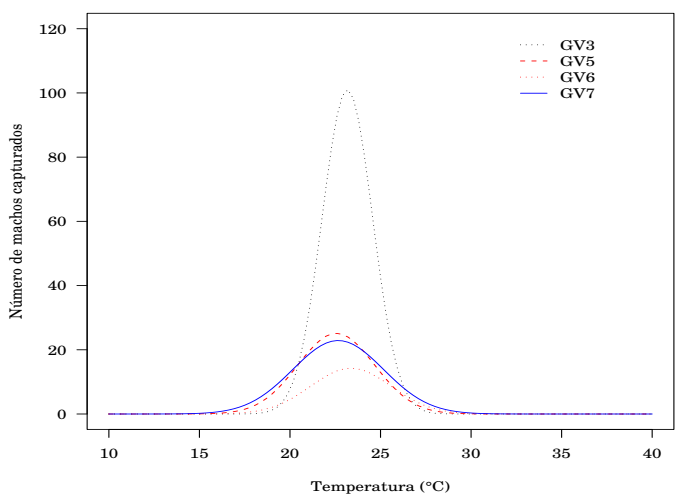

Figura 18 - Estimativas de ocorrência de Ecdytolopha aurantiana para o solo GS11 (LE3) em função da temperatura, variedades de citros, aplicação de agroquímicos e idade das plantas. A - plantas com idade de 5 anos e com aplicação de agroquímicos; B - plantas com idade de 5 anos e sem aplicação de agroquímicos; $\mathrm{C}$ - plantas com idade de 10 anos e com aplicação de agroquímicos; D - plantas com idade de 10 anos e sem aplicação de agroquímicos; E - plantas com idade de 15 anos e com aplicação de agroquímicos; F - plantas com idade de 15 anos e sem aplicação de agroquímicos 

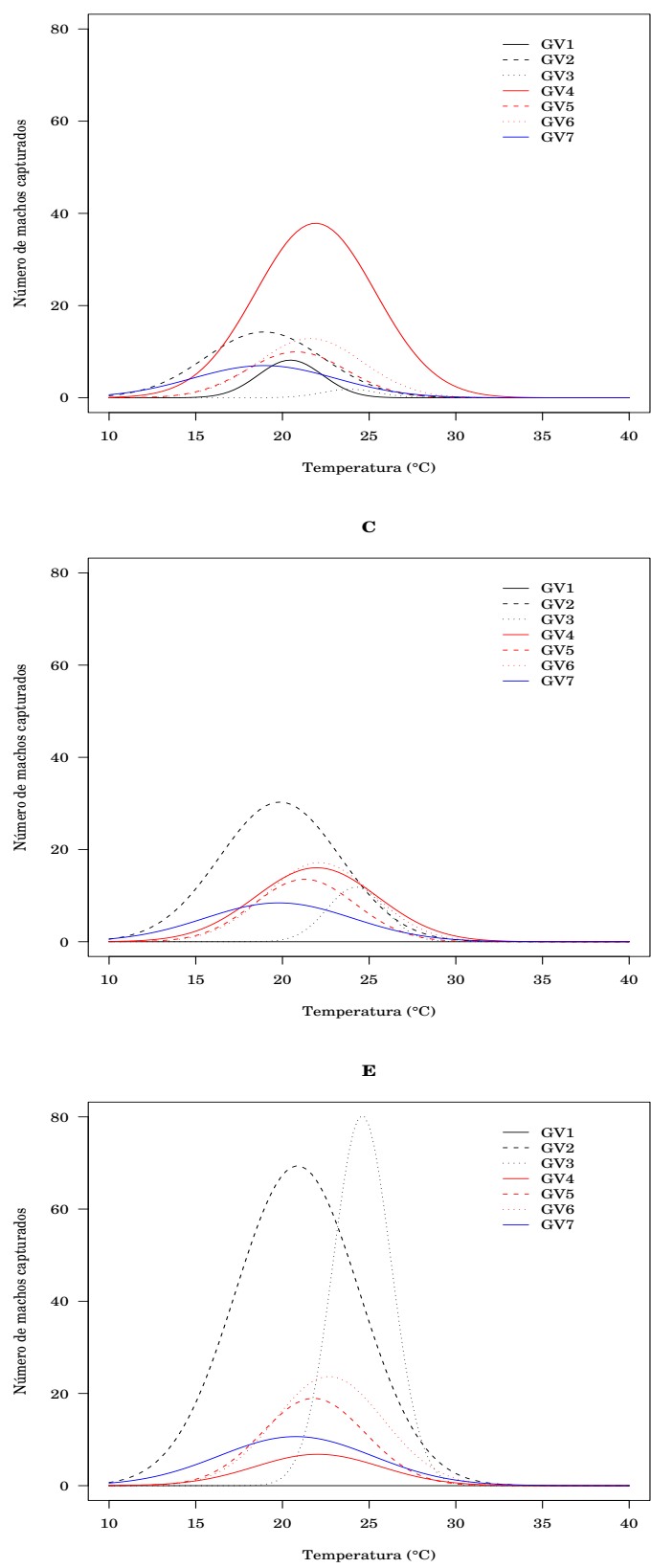

B

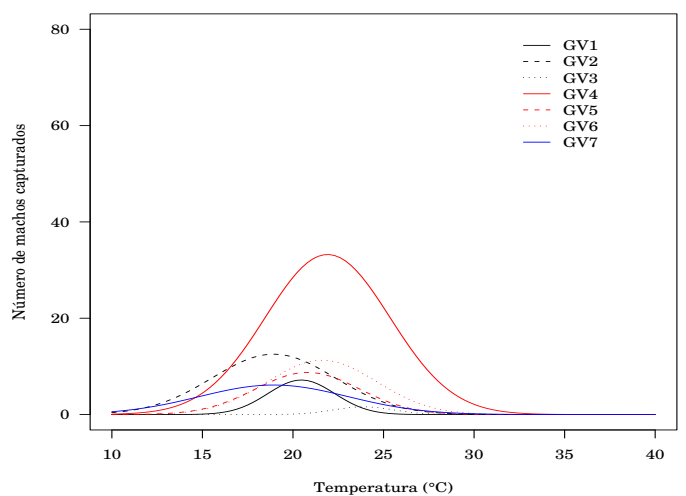

D

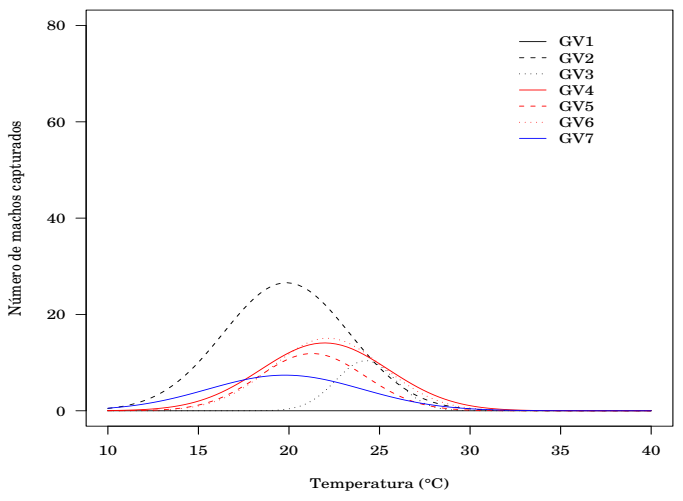

$\mathbf{F}$

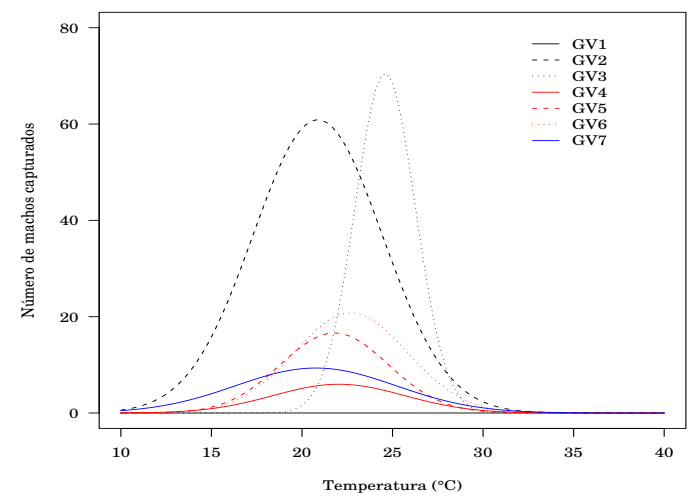

Figura 19 - Estimativas de ocorrência de Ecdytolopha aurantiana para o solo GS12 (AQ e HI) em função da temperatura, variedades de citros, aplicação de agroquímicos e idade das plantas. A - plantas com idade de 5 anos e com aplicação de agroquímicos; B - plantas com idade de 5 anos e sem aplicação de agroquímicos; $\mathrm{C}$ - plantas com idade de 10 anos e com aplicação de agroquímicos; D - plantas com idade de 10 anos e sem aplicação de agroquímicos; E - plantas com idade de 15 anos e com aplicação de agroquímicos; F - plantas com idade de 15 anos e sem aplicação de agroquímicos 


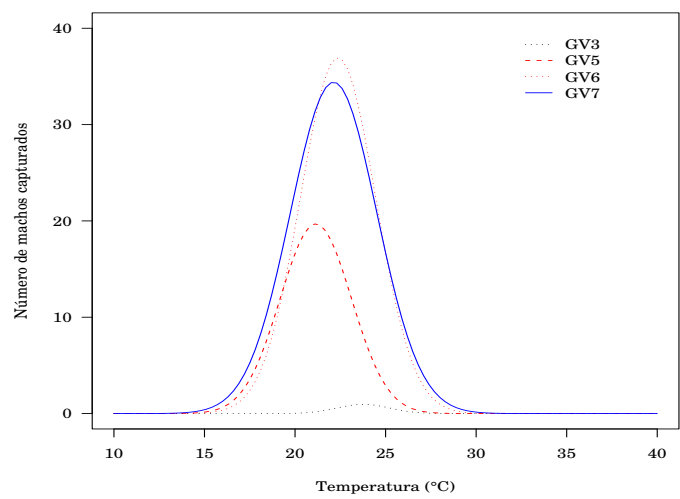

$\mathbf{C}$
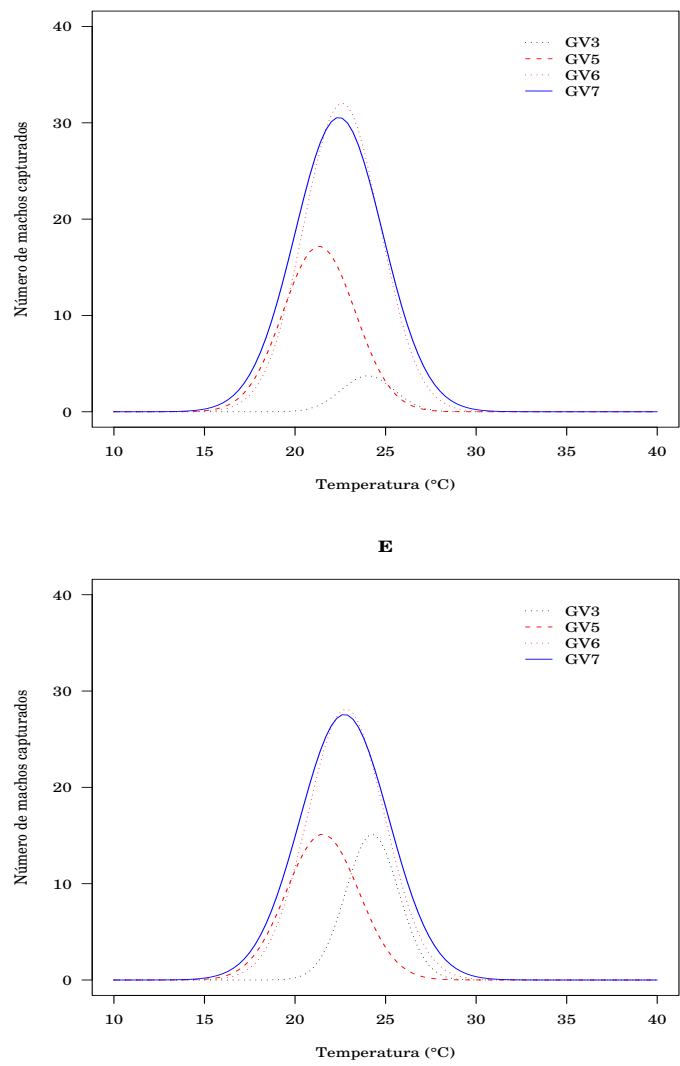

B

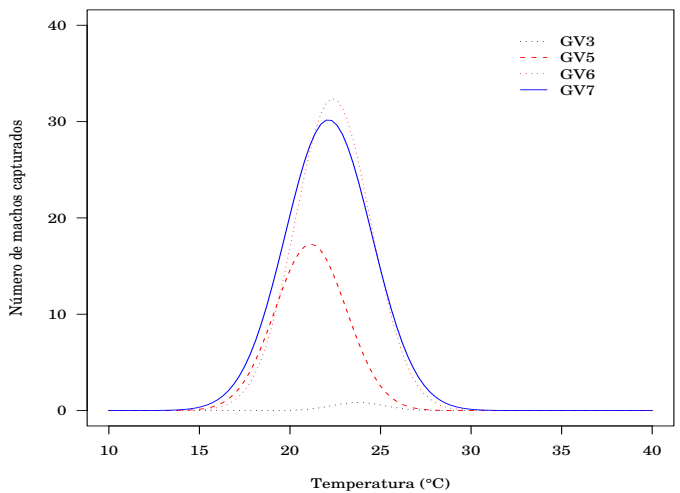

$\mathbf{D}$
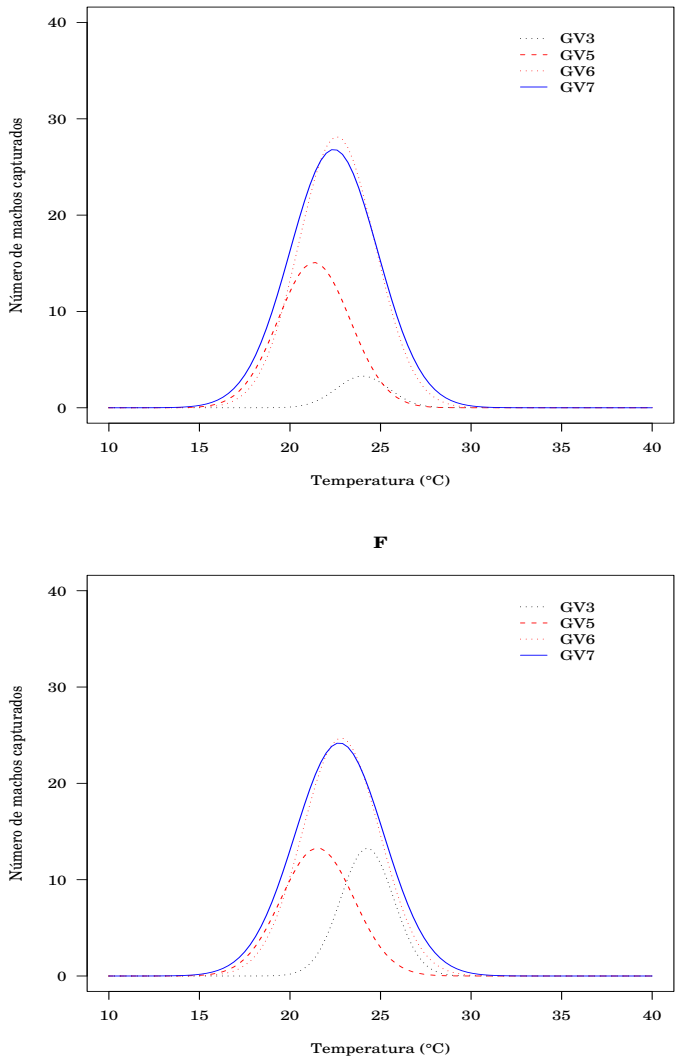

Figura 20 - Estimativas de ocorrência de Ecdytolopha aurantiana para o solo GS13 (PE1, LR1 e TR2) em função da temperatura, variedades de citros, aplicação de agroquímicos e idade das plantas. A - plantas com idade de 5 anos e com aplicação de agroquímicos; B - plantas com idade de 5 anos e sem aplicação de agroquímicos; C - plantas com idade de 10 anos e com aplicação de agroquímicos; D - plantas com idade de 10 anos e sem aplicação de agroquímicos; E - plantas com idade de 15 anos e com aplicação de agroquímicos; F - plantas com idade de 15 anos e sem aplicação de agroquímicos 
Os resultados apresentados indicam que as variáveis: variedade de citros, tipo de solo, idade da planta e temperatura influenciam a ocorrência de $E$. aurantiana no campo, não somente isoladamente, mas também de forma conjunta, com interações das diferentes variáveis.

A influência da variedade de citros na ocorrência de E. aurantiana pode estar relacionada com a diferença de pH e espessura da casca, características estas que afetam diretamente a viabilidade dos estágios imaturos de E. aurantiana (Parra et al., 2001). Variações na temperatura para o pico de ocorrência, podem estar relacionadas com o fato de que as variedades podem ter seu período de frutificação em épocas diferentes (Gallo et al., 1977), portanto, propiciando uma época de ocorrência de $E$. aurantiana variável para cada variedade, pois embora ataque também frutos verdes em altas populações da praga, a preferência do bicho-furão é por frutos maduros (Parra et al., 2001).

A influência da idade muito provavelmente está relacionada com uma maior produção de frutos em plantas mais velhas (Tubelis et al., 1999; Tubelis \& Salibe, 1992, 1989); assim, plantas mais velhas possuem maior ocorrência de $E$. aurantiana por possuírem mais recursos a serem explorados.

A ocorrência de E. aurantiana aparentemente independe da aplicação ou não de agroquímicos. Locais onde houve a aplicação de produtos como Dipel (33.60g/l) ou Decis25CE (25g/l) apresentaram uma maior ocorrência deste inseto, comparados com locais onde não houve nenhuma aplicação. Isto, sugere que a ocorrência da praga é mais freqüente em algumas áreas do que outras, apesar de um maior número de pulverizações nas áreas mais infestadas, com base no nível de controle de 6 ou mais machos por armadilha por semana de acordo com a metodologia de (Bento et al., 2001a,b). Entretanto, isto não indica necessariamente que os produtos utilizados foram ineficientes. Áreas com maior incidência de E. aurantiana e 
conseqüentemente com um maior número de aplicações de agroquímicos poderiam estar associadas a diversos fatores, tais como influência de matas próximas, áreas de baixada e época de colheita, dentro outras. Por outro lado, a escolha do produto, modo e momento de aplicação (dias após a constatação do nível de controle) e dosagem, poderiam comprometer a eficiência do mesmo; ou ainda a eliminação de inimigos naturais por aplicações sucessivas na área, resultaria numa maior incidência da praga.

A variável que mais influenciou a ocorrência de E. aurantiana foi o tipo de solo da área. Esta maior influência, pode ser devido ao fato do tipo de solo afetar E. aurantiana diretamente e indiretamente. A influência direta do solo, pode estar relacionada com o comportamento que este inseto tem de se transformar em pupa no solo; assim, a viabilidade pupal estaria intimamente ligada às características físico-químicas do solo (Garcia, 1998). A influência indireta pode estar ligada ao fato do tipo de solo poder alterar as características dos frutos (Erickson, 1973), principalmente em relação ao seu pH e espessura da casca que, como comentando anteriormente, podem afetar a viabilidade dos estágios imaturos de E. aurantiana (Parra et al., 2001).

Apesar destas variáveis explicarem parte da ocorrência de $E$. aurantiana no campo, o modelo ainda precisa ser melhorado, especialmente a partir da formação de um banco de dados, elaborado com a coleta de dados da ocorrência de E. aurantiana por períodos mais longos; aumentando muito a capacidade de previsão da praga. No entanto, o simples levantamento populacional de E. aurantiana não é suficiente, havendo necessidade de coleta de dados do local, incluindo temperatura, umidade relativa do ar, tipo de solo, variedade, aplicação de agroquímicos, etc. Quanto maior for o número de variáveis, mais fácil será confeccionar modelos que expliquem a ocorrência de E. aurantiana. A percentagem de explicação de cada 
variável no modelo e a sua respectiva importância poderá ser fundamental para melhorar a precisão do modelo. Por exemplo, o pH do fruto pode ser mais importante para o modelo do que a informação relacionada à variedade envolvida.

Pesquisas complementares de laboratório também são de suma importância para a otimização do modelo, incluindo susceptibilidade de variedades ao ataque da praga, efeito do tipo de solo na emergência de adultos, além de outros aspectos da biologia, comportamento e ecologia deste inseto.

\subsubsection{Exemplo prático para utilização do modelo}

Será, a seguir, ilustrado um exemplo para um agricultor do estado de São Paulo que esteja interessado em saber qual o potencial de ocorrência de E. aurantiana na sua propriedade. Sua propriedade está localizada na latitude sul $\left(22^{\circ} 4^{\prime} 50^{\prime \prime}\right)$, longitude oeste $\left(48^{\circ} 39^{\prime} 33.84^{\prime \prime}\right)$, a uma altitude de 650 metros e a 400 quilômetros de distância do oceano. Os três primeiros parâmetros (latitude, longitude e altitude) são conseguidos com o uso de um aparelho de GPS. O último parâmetro pode ser calculado com programas relacionados a mapas e coordenadas geográficas ou mesmo medindo-se em um mapa que tenha escala. Para utilizarem-se os dados de latitude e longitude, é necessário transformá-los do formato GMS (graus, minutos e segundos) para minutos. Assim:

$$
\begin{gathered}
\text { latitude }(\text { minutos })=22 \times 60+4+\frac{50}{60}=1324.83 \\
\text { longitude }(\text { minutos })=48 \times 60+39+\frac{33.84}{60}=2919.56
\end{gathered}
$$

Além destes parâmetros geográficos são necessárias informações sobre o tipo de solo da área, variedade de citros cultivada, idade do pomar. Se o referido agricultor tiver em sua propriedade a variedade Pera Rio (GV5), o tipo de solo seja 
LE2 (GS7) (Tabela 1) e o seu pomar tenha uma idade de 15 anos e ele não usa nenhum agroquímico para controle de E. aurantiana.

Para simular o potencial de ocorrência de E. aurantiana neste local, o agricultor necessitará de um computador que tenha o programa R (http://www . r-project.org) instalado. A seguir ele deverá copiar o conteúdo do anexo B, para um arquivo com um editor de texto, e gravar o arquivo, no formato texto puro (ASCII, TXT), com o nome que ele achar mais conveniente (ex. BF.R). O programa R é aberto a seguir, lendo-se o arquivo que foi gravado [ex. source("BF.R")]; assim, o programa que simula o potencial de ocorrência de E. aurantiana terá sido carregado na memória.

Para utilizar o programa e simular a ocorrência de E. aurantiana para este agricultor, digita-se o seguinte:

$\mathrm{BF}($ agroquimico="sem" , solo="GS7" , variedade="GV5" , idade=15)

Portanto, foram utilizados GS7 e GV5 para designar o tipo de solo e a variedade respectivamente, ao invés de LE2 e Pera Rio. Para saber a qual grupo a variedade e o solo pertencem, basta consultar as Tabelas 4 e 6 respectivamente. Assim, ele terá uma curva de ocorrência de E. aurantiana em função da temperatura (Figura 21A).

O referido agricultor poderá, a seguir, desejar saber a dinâmica populacional de E. aurantiana ao longo do ano. Para tal, deverá fornecer as características geográficas da sua região, da seguinte forma:

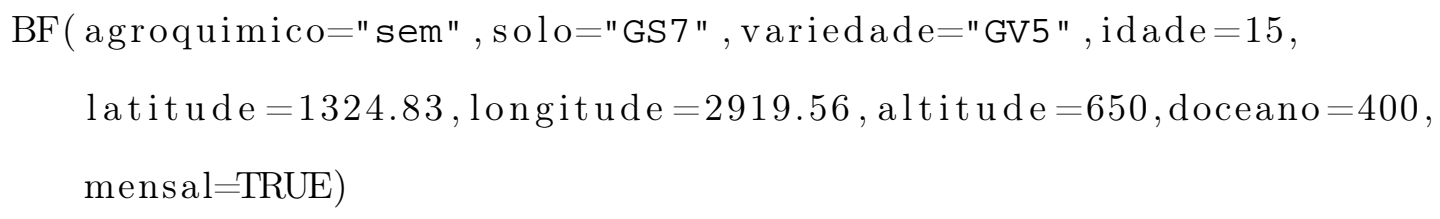


Será então gerado um gráfico com o nível populacional de E. aurantiana ao longo do ano, evidenciando quais as épocas em que este inseto irá se tornar problemático (Figura 21B). Desta forma, o agricultor poderá intensificar sua amostragem com armadilhas de feromônio sexual nestas épocas críticas.

Assim, para se utilizar o modelo, é necessário que se tenha o programa $\mathrm{R}$ instalado no computador e que se tenha algum conhecimento da linguagem $\mathrm{R}$. Como isto não é uma realidade para a maioria dos usuários potenciais do modelo, foi desenvolvido um sistema "web" que permitirá ao interessado entrar com estas informações e obter os resultados, sem a necessidade de se saber a linguagem $\mathrm{R}$ e sem ter o programa $\mathrm{R}$ instalado. 
$\mathbf{A}$

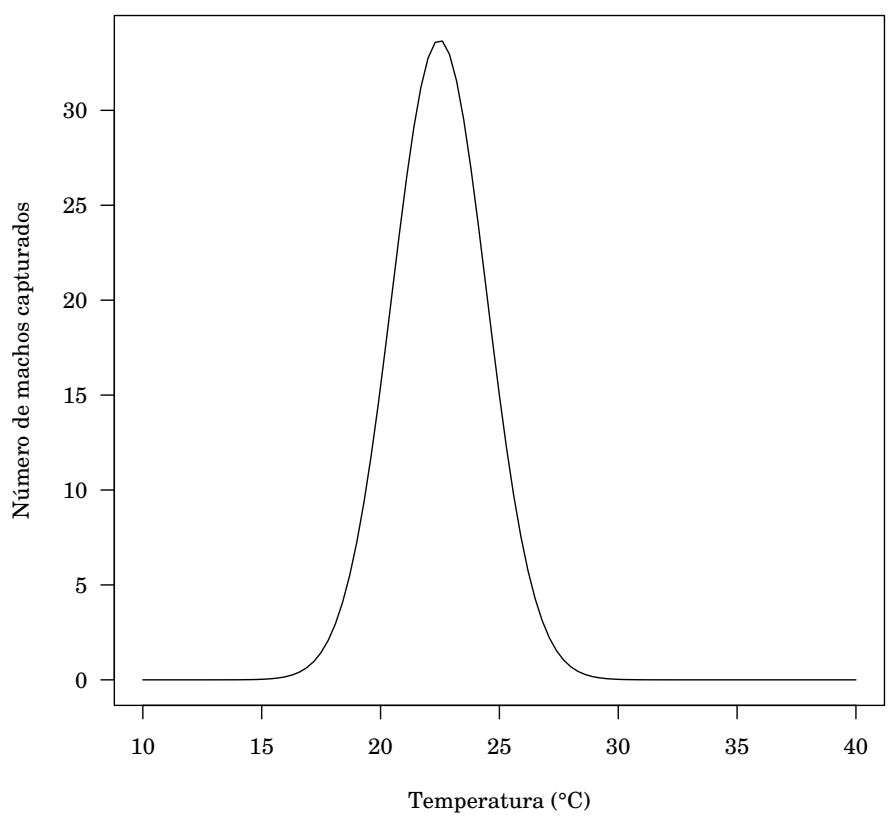

B

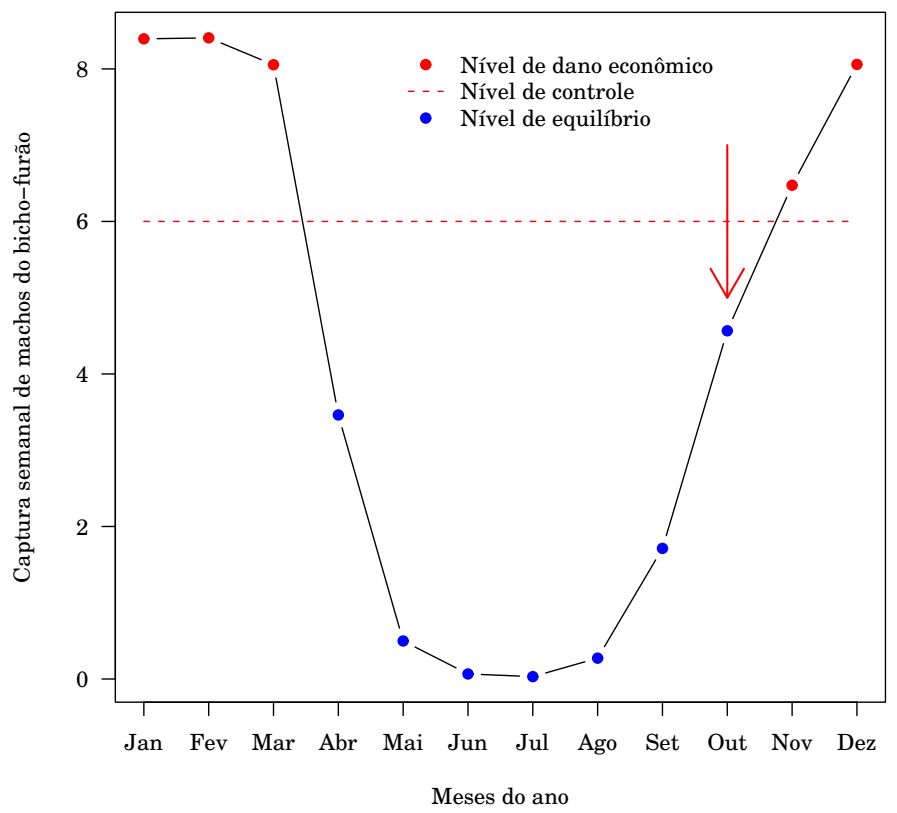

Figura 21 - A - Estimativas de ocorrência de Ecdytolopha aurantiana (número de machos por armadilha por mês) em função da temperatura. B - Estimativas de ocorrência de Ecdytolopha aurantiana durante o ano (número de machos por armadilha por semana). A seta indica que o agricultor deve estar alerta, instalando armadilhas de feromônio na área, a partir desta data. Estimativa feita para a variedade Pera Rio, solo tipo LE2 e idade do pomar de 15 anos 


\subsection{SIAC - Sistema Integrado de Apoio à Citricultura}

Com o intuito de facilitar o uso do modelo pelos citricultores e pesquisadores, criou-se um sistema "web" que permite o uso do modelo sem a necessidade de instalação ou de aprendizagem de programas extras. Nele, o usuário poderá especificar a variação de temperatura de sua região de forma direta, ou especificar dados de latitude, longitude, altitude e distância do oceano, para estimar as temperaturas. Além da temperatura, ele deverá informar a idade das plantas, variedade cultivada, tipo de solo e se ocorre a aplicação de um dos dois produtos que foram avaliados neste trabalho. Para esta escolha aparecerá um "menu" constando as opções a serem escolhidas. Feito isto, os dados serão enviados ao sistema que retornará com um gráfico mostrando como será a ocorrência de E. aurantiana na região em função da temperatura. Um exemplo deste módulo pode ser visto na Figura 22.

Além desta funcionalidade de se utilizar o modelo aqui desenvolvido para simular o potencial de ocorrência de E. aurantiana, o SIAC conta com diversas outras funcionalidades. Estas funcionalidades extras servem de apoio ao citricultor, dando subsídio para que este, além de utilizar o modelo, saiba o significado deste e quais medidas deve tomar. Este subsídio seria fornecido pelo pesquisadores, que também seriam usuários do sistema. Então, estas funcionalidades extras seriam responsáveis por uma maior interação do setor produtivo e setor de pesquisa. A seguir, uma breve explicação de cada uma das funcionalidades extras do SIAC.

Ao se digitar o endereço eletrônico do $\mathrm{SIAC}^{3}$, o usuário entrará na página principal. Esta página será o ponto de partida para o uso do sistema. Na página principal, o usuário encontrará atalhos para os outros módulos do sistema, visualizará enquetes sobre assuntos relacionados com a citricultura, e terá acesso rápido às notícias mais recentes (Figura 23).

\footnotetext{
${ }^{3}$ endereço que só existirá caso o SIAC seja realmente implementado.
} 
Para que o sistema possa ser utilizado em toda sua amplitude, é necessário que o usuário se cadastre. Uma vez cadastrado, ele terá acesso a todas as funções extras do SIAC, sendo elas:

1. módulo destinado a simular o potencial de ocorrência de E. aurantiana (Figura 22).

2. módulo destinado à publicação de artigos gerais sobre citricultura. Estes artigos poderiam ser postados por pesquisadores envolvidos na área (Figura 24).

3. módulo destinado à disponibilização de arquivos diversos para os usuários, como por exemplo o programa em $\mathrm{R}$ para simular o potencial de ocorrência de E. aurantiana (Figura 25).

4. módulo destinado a manter uma base de dados de conhecimento, tal como uma enciclopédia, onde o usuário poderá entender o significados de termos técnicos e desta forma interagir melhor com o setor de pesquisa (Figura 26).

5. módulo destinado à manutenção de uma base de dados das perguntas mais freqüentes dos usuários e respostas para estas perguntas; desta forma, pode-se adquirir conhecimento rápido e evitar o excesso de perguntas repetidas (Figura 27).

6. módulo para criação de fóruns onde os usuários poderão compartilhar suas experiências com outros usuários, agricultores ou pesquisadores. É um tipo de lista de discussão que não é utilizada via e-mail (Figura 28).

7. módulo de cadastro onde os usuário poderão se cadastrar no sistema, apesar do sistema aceitar ser visualizado por pessoas não cadastradas; entretanto, algumas funcionalidades somente serão disponibilizadas para usuários cadastrados (Figura 29). 
8. módulo onde os usuários podem manter contato, de forma privada, com outros usuários, diferentemente dos fóruns em que as discussões são de domínio público (Figura 30).

9. módulo onde os usuário poderão ter acesso a revisões de produtos e técnicas utilizadas na citricultura. Esta revisões obviamente seriam realizadas pelos usuários pesquisadores. Estes usuários poderão enviar suas revisões sobre algum produto de forma autônoma, ou seja, sem a necessidade de um especialista em informática (Figura 32).

10. módulo onde estas revisões poderão ser redigidas ou simplesmente coladas de um editor de texto qualquer para envio ao sistema (Figura 33).

11. módulo para se procurar qualquer informação dentro do sistema (Figura 34).

12. módulo para se encontrar os artigos publicados classificados por assuntos (Figura 35).

13. módulo onde o usuário poderá indicar o sistema a outra pessoa que ainda não o conhece (Figura 31).

14. módulo de estatística do sistema, como todo sistema, é muito importante saber como se dá o acesso a ele (Figura 36).

15. módulo para leitura de notícias; além das notícias poderem ser acessadas pela página principal, elas pode ser acessadas também de forma direta (Figura 37).

16. módulo para envio de notícias, que poderão ser enviadas pelos usuários utilizando o próprio sistema, sem a necessidade de conhecimentos de HTML ou qualquer outra linguagem de programação (Figura 38). 
17. módulo de enquetes, onde é mostrado o resultados das enquetes realizadas com os usuários (Figura 39).

Este pode ser considerado o início do SIAC e várias funcionalidades poderão ser adicionadas em forma de módulos. Uma funcionalidade importante a ser adicionada no futuro seria a coleta de dados dos agricultores. Se todo agricultor que esteja fazendo monitoramento de E. aurantiana entrasse com os dados no sistema, começaria a se ter uma base de dados sobre este inseto e desta forma estes dados poderiam ser utilizados para melhorar os modelos e torná-los mais confiáveis. Isto geraria um círculo virtuoso, ou seja, quanto mais dados forem disponibilizados, melhor é o modelo e conseqüentemente melhor é a aceitação do sistema e conseqüentemente mais dados seriam coletados. Já existe um sistema sendo construído para a catalogação de dados de biodiversidade, o BioMa http://sourceforge.net/projects/bioma/. Este sistema poderia ser integrado ao SIAC para fazer estas coletas de dados que poderiam ser utilizados no refinamento do modelo. 


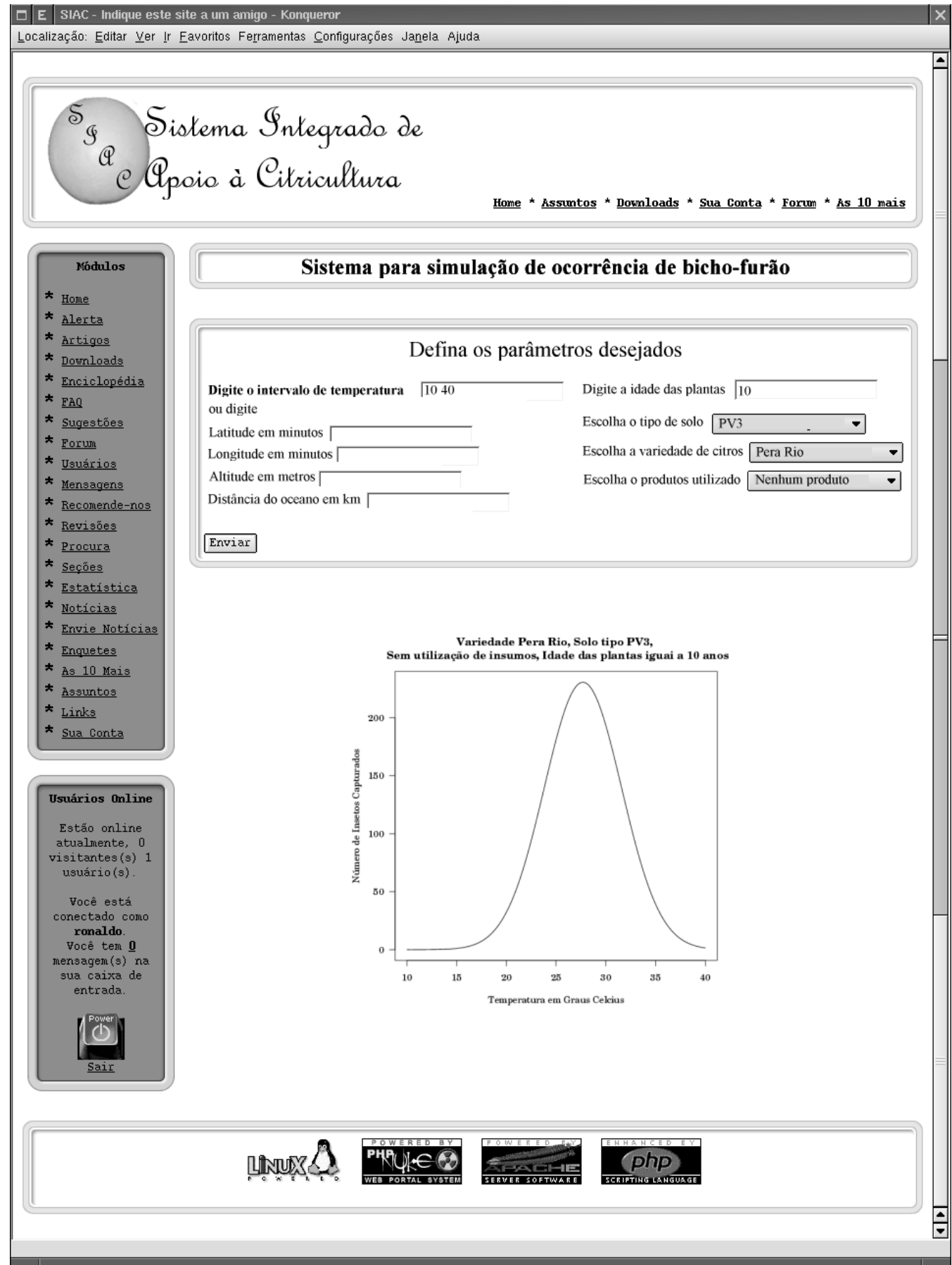

Figura 22 - Módulo do SIAC que pode ser utilizado para a simulação de ocorrência de Ecdytolopha aurantiana utilizando-se o modelo desenvolvido 


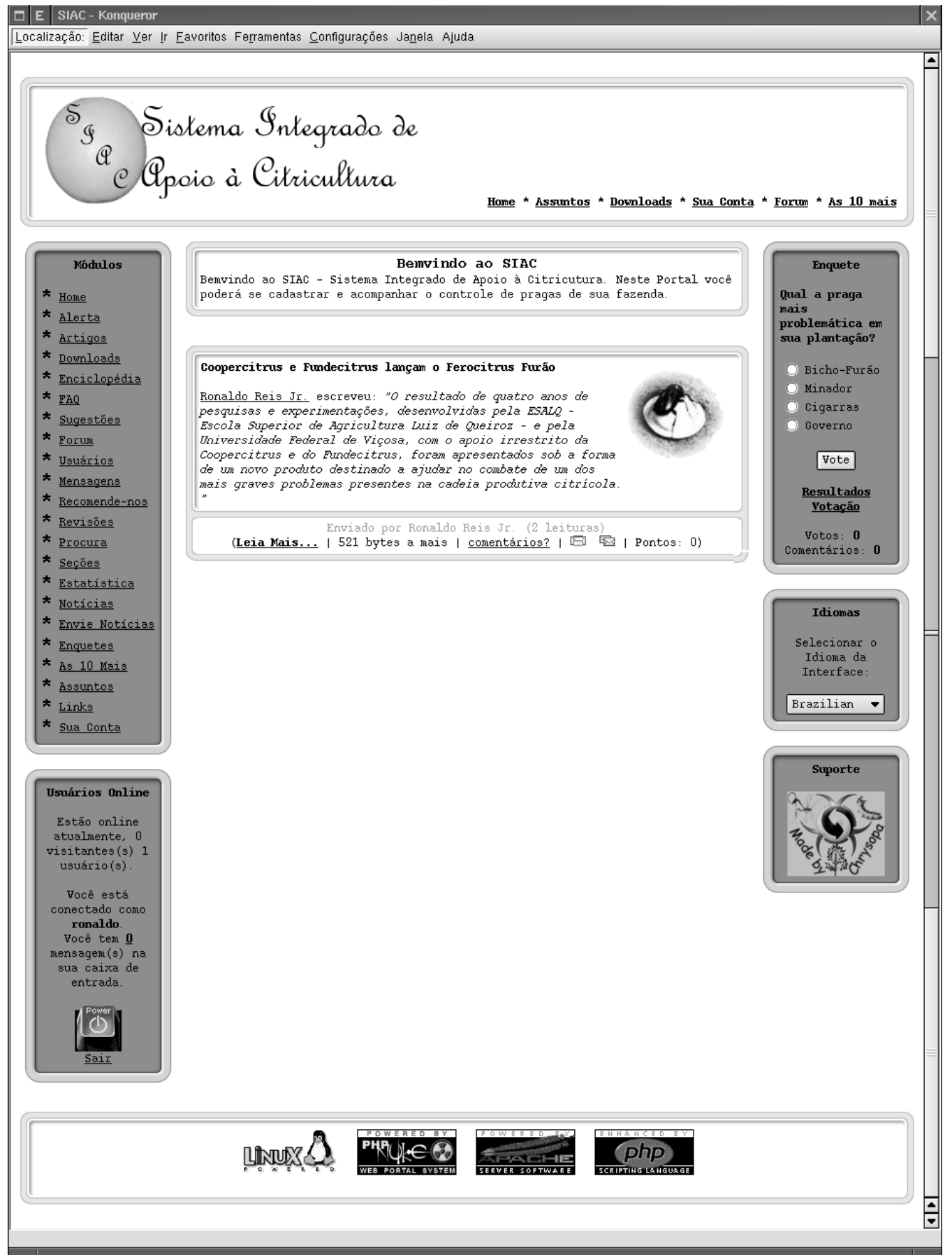

Figura 23 - Página principal do SIAC. Esta é o ponto de partida para os usuários 


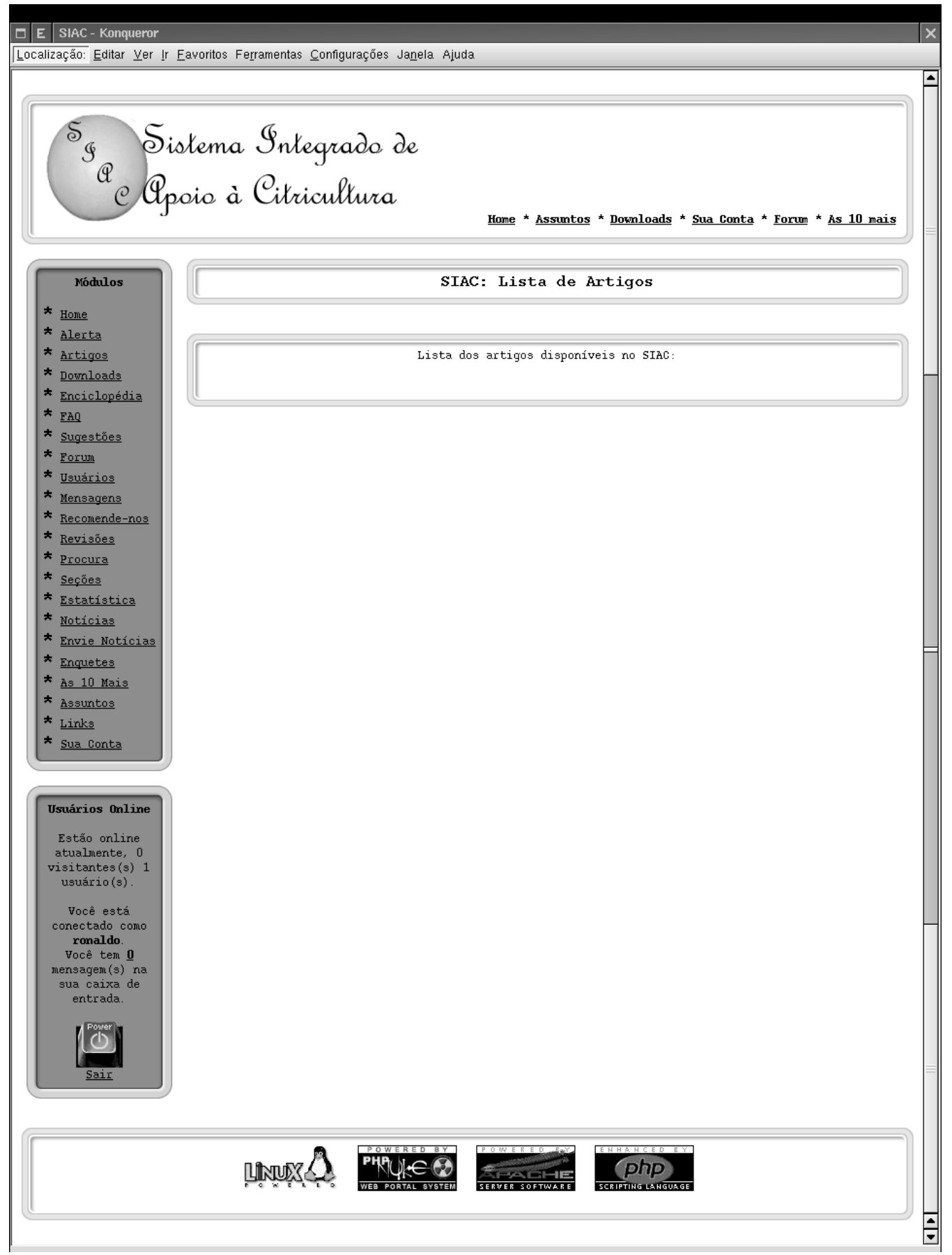

Figura 24 - Módulo de artigos do SIAC, onde poderão ser lidos artigos diversos relacionados ao setor citrícola 


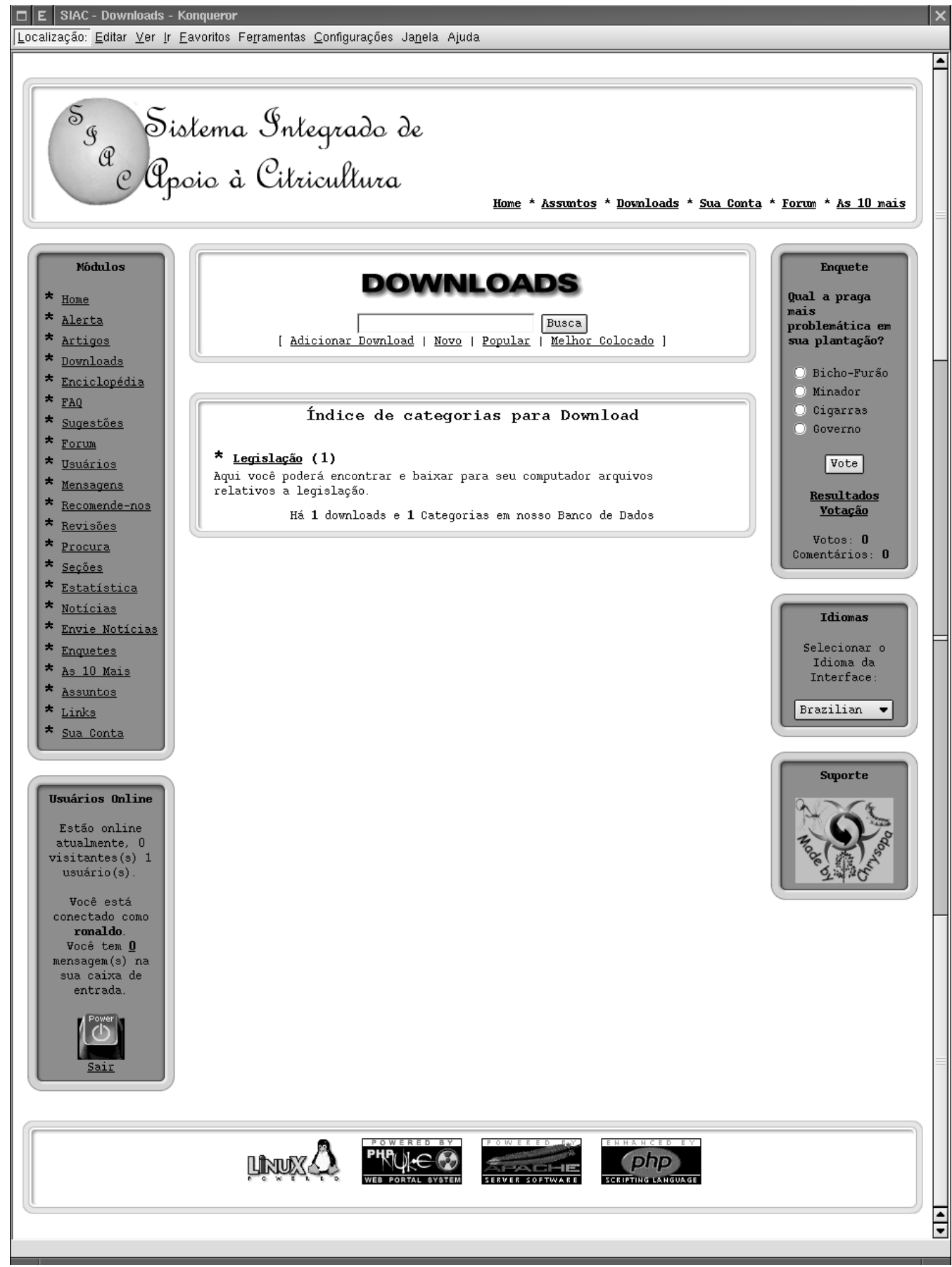

Figura 25 - Módulo de "downloads" do SIAC, onde os usuários terão acesso a arquivos, como por exemplo o programa para simular o potencial de ocorrência de Ecdytolopha aurantiana 


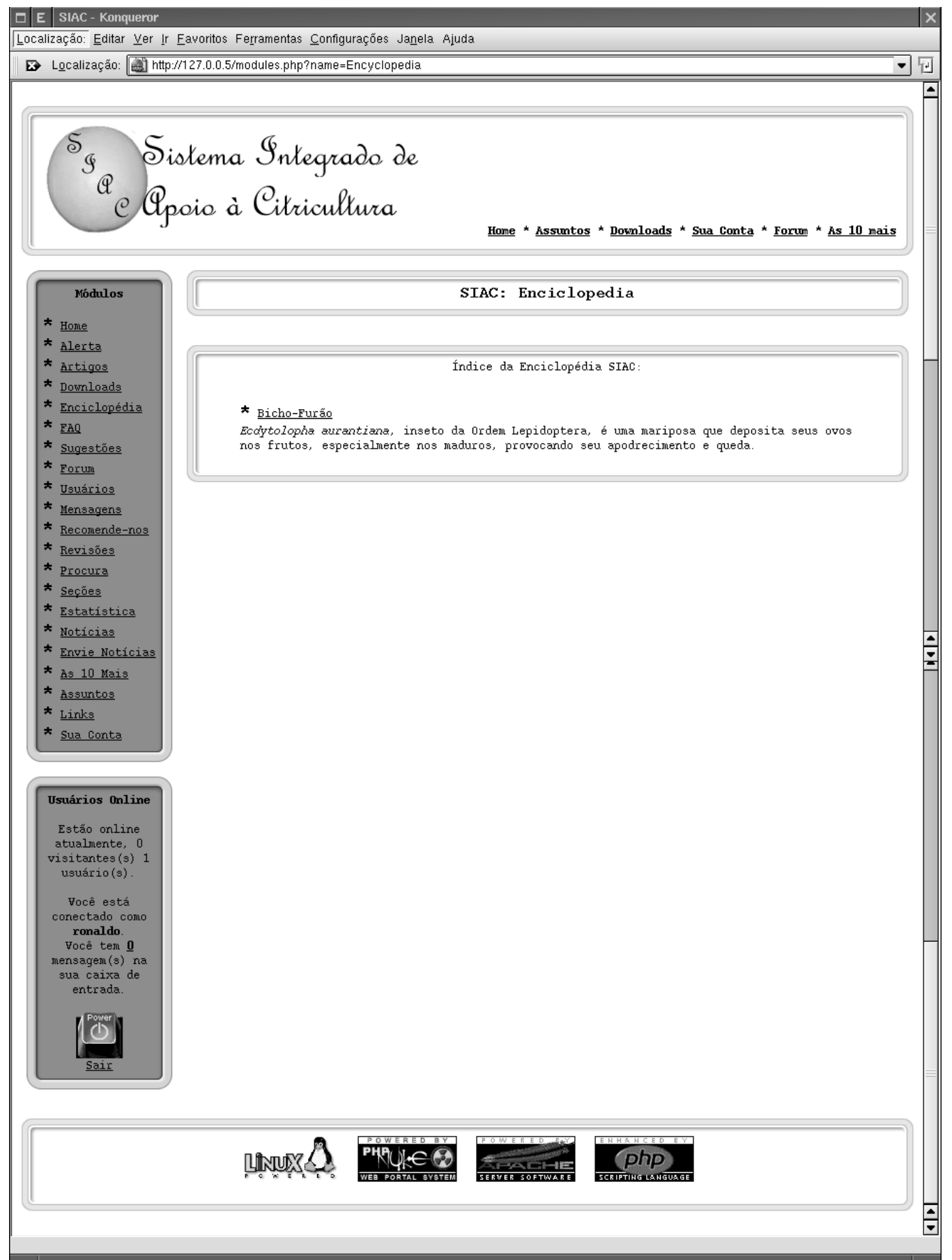

Figura 26 - Módulo de enciclopédia do SIAC, neste local os usuário poderão ter acesso a informações técnicas de forma fácil de ser entendida 


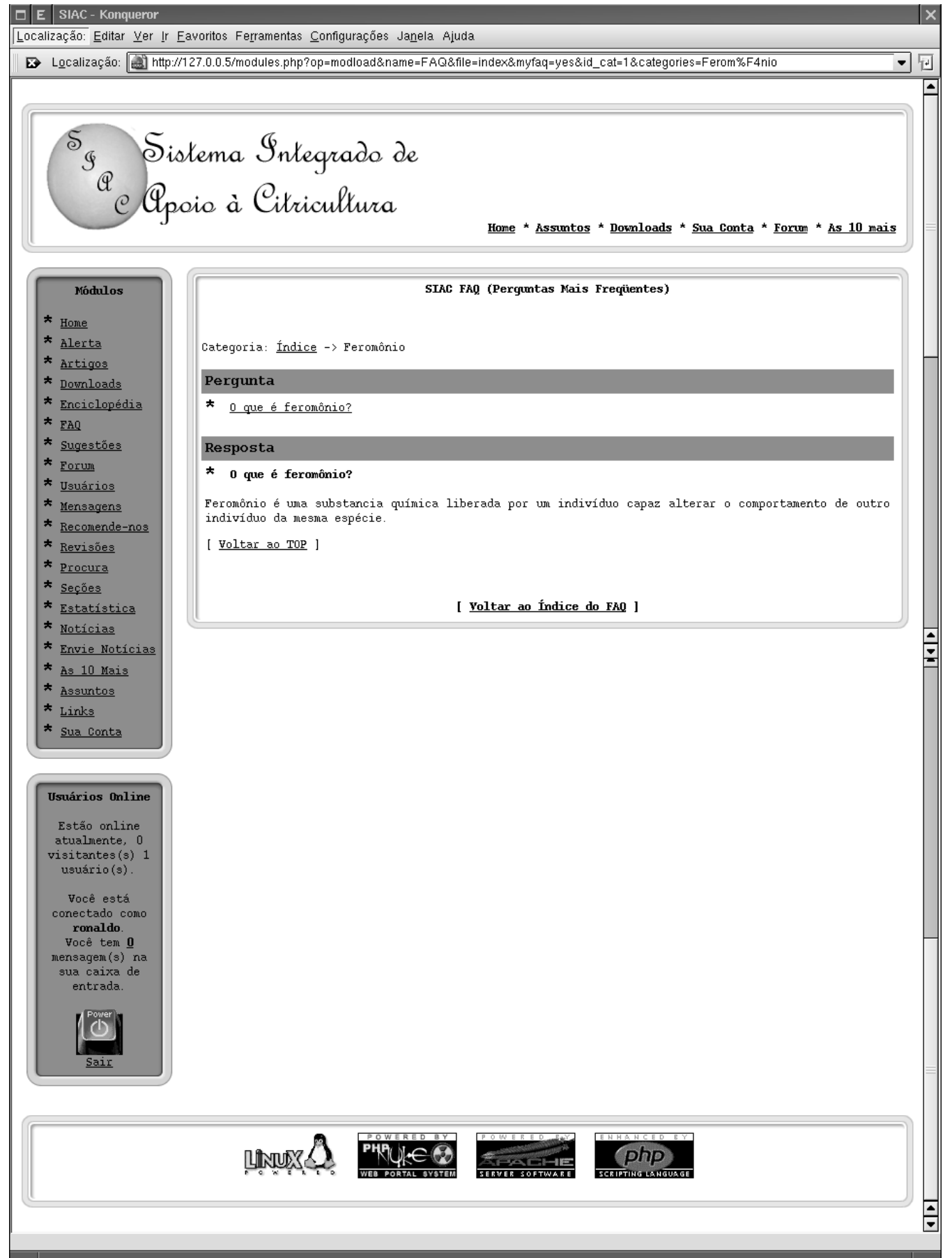

Figura 27 - Módulo de FAQ (Frequently Asked Questions) do SIAC, neste local estarão um conjunto das perguntas mais freqüentes com as respectivas respostas 


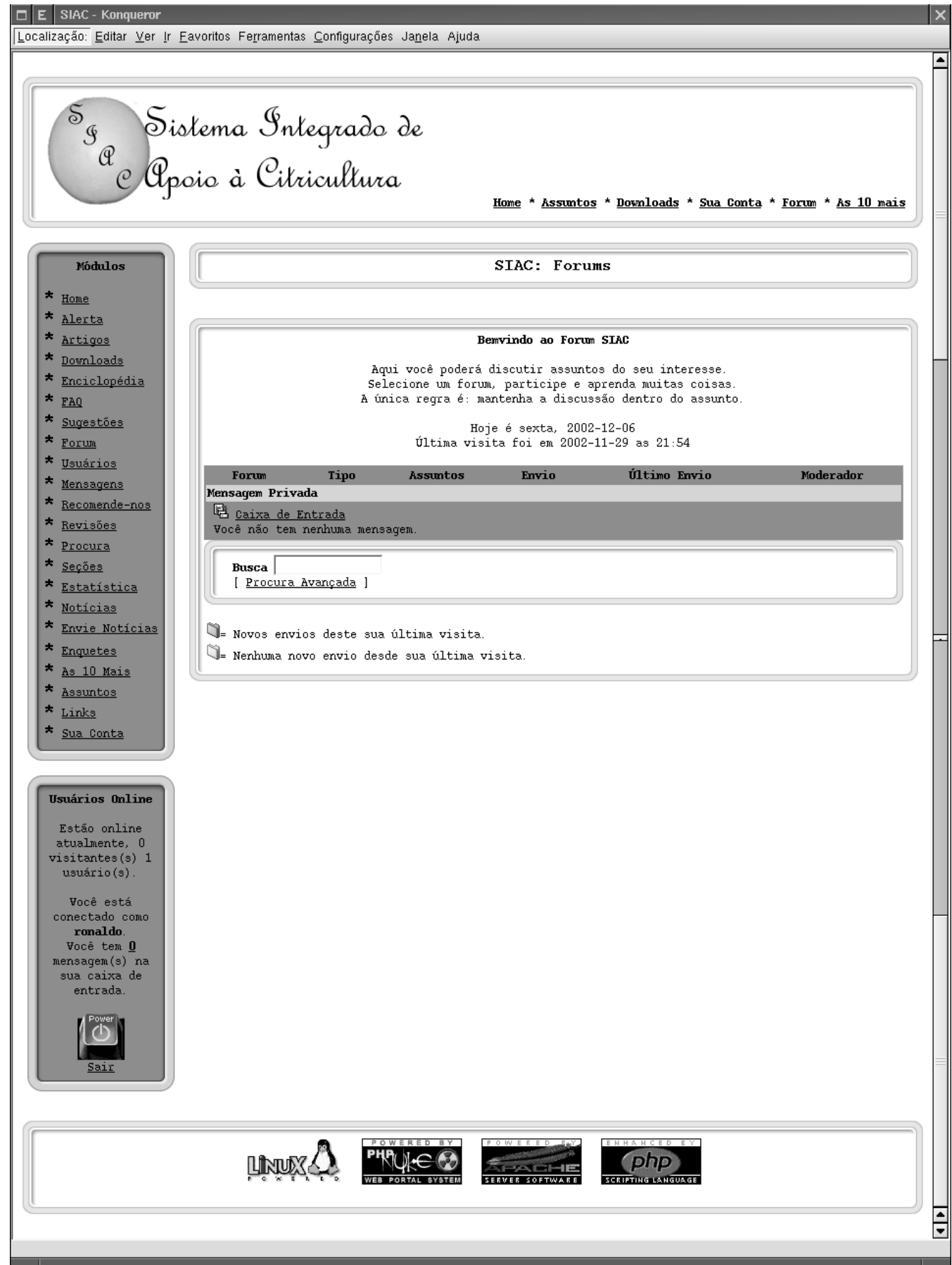

Figura 28 - Módulo de fórum do SIAC, local onde os usuário poderão debater qualquer assunto pertinente de forma pública 


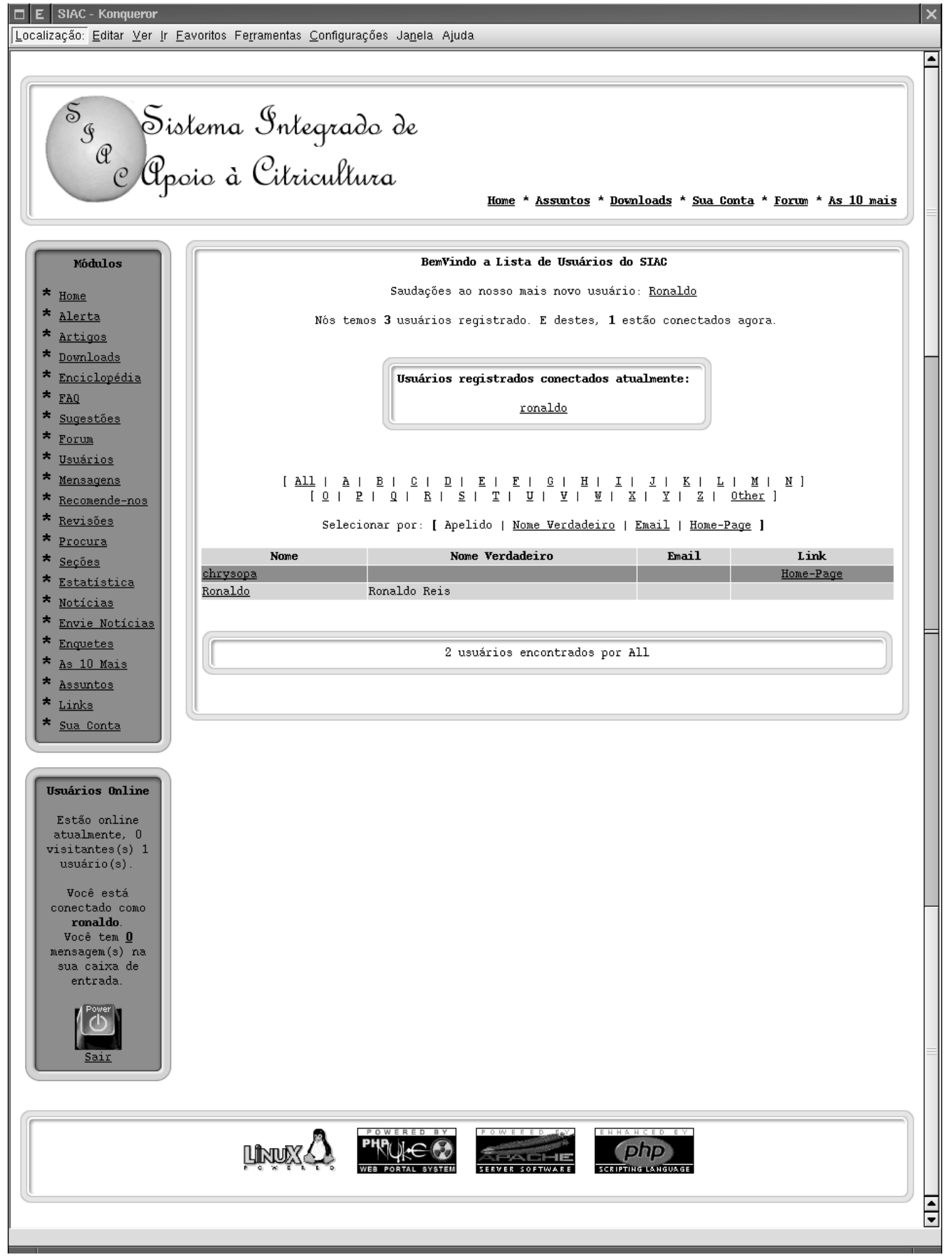

Figura 29 - Módulo de usuários do SIAC, local onde os usuário poderão se cadastrar no sistema e personalizar o SIAC para suas preferências 


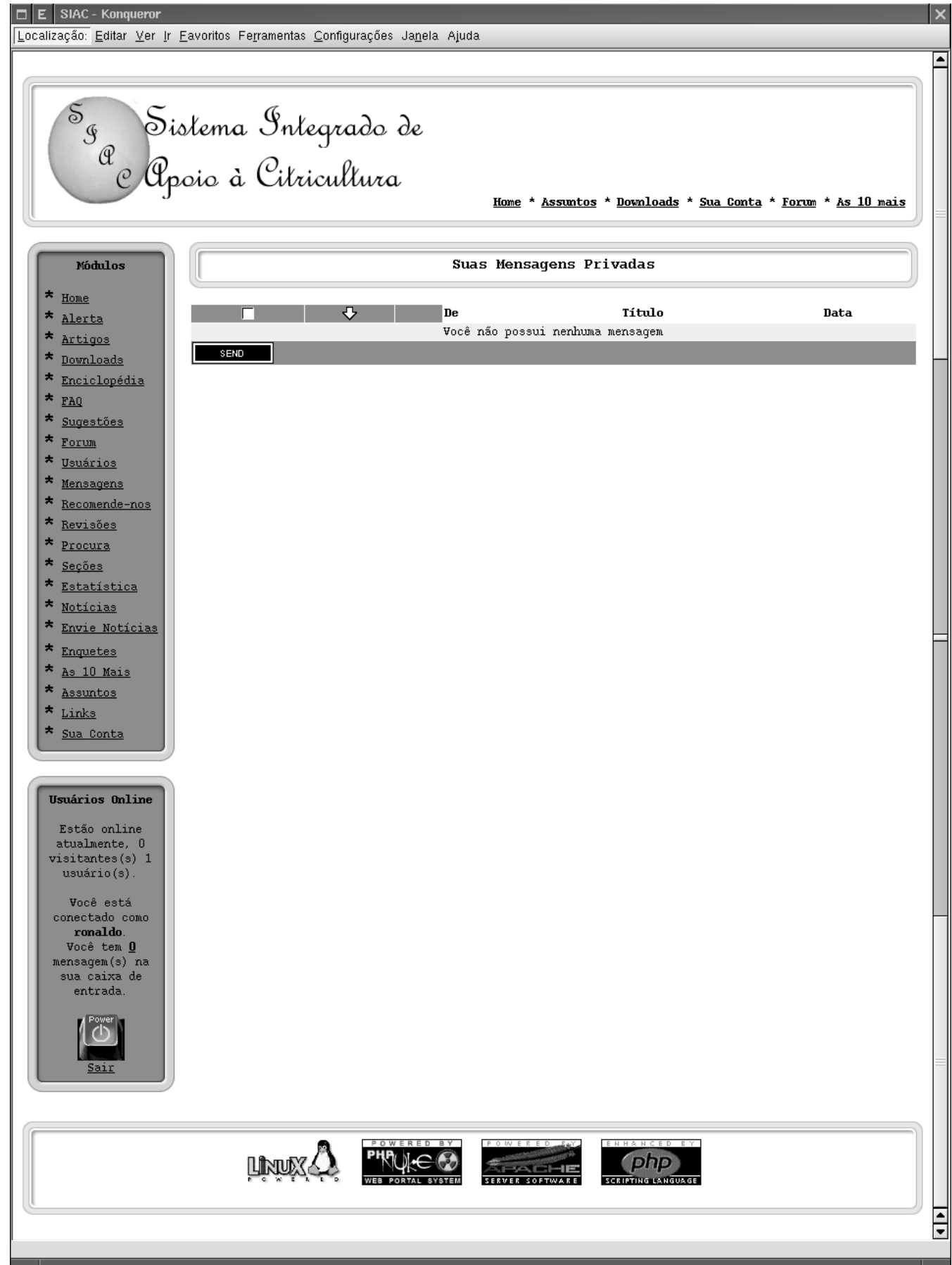

Figura 30 - Módulo de mensagens do SIAC, aqui os usuário poderão debater assuntos pertinentes de forma privada 


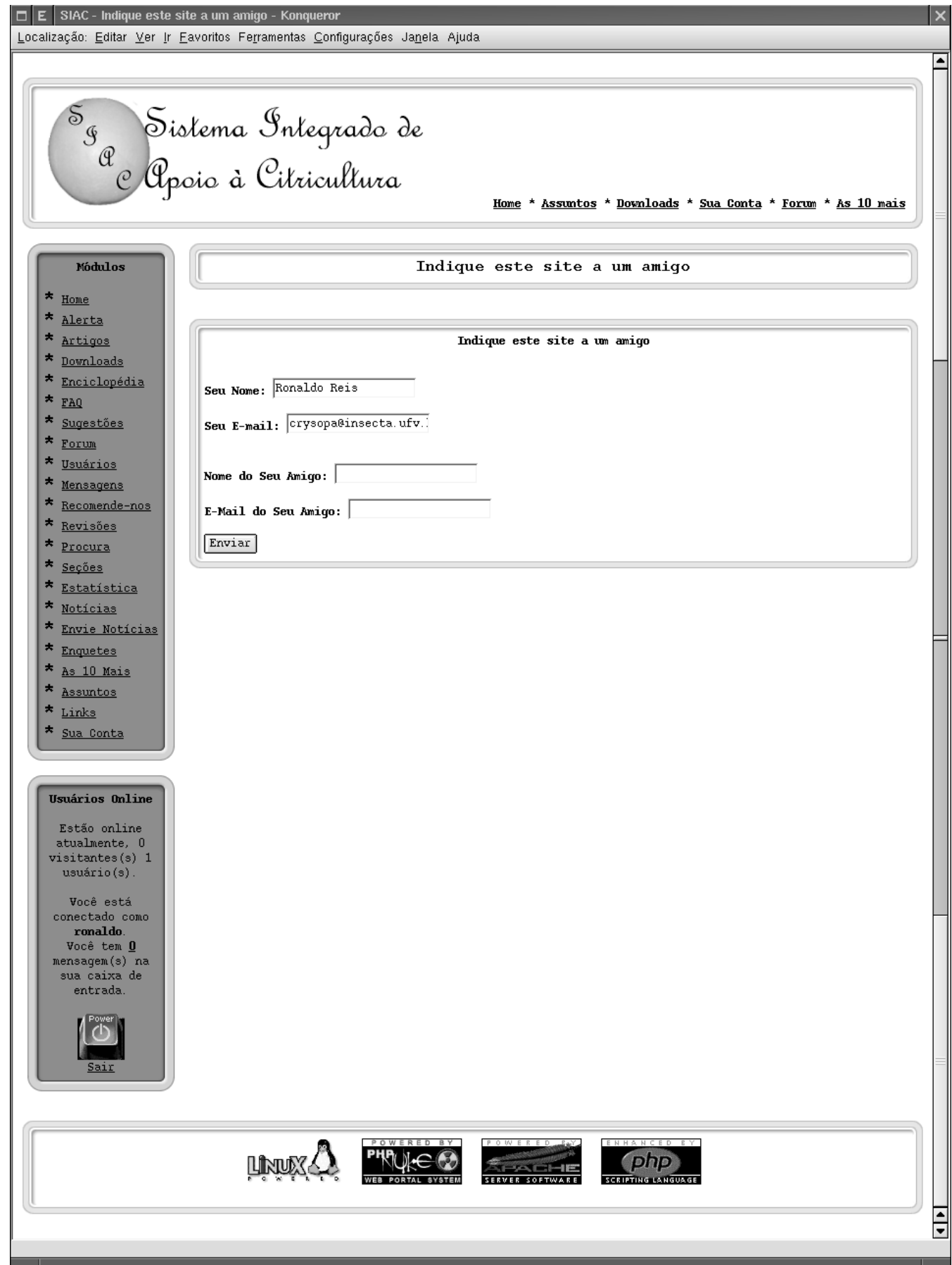

Figura 31 - Módulo de indicações do SIAC, local para indicar o SIAC a uma pessoa que ainda não conheça o sistema 


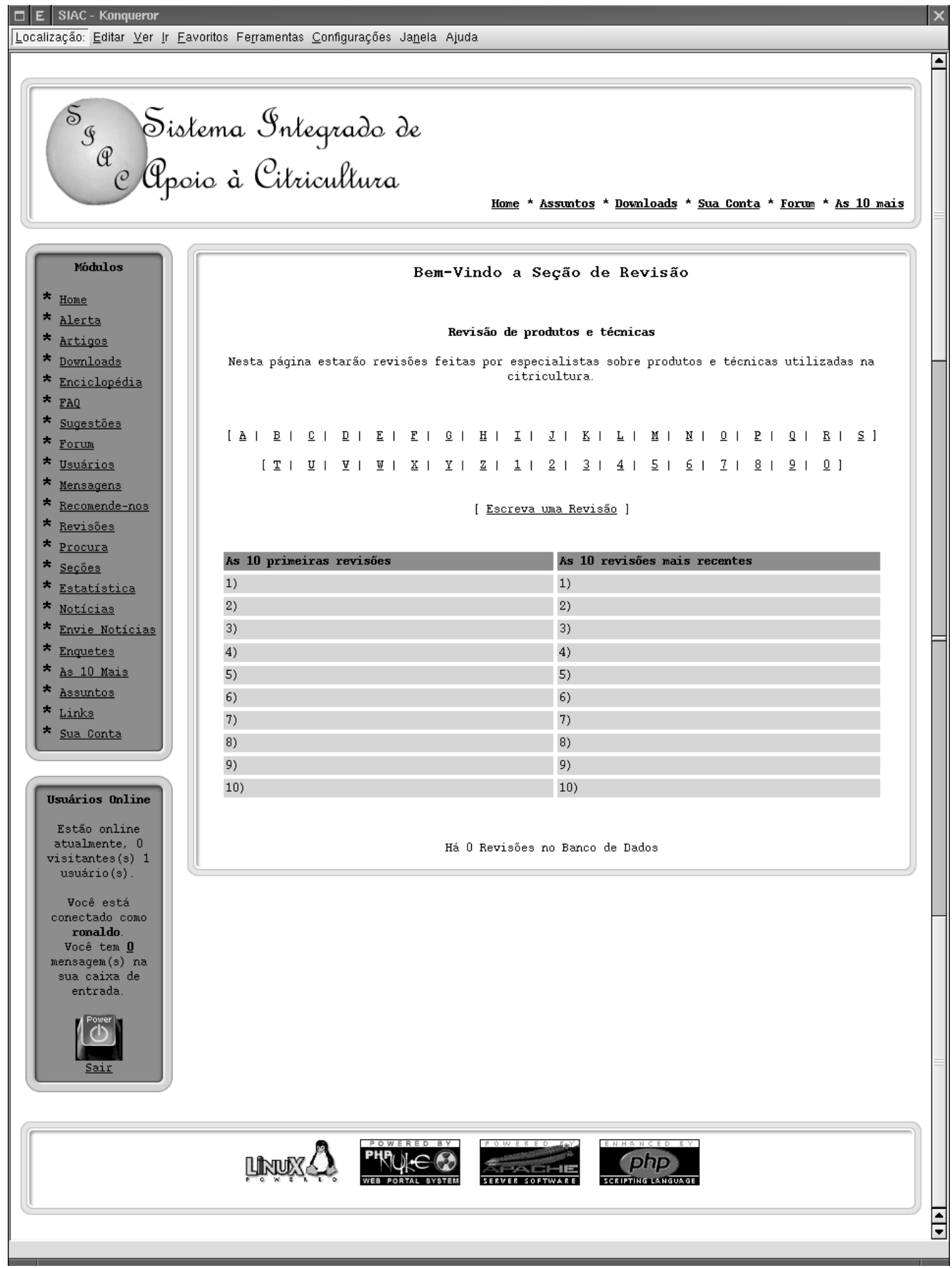

Figura 32 - Módulo de revisões do SIAC, local onde os usuário poderão ter conhecimento de revisões, feitas por pesquisadores, de produtos e técnicas utilizadas na citricultura 


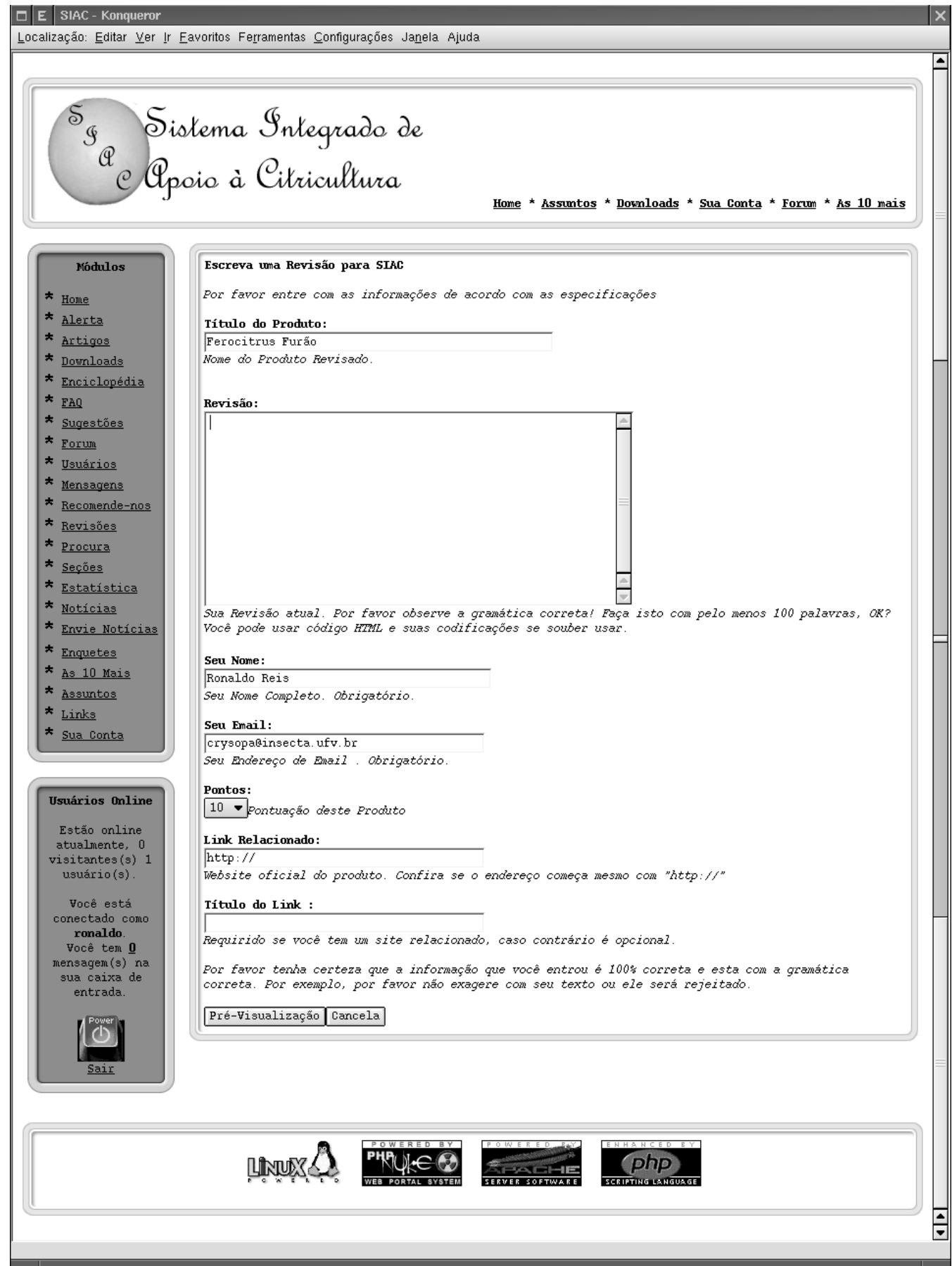

Figura 33 - Módulo de envio de revisões do SIAC, local onde o pesquisador poderá redigir suas revisões e enviar ao sistema 


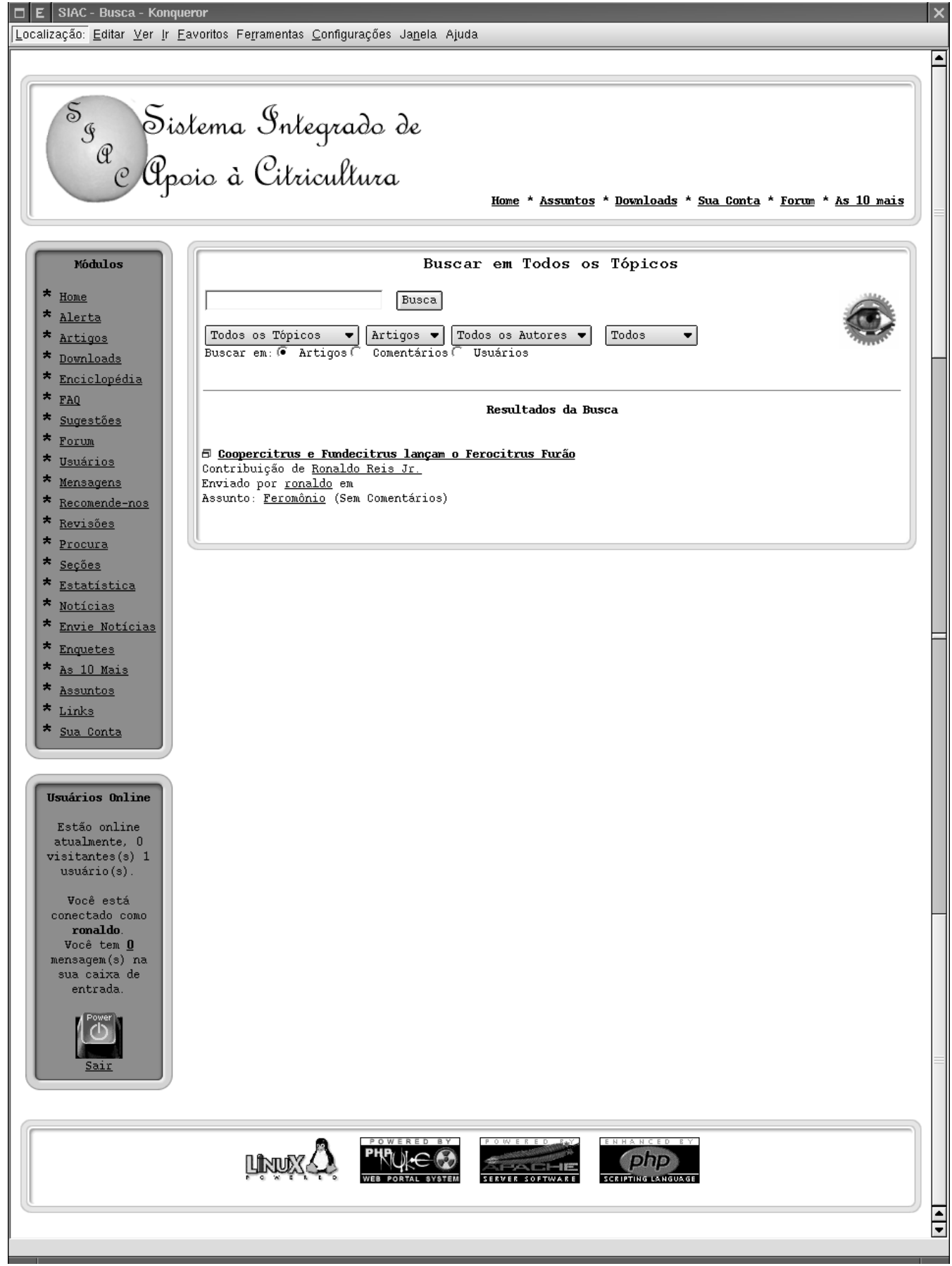

Figura 34 - Módulo de procura do SIAC, local onde os usuário poderão procurar por qualquer informação dentro do SIAC 


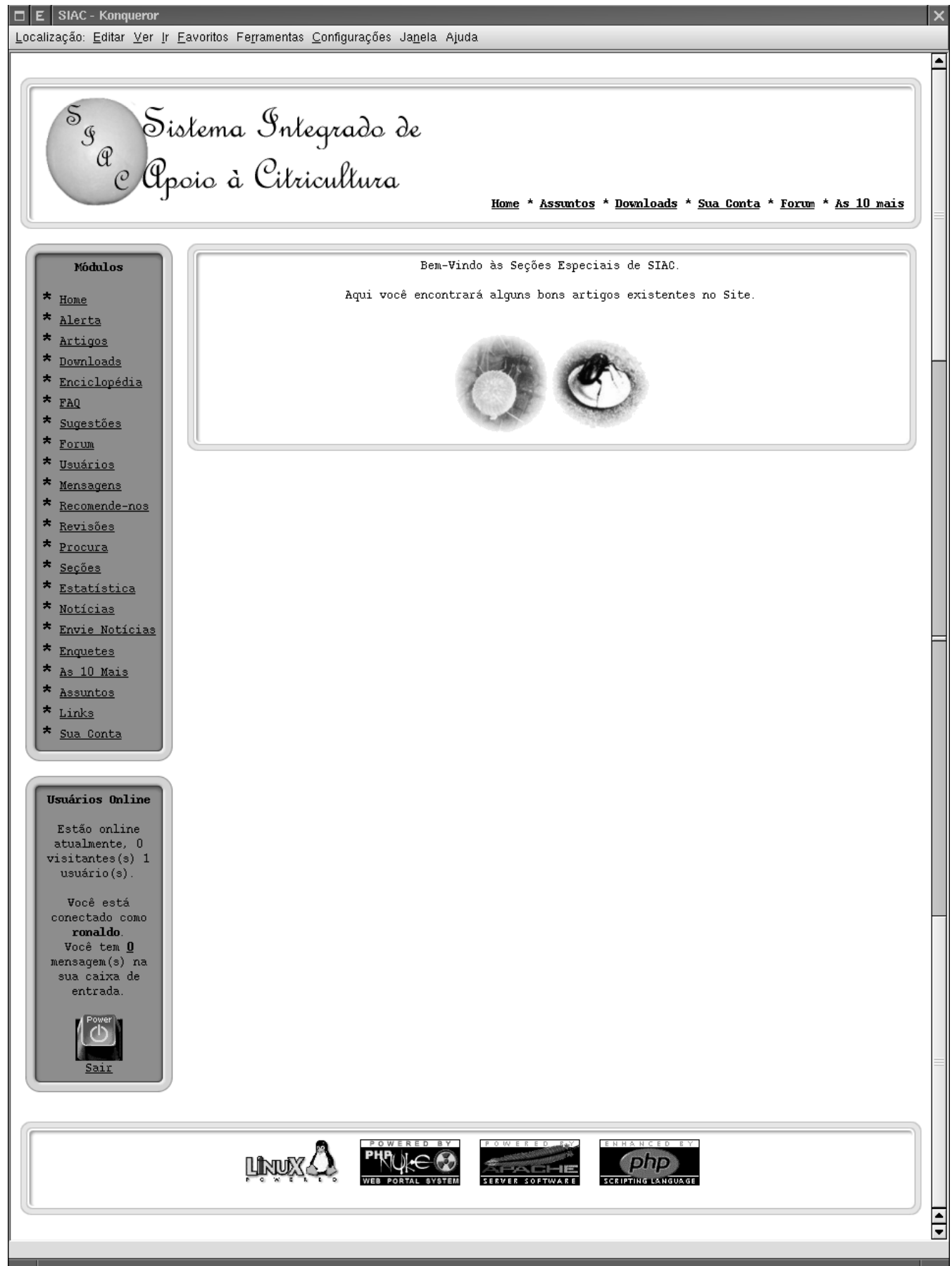

Figura 35 - Módulo de seções do SIAC, local onde os artigos estarão organizados por assunto de forma a facilitar a leitura 


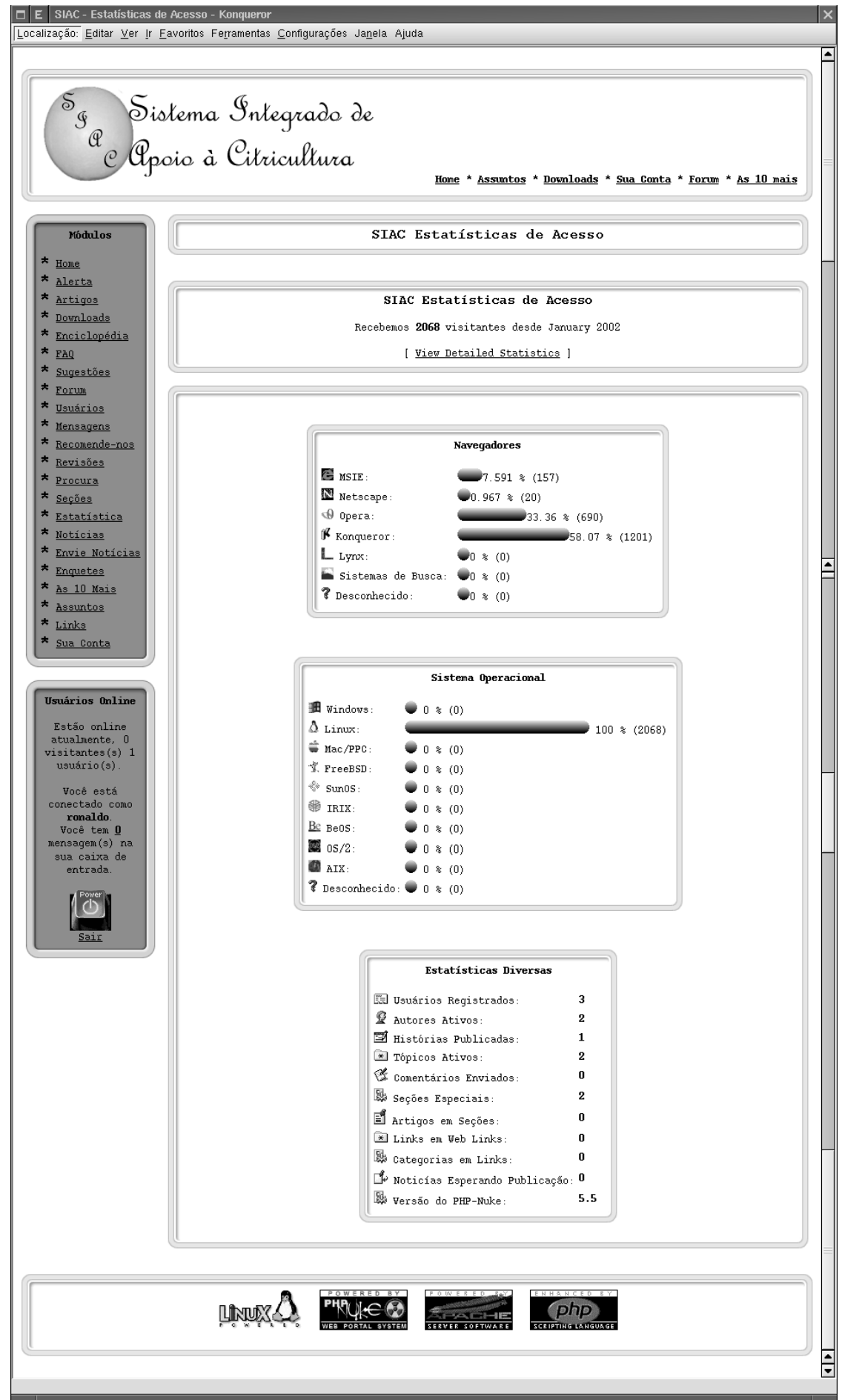

Figura 36 - Módulo de estatistica do SIAC, local onde são mostradas as estatísticas de acesso ao sistema 


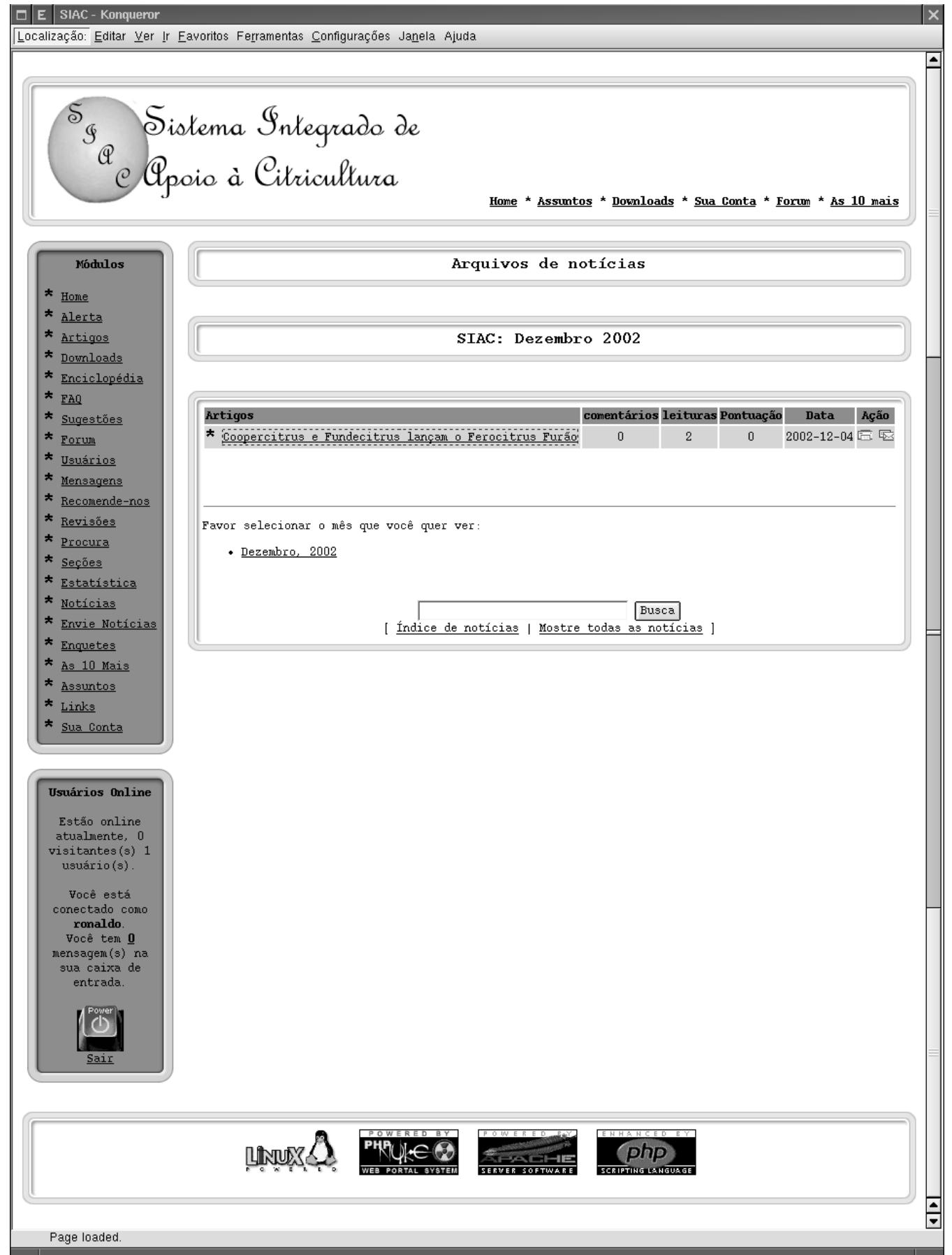

Figura 37 - Módulo de notícias do SIAC, local onde os usuário terão acesso a todas as notícias publicadas no sistema 


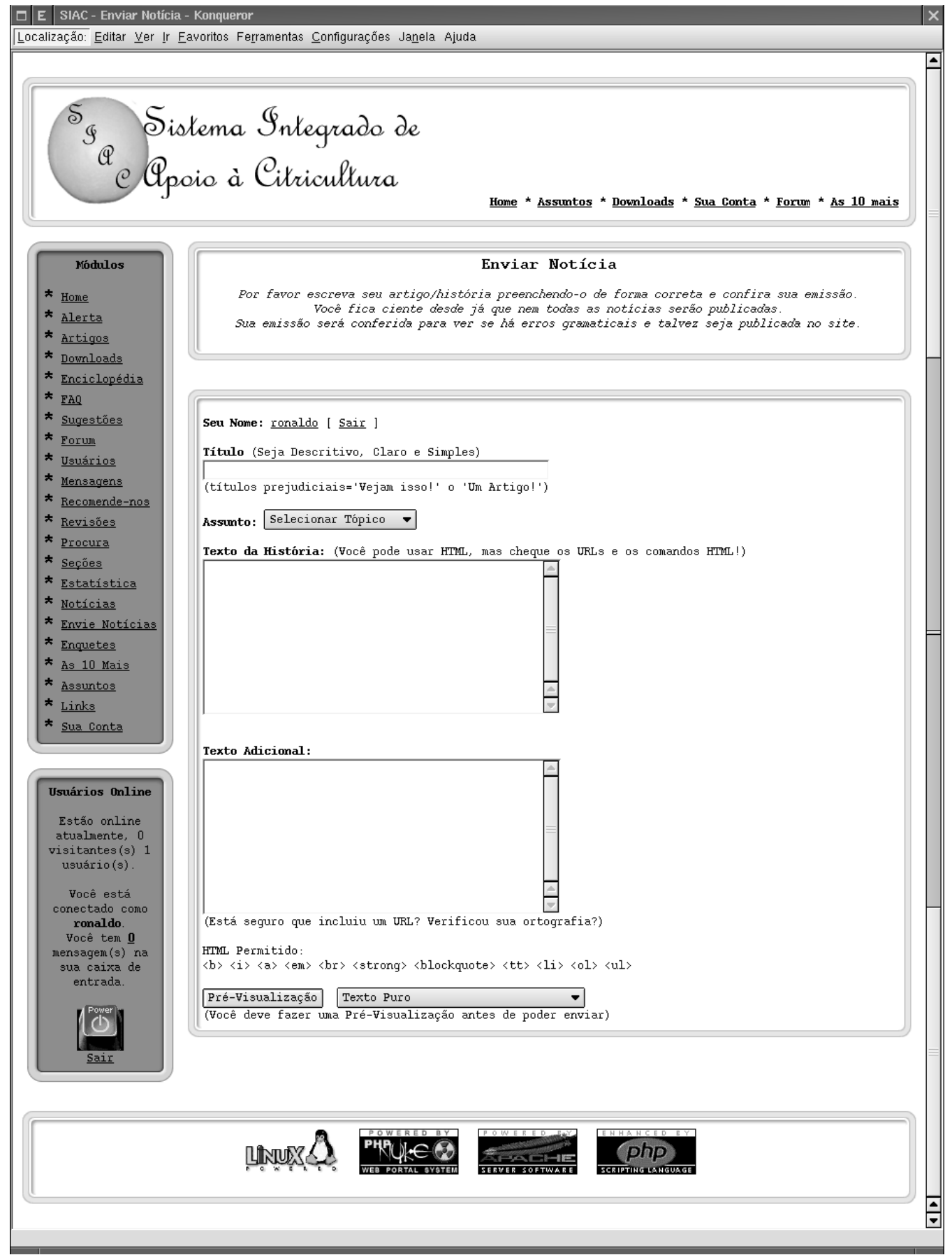

Figura 38 - Módulo para envio de notícias do SIAC, neste local os usuários poderão disponibilizar toda e qualquer notícia pertinente ao SIAC 


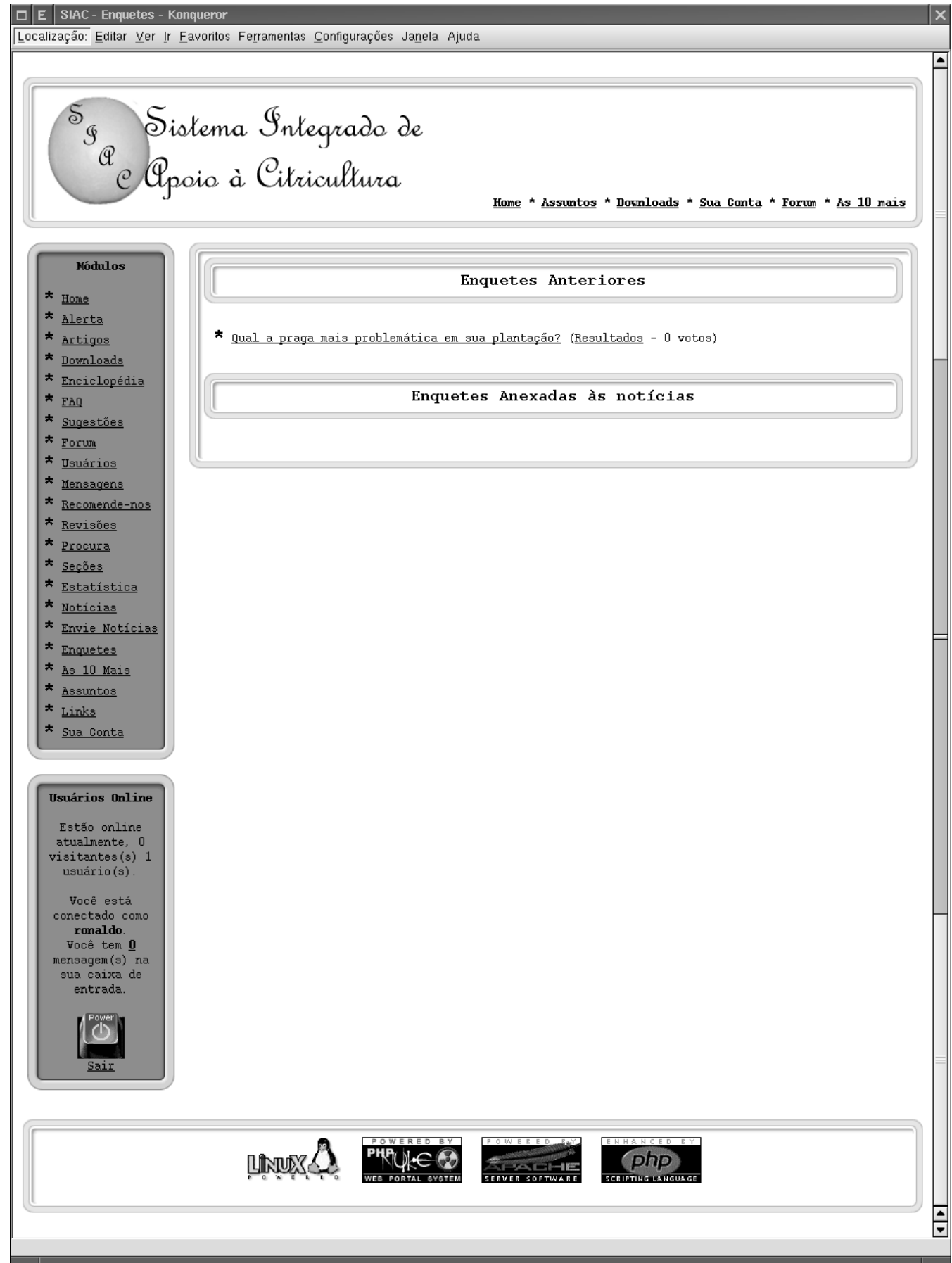

Figura 39 - Módulo de enquetes do SIAC, neste local estarão os resultados das enquetes realizadas com os usuário 


\section{CONCLUSÕES}

1. O tipo de solo, temperatura do local, variedade de citros, idade das plantas e uso de agroquímicos para controle de Ecdytolopha aurantiana (Lima, 1927) (Lepidoptera: Tortricidae), influenciam na dinâmica populacional deste inseto.

2. A maior influência sobre a flutuação do bicho-furão foi exercida pelo tipo de solo, seguindo-se temperatura local, variedade de citros, idade das plantas e uso de agroquímicos para controle de E. aurantiana.

3. A ocorrência de E. aurantiana em função da temperatura é diferente para cada combinação de tipo de solo, variedade de citros, idade das plantas e uso de agroquímicos.

4. O modelo desenvolvido pode prever o potencial de ocorrência de E. aurantiana em função da temperatura ou de meses do ano levando-se em consideração o tipo de solo, variedade de citros, idade das plantas e aplicação de agroquímicos.

5. O programa elaborado em linguagem $R$ conta com equações para simular as diversas situações de ocorrência de E. aurantiana.

6. O SIAC é um sistema que facilita o uso do modelo, sem a necessidade de conhecimento de R. 
7. O SIAC fornece uma gama de recursos que visa facilitar o acesso do citricultor às informações e ao pesquisador acesso aos problemas do citricultor, criando com isto uma maior interação de ambos os setores.

8. O modelo de previsão de ocorrência do bicho-furão pode ser aperfeiçoado com coleta de dados mais regulares e de forma contínua. 
ANEXOS 


\section{ANEXO A - tempest: Programa utilizado para estimar as tem- peraturas médias utilizadas no modelo}

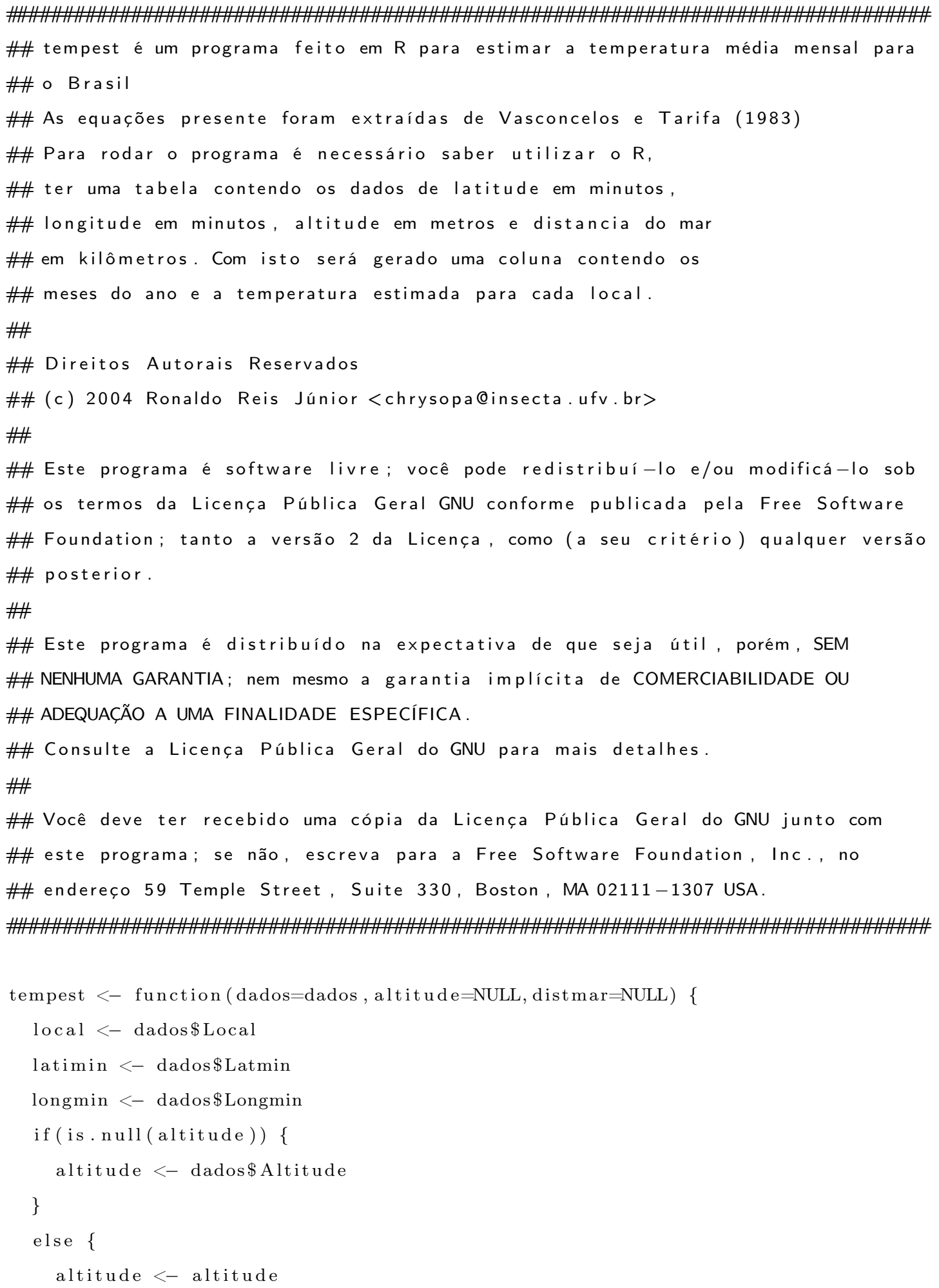




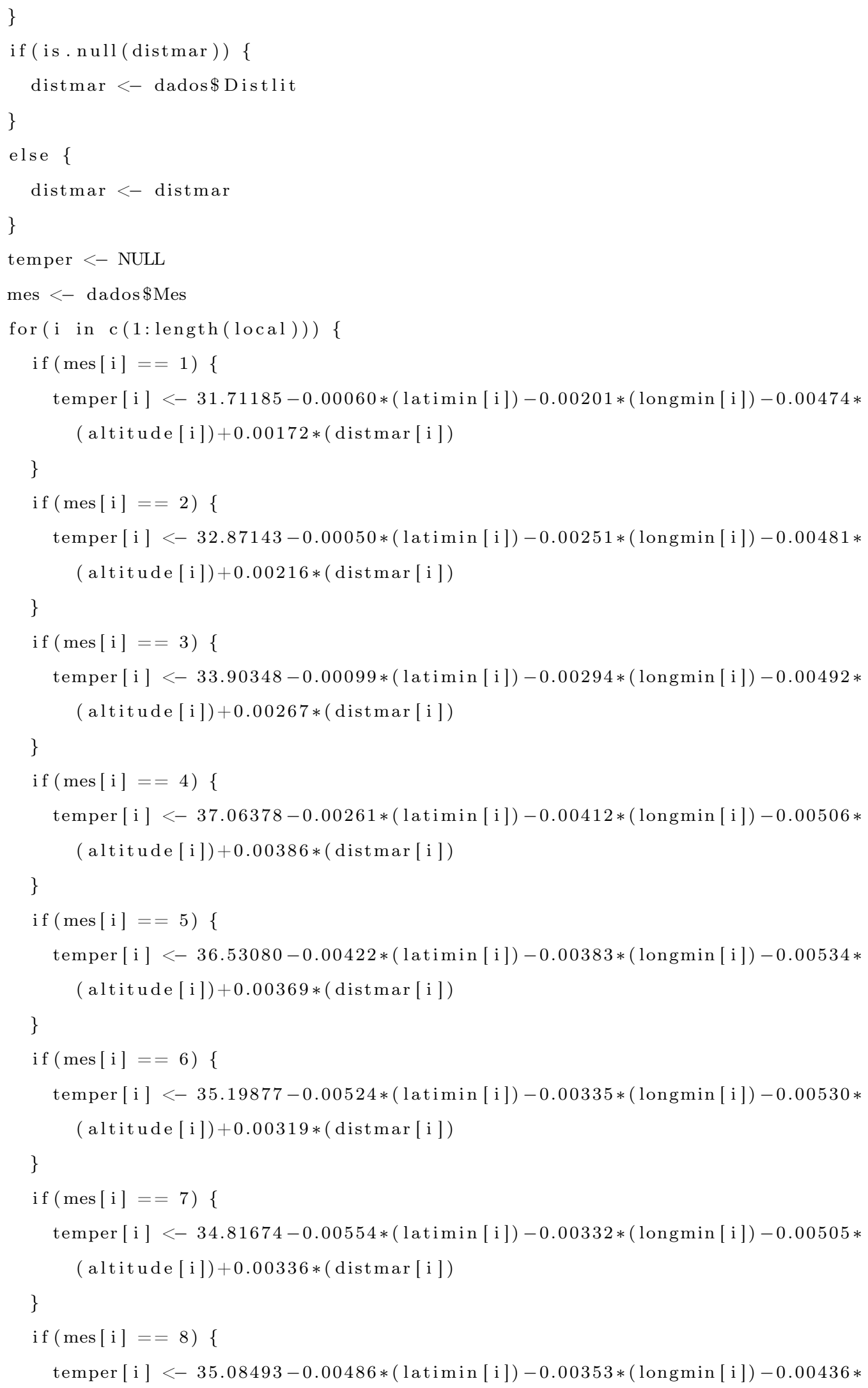




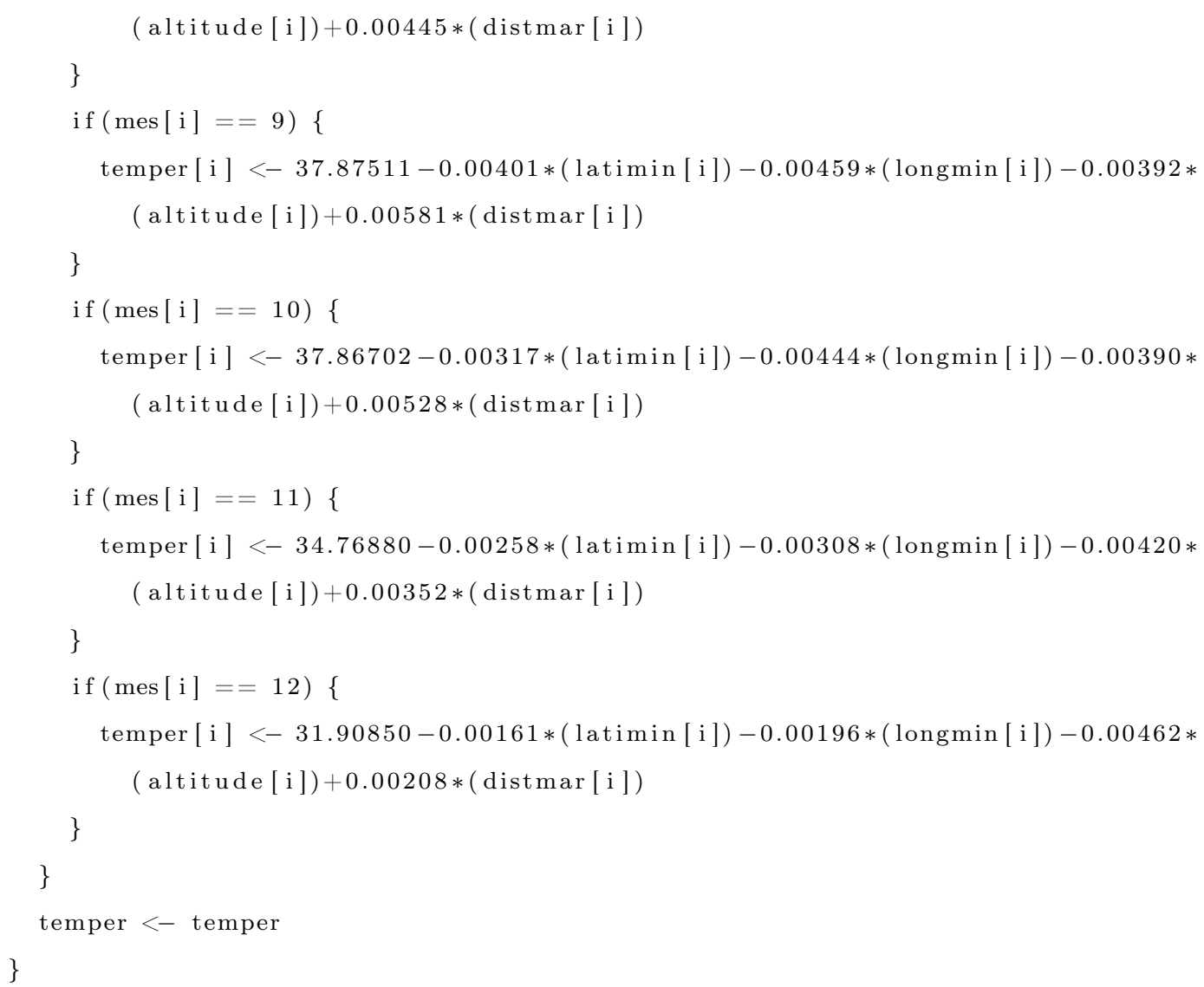




\section{ANEXO B - BF: Programa utilizado para gerar as equações e crias os gráficos do modelo}

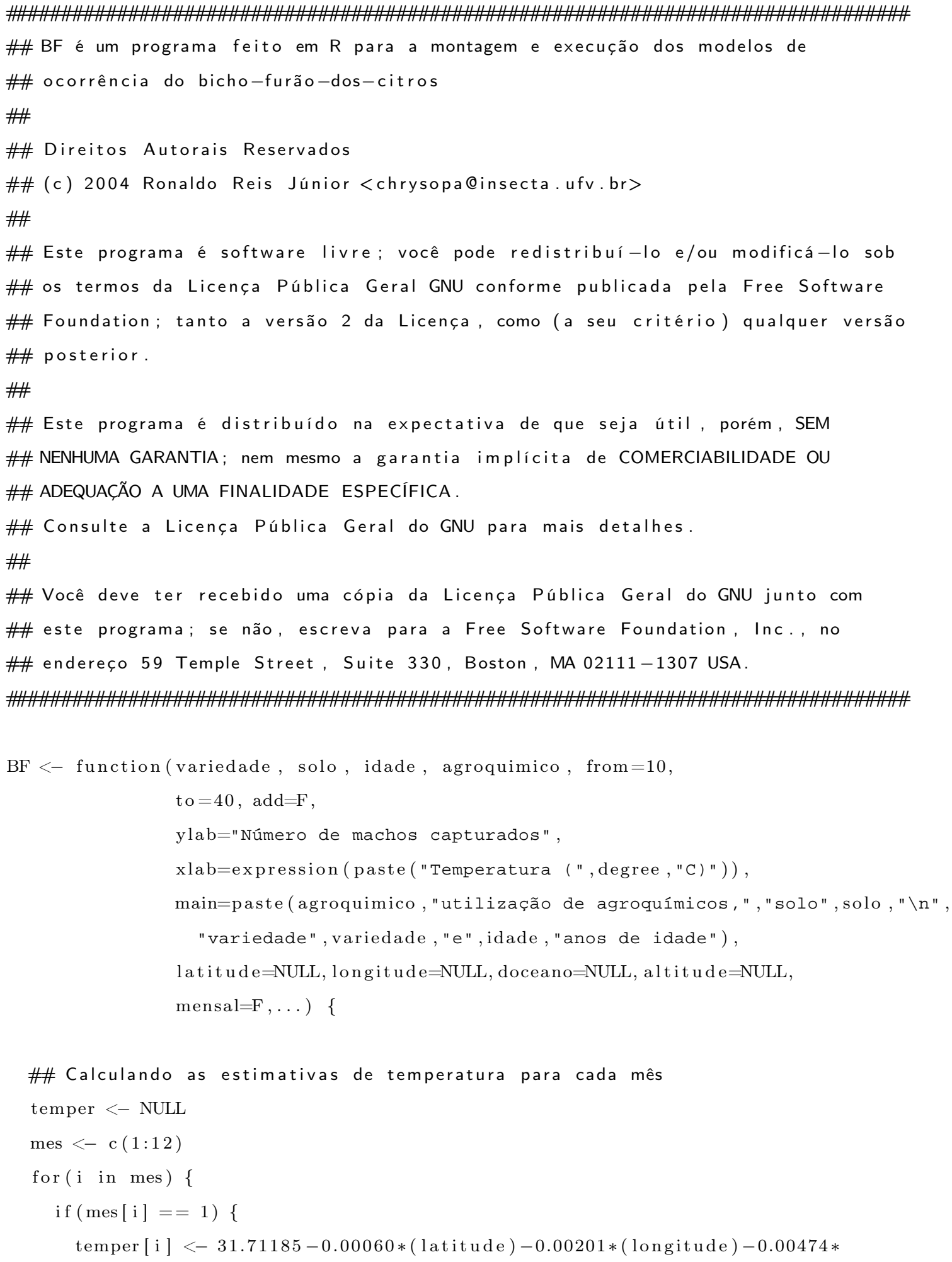




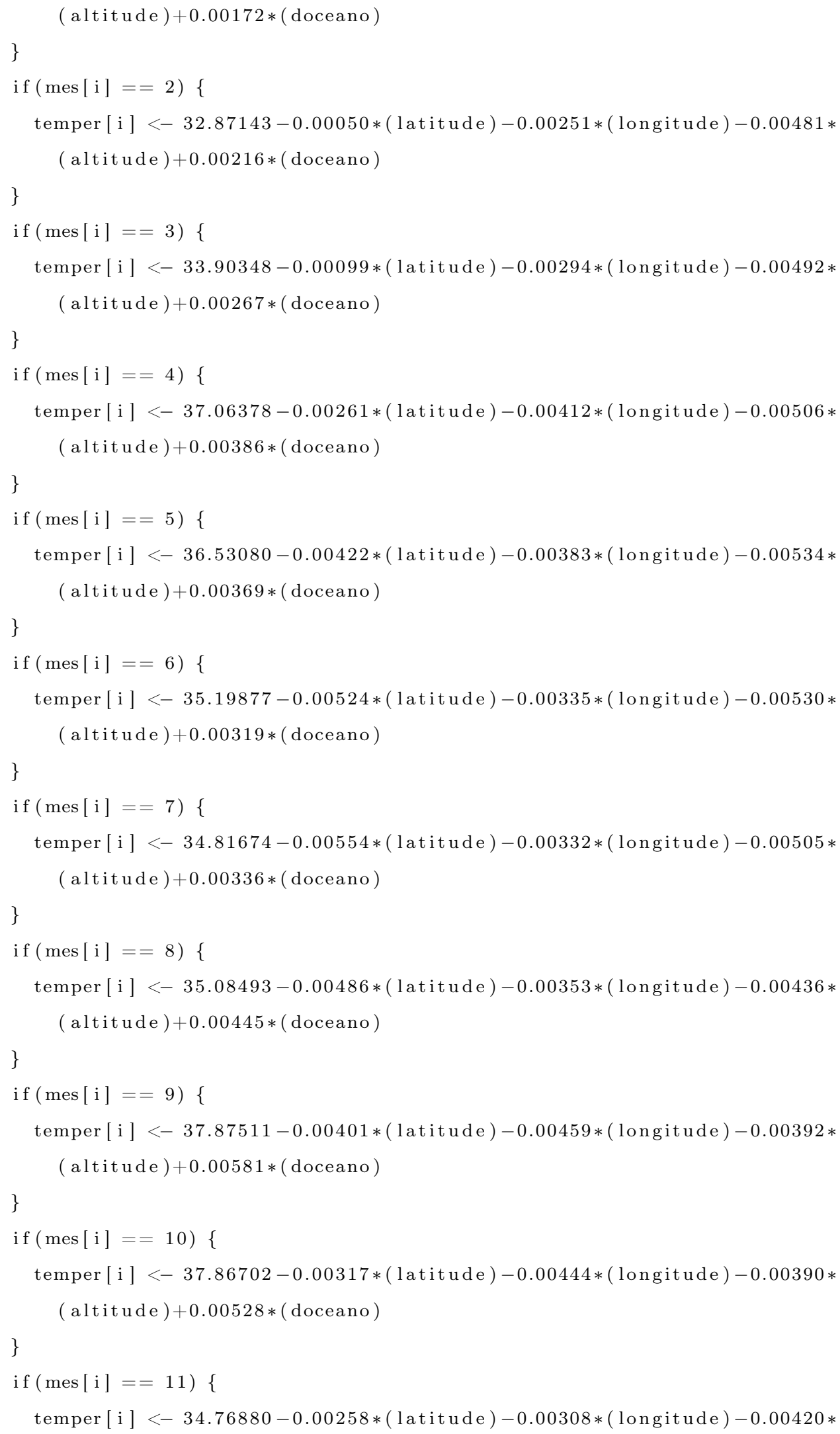




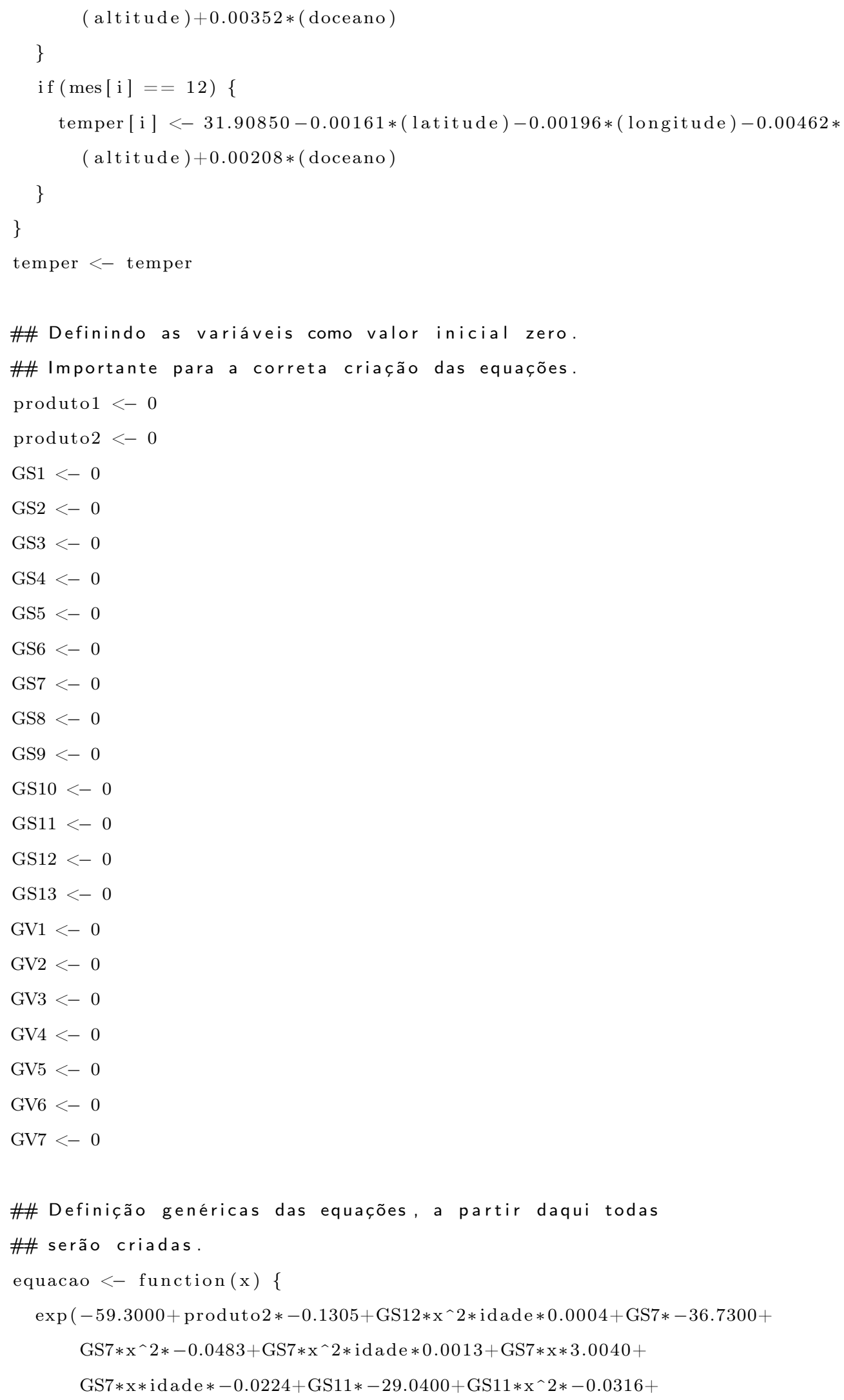




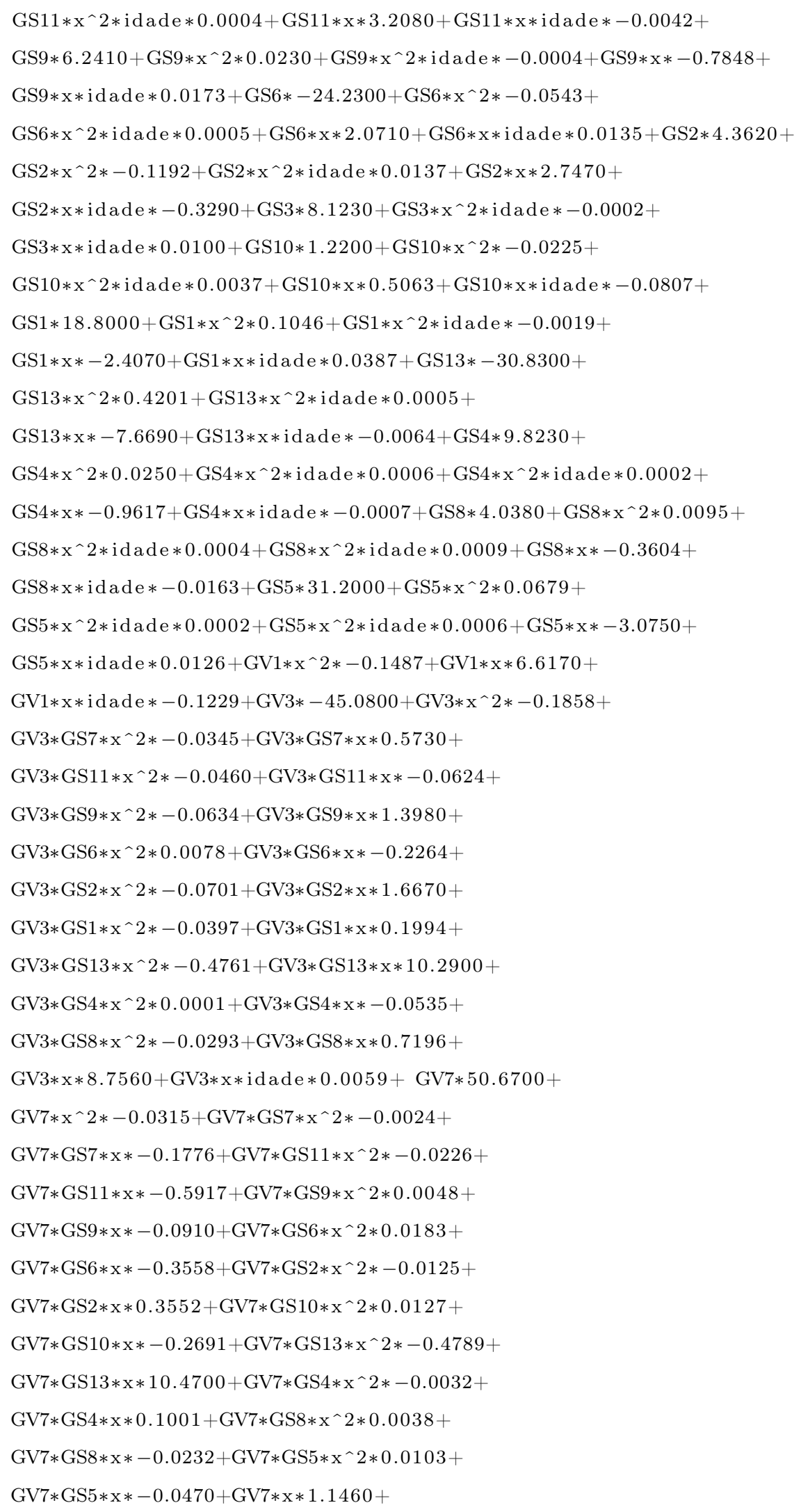




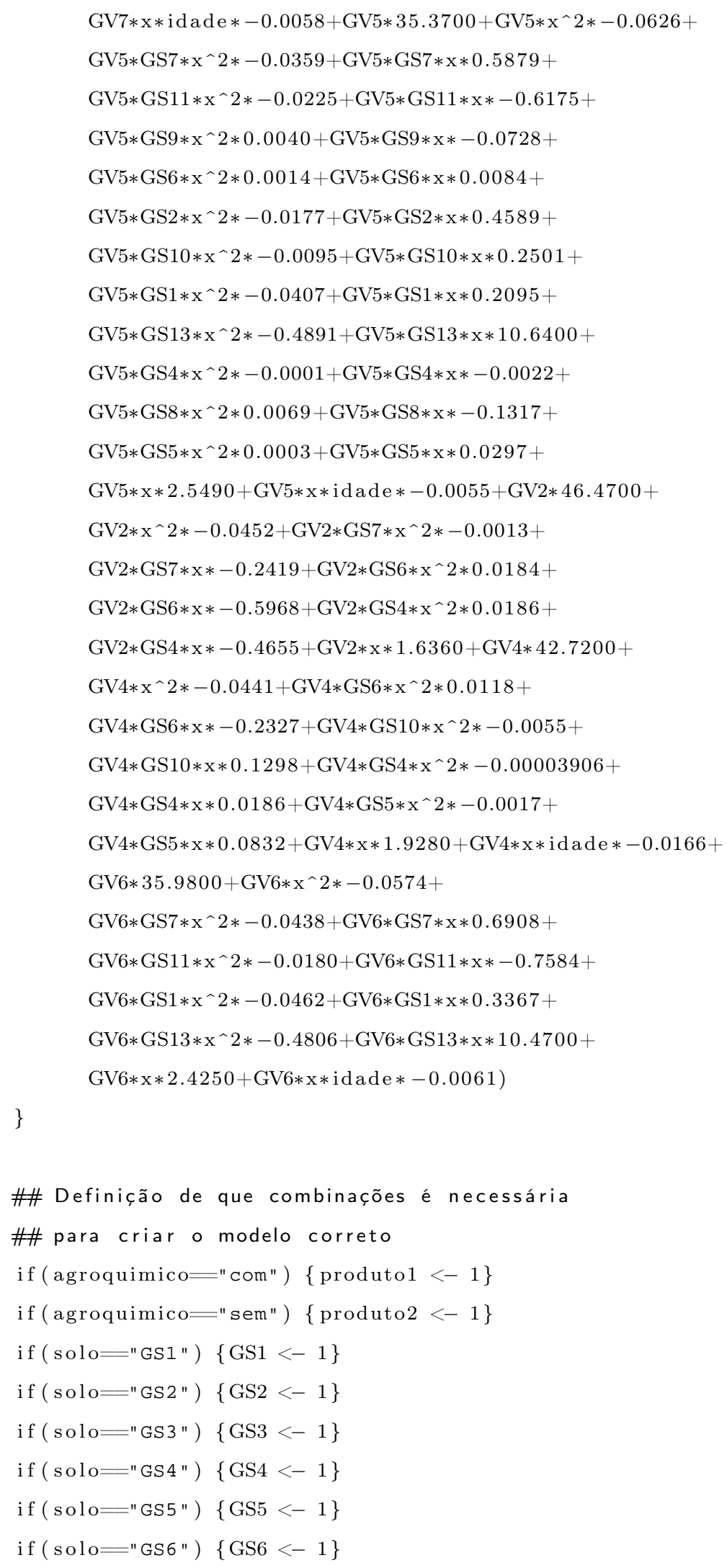




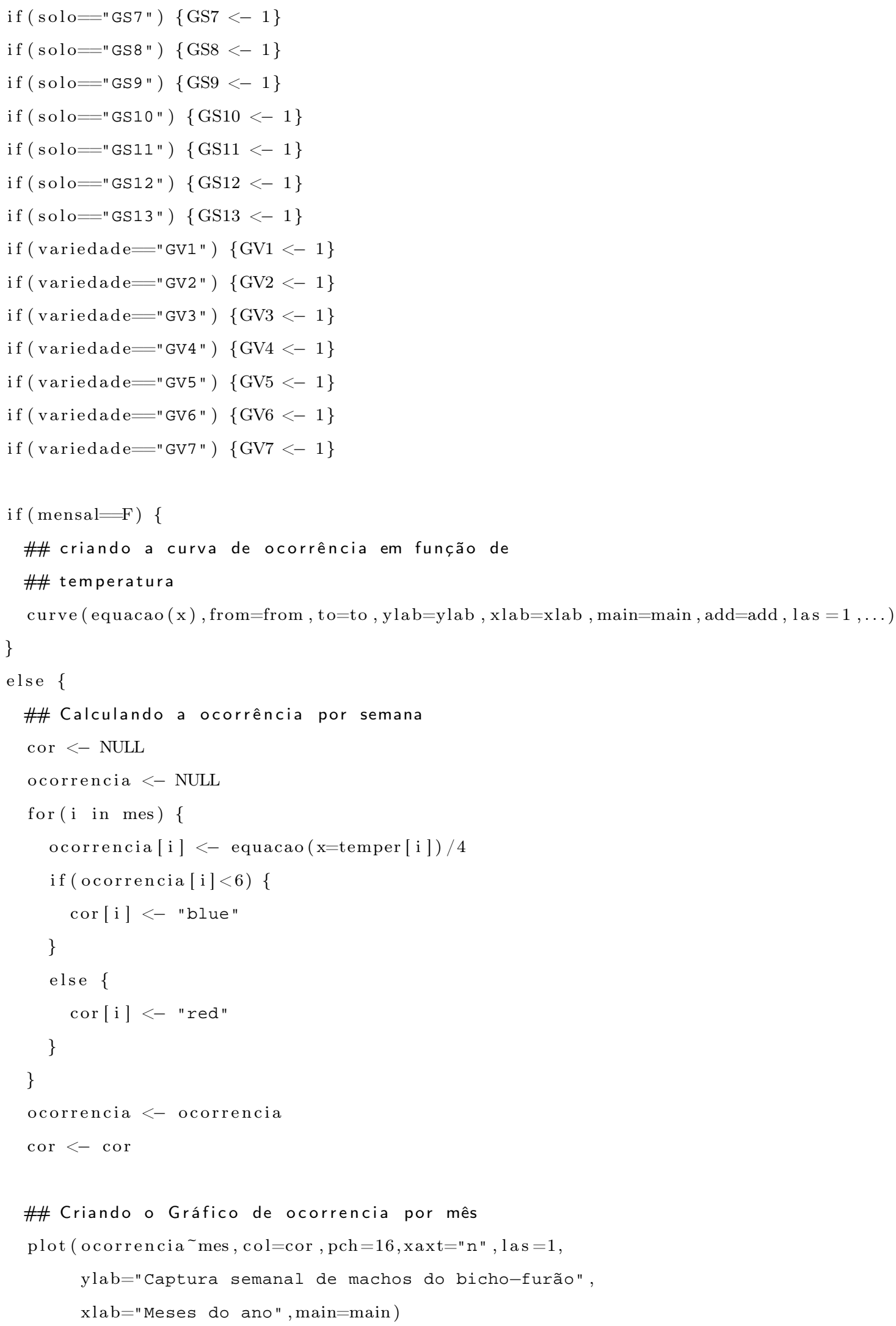


lines (mes, ocorrencia, col="black" , type="c")

axis (1, at=mes, labels = c("Jan", "Fev", "Mar", "Abr" , "Mai" , "Jun" ,

"Jul" , "Ago" , "Set " , "Out " , "Nov" , "Dez" ), srt=45)

legend $(5, \max$ (ocorrencia), legend=c("Nível de dano econômico",

"Nível de controle",

"Nível de equilíbrio"),

bty $=" \mathrm{n} ", \mathrm{pch}=\mathrm{c}(16,-1,16), \mathrm{lty}=\mathrm{c}(0,2,0), \mathrm{col}=\mathrm{c}($ "red" , "red" , "blue" ) $)$

segments $(1,6,12,6$, lty $=2, \operatorname{col}="$ red" $)$

\}

\} 


\section{Referências Bibliográficas}

ACUÑA, S. T.; BARCHINI DE GIMÉNEZ, G. Simulation model for integrated pest management of agricultural ecosystems. Boletin de Sanidad Vegetal, v.22, n.4, p.761-772, 1996.

BENTO, J. M. S.; VILELA, E. F.; PARRA, J. R. P.; LEAL, W. S. Monitoramento do bicho-furão-dos-citros com feromônio sexual: bases comportamentais para utilização dessa nova estratégia. Laranja, v.22, n.2, p.351-366, 2001b.

BENTO, J. M. S.; PARRA, J. R. P.; VILELA, E. F.; WALDER, J. M.; LEAL, W. S. Sexual behavior and diel activity of citrus fruit borer Ecdytolopha aurantiana. Journal of Chemical Ecology, v.27, n.10, p.2053-2065, 2001a.

BUTT, D. J.; XU, X. M. VentemTM - a computerised apple scab warning system for use on farms. Integrated Control of Pome Fruit Diseases, v.17, p.247-251, 1994.

CARVALHO, D. R. Comparação de métodos de monitoramento e controle do bichofurão, Ecdytolopha aurantiana (Lima, 1927) (Lepidoptera, Tortricidae), em citros. Piracicaba, 2003. 38p. Dissertação (Mestrado) - Escola Superior de Agricultura "Luiz de Queiroz", Universidade de São Paulo.

CHOW, T. L.; BERNARD, G. A versatile, fully automated, real-time potato late blight alert unit. Computers and Electronics in Agriculture, v.23, n.1, p.55-69, 1999. 
CRAWLEY, M. Statistical computing: an introduction to data analysis using S-Plus. Baffins Lane: John Wiley, 2002. 761p.

ERICKSON, L. C. The citrus industry: production technology. Berkeley: University of California, 1973. p.86-126: The general physiology of citrus.

ESPANHA. Ministério de Agricultura, Pesca y Alimentación. System of control, alert and valuation. Population levels of olive fly. 1: General description. Agricultura, v.707, p.524-531, 1991a.

ESPANHA. Ministério de Agricultura, Pesca y Alimentación. System of control, alert and valuation. Population levels of olive fly. 2: Computer application. Agricultura, v.707, p.532-534, $1991 b$.

FACHINELLO, J. C. Avanços com a produção integrada de pêssego. Informe Agropecuário, v.22, n.213, p.61-66, 2001a.

FACHINELLO, J. C. Produção Integrada de frutas - um breve histórico. Informe Agropecuário, v.22, n.213, p.15-18, 2001b.

FNP CONSULTORIA \& COMÉRCIO. Agrianual - 2001: anuário da agricultura brasileira. São Paulo, 2001. 516p.

FOCKS, D.; HAILE, D.; DANIELS, E.; MOUNT, G.A. Dynamic life table model for Aedes aegypti (Diptera, Culicidae) - Simulation and Validation. Journal of Medical Entomology, v.30, p.1018-1028, 1993.

FONSECA, J. P. Combate à lagarta das laranjas, Gymnandrosoma aurantianum Costa Lima. Chácaras e Quintais, v.50, p.215-216, 1934. 
FRAGUAS, J. C.; FADINI, M. A. M.; SANHUEZA, R. M. V. Componentes básicos para elaboração de um programa de produção integrada de frutas. Informe Agropecuário, v.22, n.213, p.19-23, 2001.

FUNDECITRUS. Citricultura sofre com o pior ataque de bicho furão dos últimos anos. Revista do Fundecitrus, v.12, n.4-5, 1996.

FUNDECITRUS. Manual de manejo do bicho furão. Araraquara, 2000a. 10p.

FUNDECITRUS. Tecnologia contra o bicho-furão. Revista do Fundecitrus, v.96, p.8-10, $2000 b$.

GALlO, D.; NAKANO, O.; SILVEIRA NETO, S.; CARVALHO, R. P. L.; BATISTA, G. C.; BERTI FILHO, E.; PARRA, J. R. P.; ZUCCHI, R. A.; ALVES, S. B.; VENDRAMIN, J. D.; MARCHINI, L. C.; LOPES, J. R. S.; OMOTO, C. Manual de entomologia agrícola. Piracicaba: FEALQ, 2002. 920p.

GAllo, J. R.; RODRIGUEZ, O.; CAMARGO, A. P.; IGUE, T. Variações anuais na produção de frutas e concentração de macronutrientes em folhas de citros, relacionadas ao balanço hídrico meteorológico e adubação, no período de 1957 a 1975. Bragantia, v.36, n.27, p.271-289, 1977.

GARCIA, M. S. Bioecologia e potencial de controle biológico de Ecdytolopha aurantiana (Lima, 1927) (Lepidoptera: Tortricidae), o bicho furão dos citros, através de Trichogramma pretiosum Riley, 1879. Piracicaba, 1998. 118p. Tese (Doutorado) - Escola Superior de Agricultura "Luiz de Queiroz", Universidade de São Paulo. 
GARCIA, M. S.; PARRA, J. R. P. Comparação de dietas artificiais, com fontes protéicas variáveis para a criação de Ecdytolopha aurantiana (Lima) (Lepidoptera: Tortricidae). Anais da Sociedade Entomológica do Brasil, v.28, p.219-232, 1999.

GARCIA, M. S.; PARRA, J. R. P.; LAROSSI, A. R.; KASTEN JUNIOR, P. Bioecology of the citrus fruit borer, and control perspectives. Laranja, v.19, p.249-260, 1998.

GETZ, R. R.; POWELL, A. A.; SIMPSON, E. H.; WATSON, D. G.; ZAZUETA, F. S.; BOTTCHER, A. B. D. The Alabama freeze alert program In: COMPUTERS IN AGRICULTURAL EXTENSION PROGRAMS, St. Joseph, 1992.

Proceedings. St. Joseph: American Society of Agricultural Engineers, 1992. p.28-31, 141-146.

GUTIERREZ, A. P.; YANINEK, J. S.; NEUENSCHWANDER, P.; ELLIS., C. K. A physiologically-based tritrophic metapopulation model of the african cassava food web. Ecological Modelling, v.123, p.225-242, 1999.

GUTIERREZ, A. P.; YANINEK, J. S.; WERMELINGER, B.; HERREN, H. R.; ELLIS, C. K. Analysis of biological control of cassava pests in Africa. III. Cassava green mite Mononychellus tanajoa. Journal of Applied Ecology, v.25, p.941950, 1988c.

GUtierReZ, A. P.; MARIOT, E. J.; CURE, J. R.; RIDDLE, C. S. W.; ELLIS, C. K.; VILlACORTA, A. M. A model of bean (Phaseolus vulgaris L.) growth types I-III: Factors affecting yield. Agricultural Systems, v.44, p.35-63, 1994. 
GUTIERREZ, A. P.; SANTOS, W. J. dos; PIZZAMIGLIO, M. A.; VILLACORTA, A. M.; ELliS, C. K.; FERNANDES, C. A. P.; TUTIDA, I. Modelling the interaction of cotton and the cotton boll weevil. II. Bollweevil (Anthonomus grandis) in Brazil. Journal of Applied Ecology, v.28, p.398-418, 1991a.

GUTIERREZ, A. P.; SANTOS, W. J. dos; VILlACORTA, A.; PIZZAMiGLIO, M. A.; ElliS, C. K.; CARVAlho, L. H.; STONE, N. D. Modelling the Interaction of Cotton and the Cotton Boll Weevil .1. A Comparison of Growth and Development of Cotton Varieties. Journal of Applied Ecology, v.28, n.2, p.371-397, $1991 b$.

GUTIERREZ, A. P.; WERMELINGER, B.; SCHULTHESS, F.; BAUMGAERTNER, J. U.; HERREN, H. R.; ELLIS, C. K.; YANINEK, J. S. Analysis of biological control of cassava pests in Africa. I. Simulation of carbon, nitrogen and water dynamics in cassava. Journal of Applied Ecology, v.25, p.901-920, 1988b.

GUTIERREZ, A. P.; NEUENSCHWANDER, P.; SCHULTHESS, F.; HERREN, H. R.; BAUMGAERTNER, J. U.; WERMELINGER, B.; LÖHR, B.; ELLIS, C. K. Analysis of biological control of cassava pests in Africa. II. Cassava mealybug Phenacoccus manihoti. Journal of Applied Ecology, v.25, p.921-940, 1988a.

HAJI, F. N. P.; MOREIRA, A. N.; LOPES, P. R. C.; FERREIRA, R. C. F.; LOPES, L. M. M.; FREIRE, L. C. L. Produção Integrada de uvas finas de mesa. Informe Agropecuário, v.22, n.213, p.57-60, 2001.

IHAKA, R.; GENTLEMAN, R. R: a language for data analysis and graphics. Journal of Computational and Graphical Statistics, v.5, n.3, p.299-314, 1996. 
KITRON, U.; PENER, H.; COSTIN, C.; ORSHAN, L.; GREENBERG, Z.; SHALOM, U. Geographic Information-System in Malaria Surveillance - Mosquito Breeding and Imported Cases in Israel, 1992. American Journal of Tropical Medicine and Hygiene, v.50, n.5, p.550-556, 1994.

LEAL, W. S.; BENTO, J. M. S.; MURATA, Y.; ONO, M.; PARRA, J. R. P.; VILELA, E. F. Identification, synthesis, and field evaluation of the sex pheromone of the citrus fruit borer Ecdytolopha aurantiana. Journal of Chemical Ecology, v.27, n.10, p.2041-2051, 2001.

LEWIS, W. J.; VAN LENTEREN, J. C.; PHATAK, S. C.; TUMLINSON, J. H. A total system approach to sustainable pest management. Proceedings of the National Academy of Sciences of the USA, v.94, p.12243-12248, 1997.

LOPES, P. R. C.; MOREIRA, A. N.; HAJI, F. N. P.; LOPES, L. M. M.; LEITE, E. M.; FREIRE, L. C. L. Produção integrada de manga. Informe Agropecuário, v.22, n.213, p.67-71, 2001.

MOLINA, R. M. S. Bioecologia de duas espécies de Trichogramma para o controle de Ecdytolopha aurantiana (Lima, 1927) (Lepidoptera : Tortricidae) em citros. Piracicaba, 2003. 80p. Dissertação (Mestrado) - Escola Superior de Agricultura "Luiz de Queiroz", Universidade de São Paulo.

NAKANO, O.; SOARES, M. Bicho-furão: biologia, hábitos e controle. Laranja, v.16, p.209-221, 1995.

PARRA, J. R. P. Controle biológico das pragas dos citros. Boletim Citrícola, v.21, p.37, 2002.

PARRA, J. R. P.; OLIVEIRA, H. N.; PINTO, A. S. Guia ilustrado de pragas e insetos benéficos dos citros. Piracicaba: A. S. Pinto, 2003. 140p. 
PARRA, J. R. P.; KASTEN JR., P.; MOLINA, R. M. S.; HADDAD, M. L. Efeito do pH no desenvolvimento do bicho-furão. Laranja, v.22, n.2, p.299-320, 2001.

PINTO, W. B. S. "Bicho-furão" considerado hoje uma das principais pragas da nossa citricultura. Laranja, v.38, p.4-5, 1994.

PINTO, W. B. S. "Bicho-furão": catação reduz infestação. Laranja, v.44, p.13, 1996.

PRATES, H. S. Resultados recentes do controle do bicho-furão - lagarta da mariposa das laranjas - Gymnandrosoma aurantianum (Lima, 1972) em citros. Informativo Coopercitrus, v.8, p.20-21, 1992.

PRATES, H. S.; PINTO, W. B. S. "Bicho-furão" - um grave problema para a citricultura paulista. Laranja, v.12, n.2, p.425-434, 1991a.

PRATES, H. S.; PINTO, W. B. S. Controle do "bicho furão" na citricultura. Informativo Coopercitrus, v.60, p.18-24, 1991b.

PRATES, H. S.; PINTO, W. B. S. Ocorrência do bicho-furão nas principais regiões citrícolas paulistas. Laranja, v.16, n.1, p.237-242, 1995.

PRATES, H. S.; PINTO, W. B. D. S.; CAETANO, A. A. Controle da "Mariposa das laranjas" - Gymnandrosoma aurantianum Lima, 1927 (Lepidoptera: Olethreutidae). In: CONGRESSO BRASILEIRO DE FRUTICULTURA, 6, Recife, 1981. Resumos. Recife: SBF, 1981. p.552-557.

SILVA, A. S.; PESSOA, M. C. P. Y.; FERRACINI, V. L.; CHAIM, A.; SILVA, C. M. S.; HERMES, L. C. Produção Integrada de frutas - o que é? Informe Agropecuário, v.22, n.213, p.5-14, 2001. 
TUBELIS, A.; SALIBE, A. A. Relações entre a produção de laranjeira Hamlin e as precipitações mensais no altiplano de Botucatu. Pesquisa Agropecuária Brasileira, v.24, n.7, p.801-806, 1989.

TUBELIS, A.; SALIBE, A. A. Relações entre a produção de laranjeira Baianinha, a idade e as precipitações mensais no altiplano de Botucatu, SP. Pesquisa Agropecuária Brasileira, v.27, n.5, p.703-707, 1992.

TUBELIS, A.; SALIBE, A. A.; PESSIM, G. Relações entre a produção de laranjeira "Westin" e as precipitações em Botucatu, SP. Pesquisa Agropecuária Brasileira, v.34, n.5, p.771-779, 1999.

VASCONCELOS, R.; TARIFA, J. R. Estimativas e representação das temperaturas no Brasil. Revista do Departamento de Geografia da USP, v.2, p.19-43, 1983.

VILELA, E. F.; DELLA LUCIA, T. M. C. Feromônios de insetos: biologia, química e aplicação. 2. ed. Ribeirão Preto: Holos, 2001. 206p.

ZUCCHI, R. A.; SILVEIRA NETO, S.; NAKANO, O. Guia de identificação de pragas agrícolas. Piracicaba: FEALQ, 1993. 193p. 
APÊNDICES 
Programa de envelopes utilizado para verificar o ajuste do modelo.

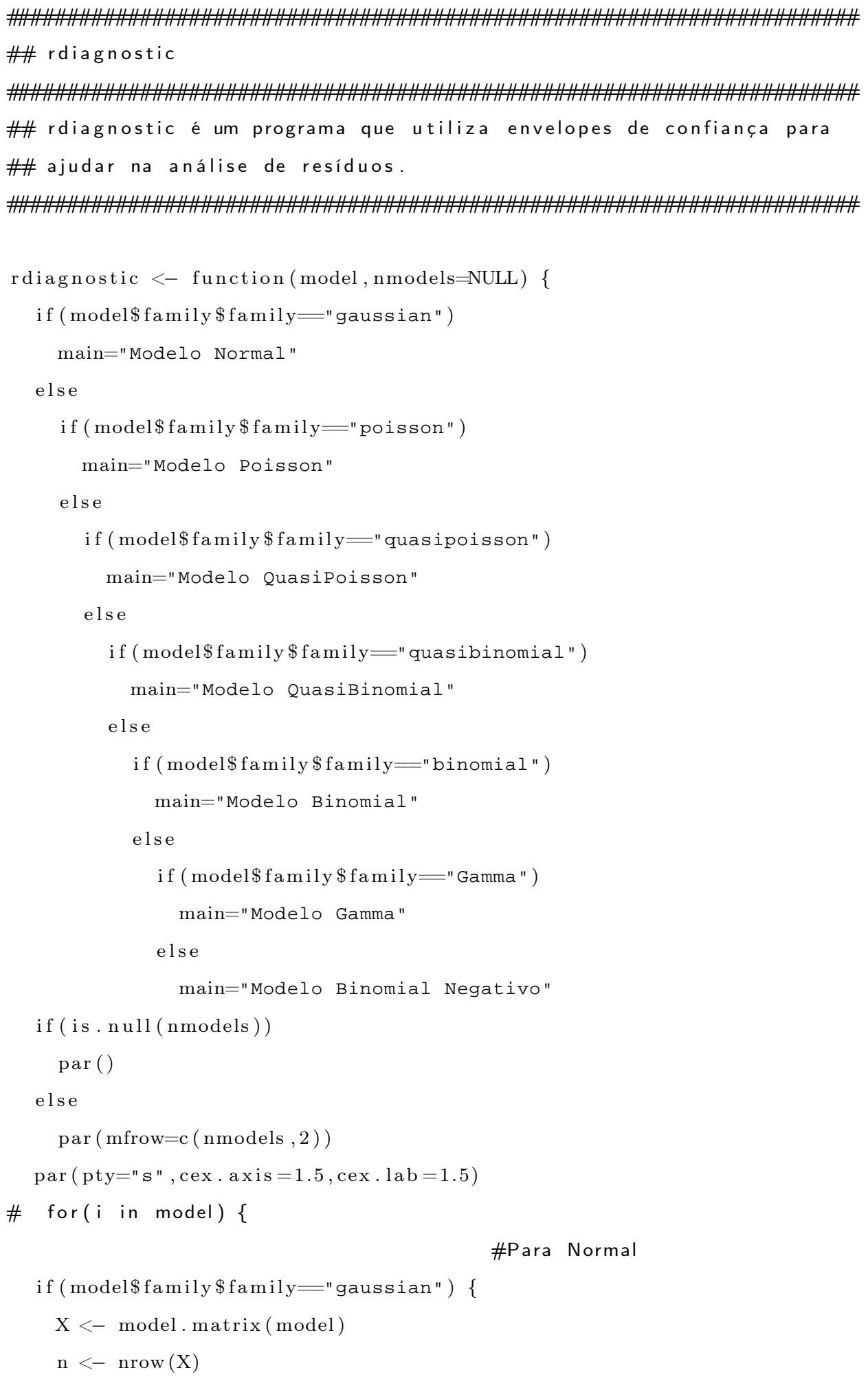




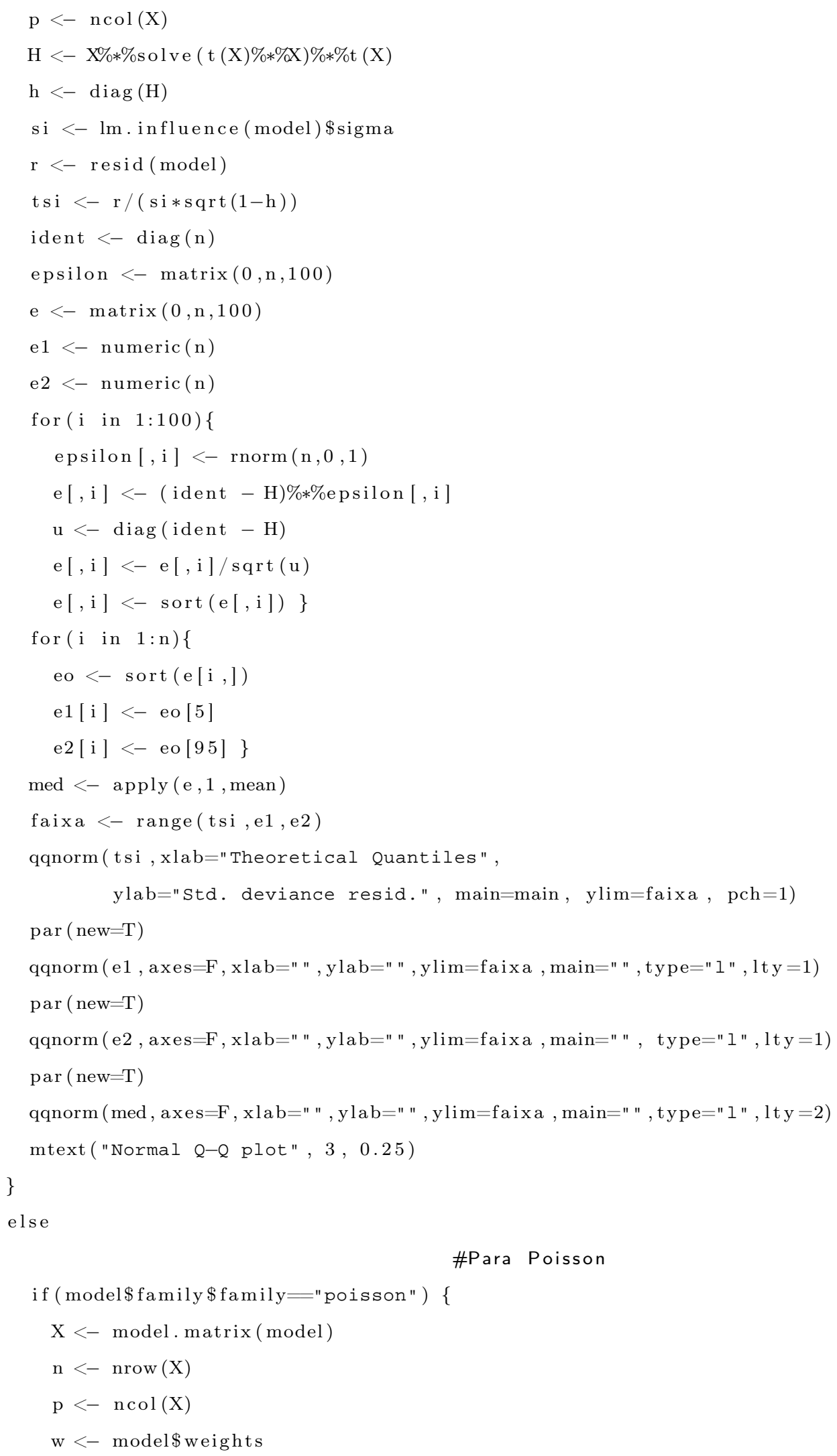




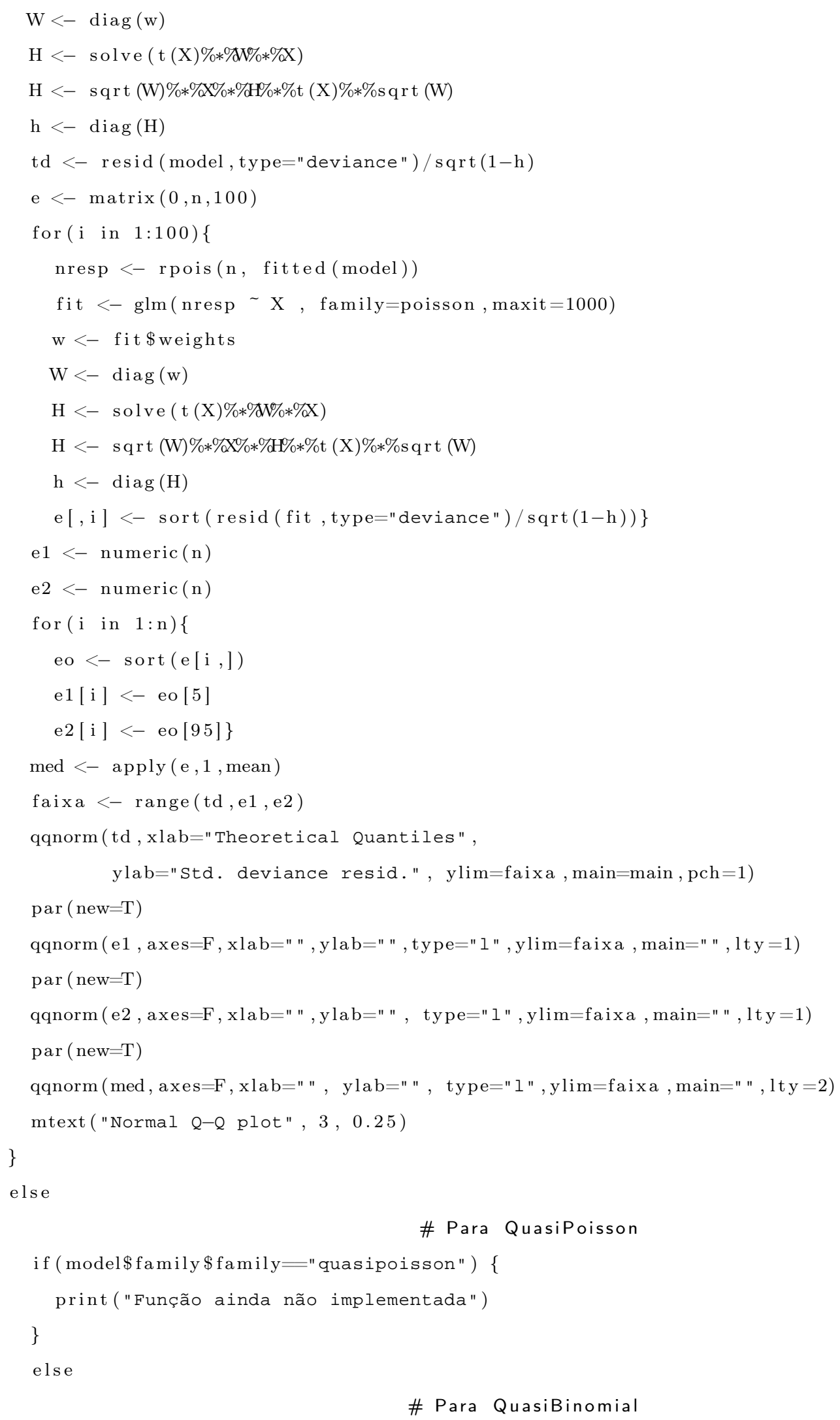




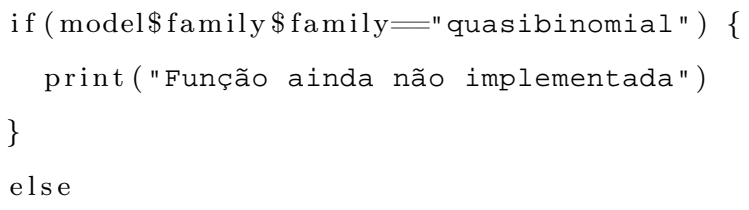




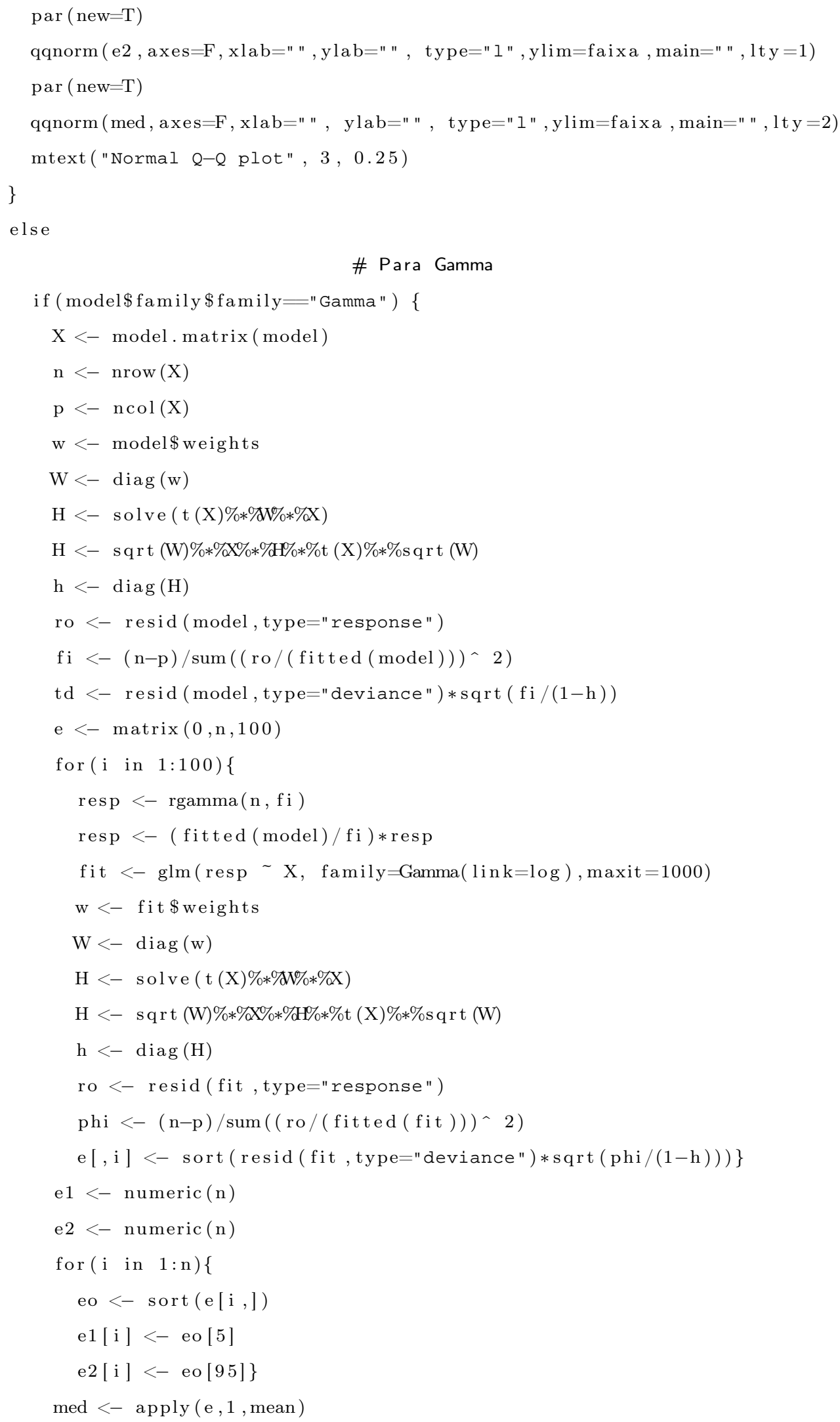




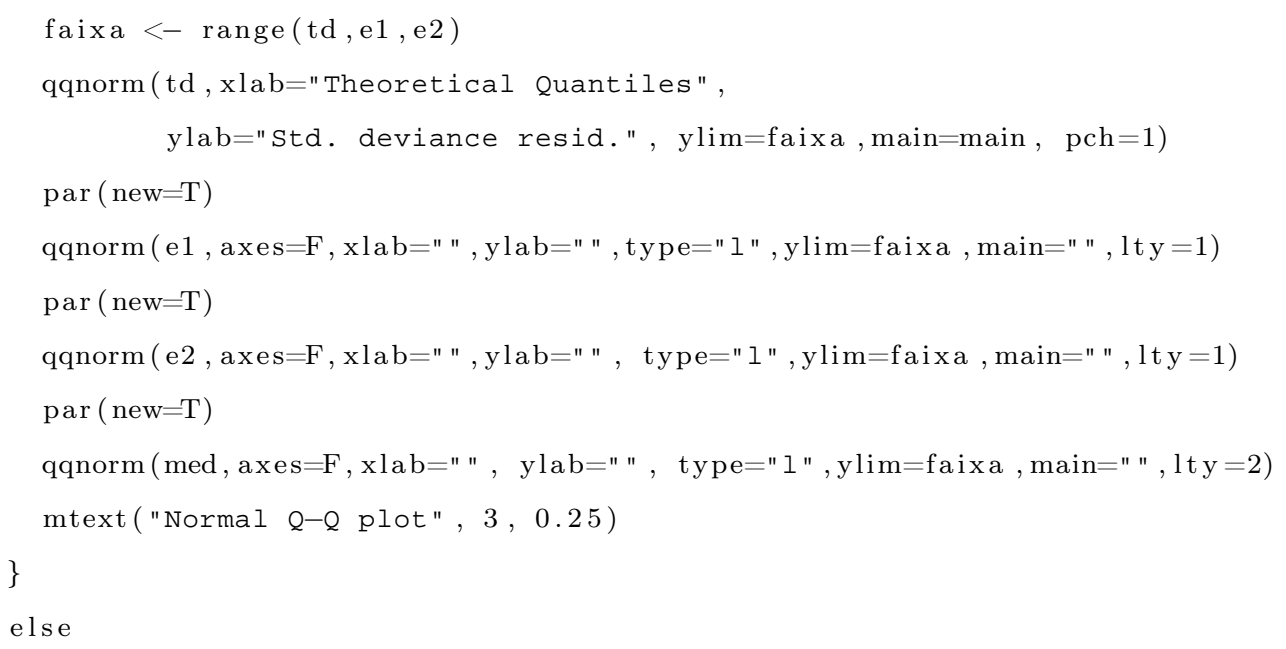




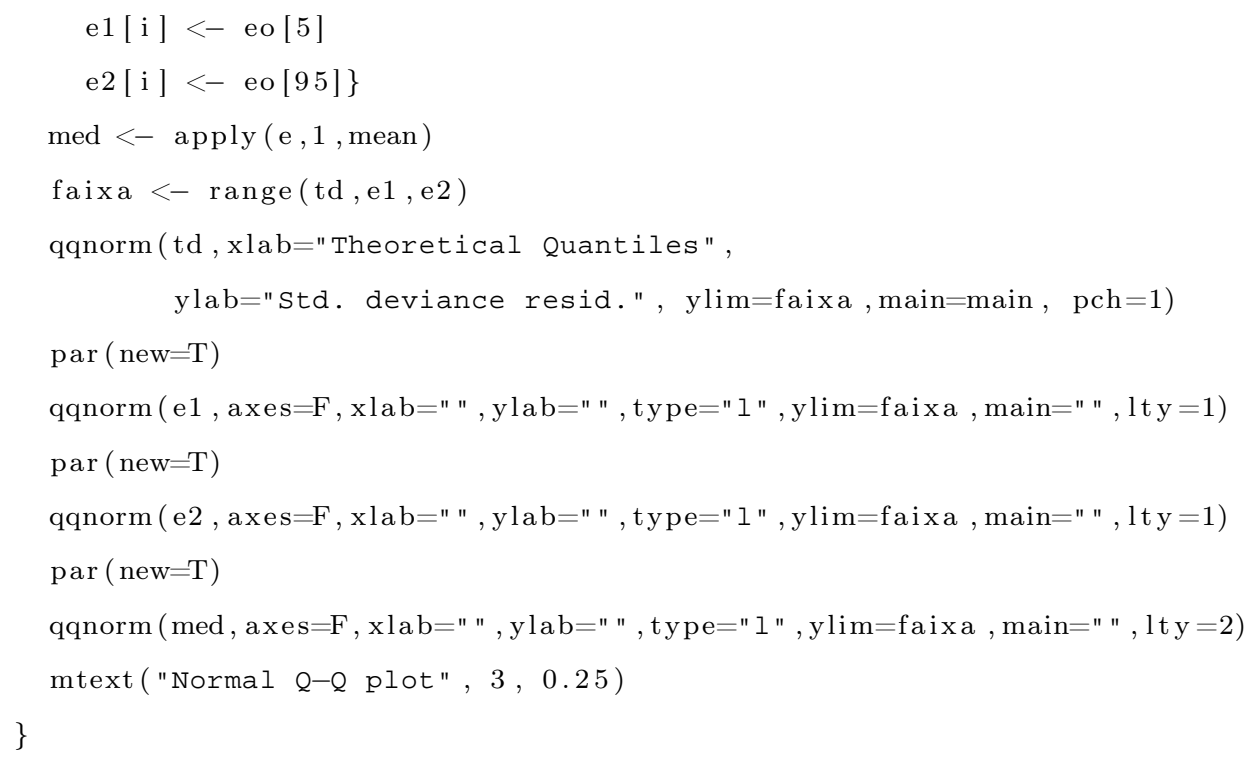

